\title{
1-O-Vinyl Glycosides via Tebbe Olefination, Their Use as Chiral Auxiliaries and Monomers
}

\author{
Jialong Yuan, Kristof Lindner, Holger Frauenrath* \\ Eidgenössische Technische Hochschule Zürich, Department of Materials \\ ETH Hönggerberg, HCI H515, CH-8093 Zürich, Switzerland \\ Email:frauenrath@mat.ethz.ch
}

\section{Supporting Information}

\section{Table of Contents}




\section{General Experimental Methods}

Unless otherwise noted, all experiments were carried out in dried Schlenk glassware in an inert $\mathrm{N}_{2}$ atmosphere. All reagents were purchased as reagent grade from commercial sources and used without further purification. Solvents were purchased as reagent grade and distilled once prior to use. Anhydrous solvents were freshly distilled and stored over molecular sieves prior to use. DCM was refluxed and distilled over $\mathrm{CaH}_{2}$; THF, diethyl ether, toluene and 1,4-dioxane were refluxed over $\mathrm{Na}$ /benzophenone and distilled; $\mathrm{CCl}_{4}$ was dried over night with molecular sieves (4 A) and distilled twice from $\mathrm{CaH}_{2}$; pyridine was distilled from $\mathrm{KOH}$.

The known thioglycosides and glycosyl bromides used as starting materials for the preparation of the 1-O-formyl glycosides (i.e., ethyl 2,3,4,6-tetra- $O$-acetyl-1-thio- $\alpha$-D-glucopyranoside, ${ }^{1}$ ethyl 2,3,4,6-tetra- $O$-benzoyl-1-thio- $\beta$-D-glucopyranoside $6,{ }^{1}$ ethyl 2,3,4,6-tetra- $O$-benzyl-1-thio$\alpha$-D-glucopyranoside, ${ }^{1}$ ethyl 2,3 -Di- $O$-benzoyl-4,6- $O$-benzylidene-1-thio- $\beta$-D-glucopyranoside, ${ }^{2}$ ethyl 2,3,4,6-tetra- $O$-benzoyl-1-thio- $\alpha$-D-mannopyranoside $\mathbf{8}{ }^{3} \quad 2,3,4,6$-tetra- $O$-acetyl-Dglucopyranosyl bromide, ${ }^{4}$ 2,3,4,6-tetra- $O$-benzoyl-D-glucopyranosyl bromide, ${ }^{5} 2,3,4,6$ tetra- $O$ benzoyl- $\alpha$-D-mannopyranosyl bromide, ${ }^{5}$ 2,3,4,6-tetra- $O$-benzoyl-D-galactopyranosyl bromide, ${ }^{6}$ 2,3,4-tri- $O$-benzoyl-D-arabinopyranosyl bromide, $^{7} \quad$ 2,3,4-tri- $O$-benzoyl- $\beta$-D-ribopyranosyl bromide $^{8}$ and 2,3,6,8,9,10,12-hepta- $O$-benzoyl- $\beta$-D-cellobiosyl bromide ${ }^{9}$ ) were all prepared analogously to published standard procedures. $^{1,10}$ 1,2:3,4-Di- $O$-isopropylidene- $\alpha$-Dgalactopyranose and 1,2:5,6-di- $O$-isopropylidene- $\alpha$-D-glucofuranose were obtained from commercial sources. DPTS (4-(N,N-dimethylamino)-pyridinium toluene-4-sulfonate) was prepared as described in the literature. ${ }^{11}$

LC/MS was carried out using an Agilent 1100 LC/MSD HPLC equipped with a Waters Symmetry C18 column $(3.9 \times 150 \mathrm{~nm}, 5 \mu \mathrm{m})$. Solutions of $20 \%$ isopropanol in water containing 
$0.1 \%$ TFA (pump A) and 20\% isopropanol in acetonitrile containing 0.1\% TFA (pump B) were used as the eluents. The compounds were eluted at a flow rate of $1 \mathrm{~mL} / \mathrm{min}$ applying a solvent gradient and detected using a UV detector. Ions were detected by a full MS1 scan with a mass range depending on the molecular weight of the compunds. GPC measurements were performed on a Viskotek GPCmax instrument in $\mathrm{CHCl}_{3}$ as the eluent $\left(1 \mathrm{~mL} / \mathrm{min}, 35{ }^{\circ} \mathrm{C}\right)$, using two PL-gel Mixed C columns and one Viskotek GMHHRN column $(300 \times 7.5 \mathrm{~mm}, 5 \mu \mathrm{m})$. Molecular weights were detected with a dual angle laser light scattering detector $\left(685 \mathrm{~nm}, 7.5^{\circ}\right.$ and $\left.90^{\circ}\right)$, a viscosity detector, as well as a refractive index detector $(685 \mathrm{~nm})$, and calculated with the software OmniSEC v4.0. Optical rotations were measured at a wavelength of $589 \mathrm{~nm}$ in a $10 \mathrm{~cm}$ cell at $25{ }^{\circ} \mathrm{C}$. For the routine $\mathrm{X}$-ray structure analysis of $\mathbf{2 a}$ and $\mathbf{3 a}$, data collection and reduction was performed at an Oxford Xcalibur CCD diffractometer. ${ }^{12}$ The structures were solved and refined with standard SHELX procedures. ${ }^{13}$ 


\section{References}

(1) Dasgupta, F.; Garegg, P. J. Acta Chem. Scand. 1989, 43, 471-475.

(2) Bochkov, A. F.; Jain, A. C. Izvestiya Akademii Nauk SSSR, Seriya Khimicheskaya 1968, 179-180.

(3) Garegg, P. J.; Maloisel, J.-L.; Oscarson, S. Synthesis 1995, 409-414.

(4) Horton, D.; Turner, W. N. J. Org. Chem. 1965, 30, 3387-3394.

(5) Ness, R. K.; Fletcher, H. G., Jr.; Hudson, C. S. J. Am. Chem. Soc. 1950, 72, 2200-2205.

(6) Mota, J. F.; Mostowicz, D.; Ortiz, C.; Pradera, M. A.; Robina, I. Carbohydr. Res. 1994, 257, $305-316$.

(7) Fletcher, H. G., Jr.; Hudson, C. S. J. Am. Chem. Soc. 1950, 72, 4173-4177.

(8) Jeanloz, R.; Fletcher, H. G., Jr.; Hudson, C. S. J. Am. Chem. Soc. 1948, 70, 4052-4054.

(9) Lichtenthaler, F. W.; Kaji, E.; Weprek, S. J. Org. Chem. 1985, 50, 3505-3515.

(10) Barczai-Martos, M.; Korosy, F. Nature 1950, 165, 369.

(11) Moore, J. S.; Stupp, S. I. Macromolecules 1990, 23, 65-70.

(12) http://www.oxford-diffraction.com/crysalis.htm

(13) G. Sheldrick: SHELXS/L-97. Program for the Solution/Refinement of Crystal Structures. University of Göttingen, Germany, 1997. 


$$
\begin{aligned}
& { }_{\mathrm{ACO}}^{\mathrm{AcO}} \underbrace{\mathrm{O}}_{\mathrm{OAC}} \mathrm{OAC} \\
& 1 a
\end{aligned}
$$

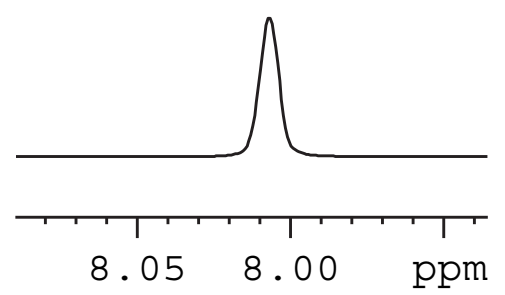

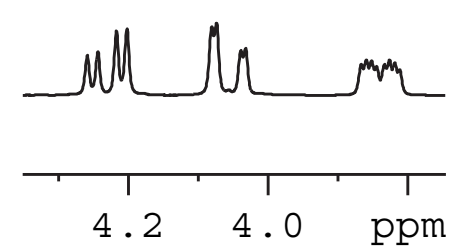

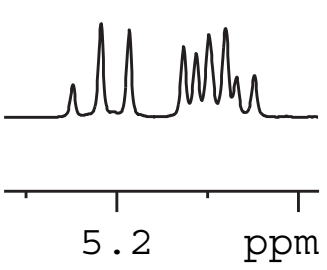


$\sim \infty 6 \infty$

सब त 06

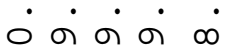

1666 เ

तન $ત$ ન

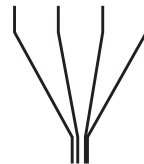

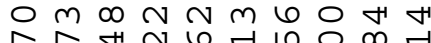

0 मी तN ए अ० Lी $\mathrm{m}$

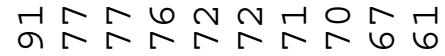

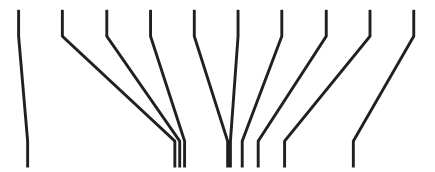

ด

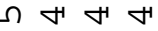

$\begin{array}{lll}\infty & \circ & \circ \\ m & \mathrm{~N} & \mathrm{~N}\end{array}$

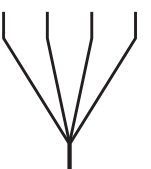

${ }_{\mathrm{O} A c}^{\mathrm{AcO}} \mathrm{OAC}$

$1 \mathrm{a}$

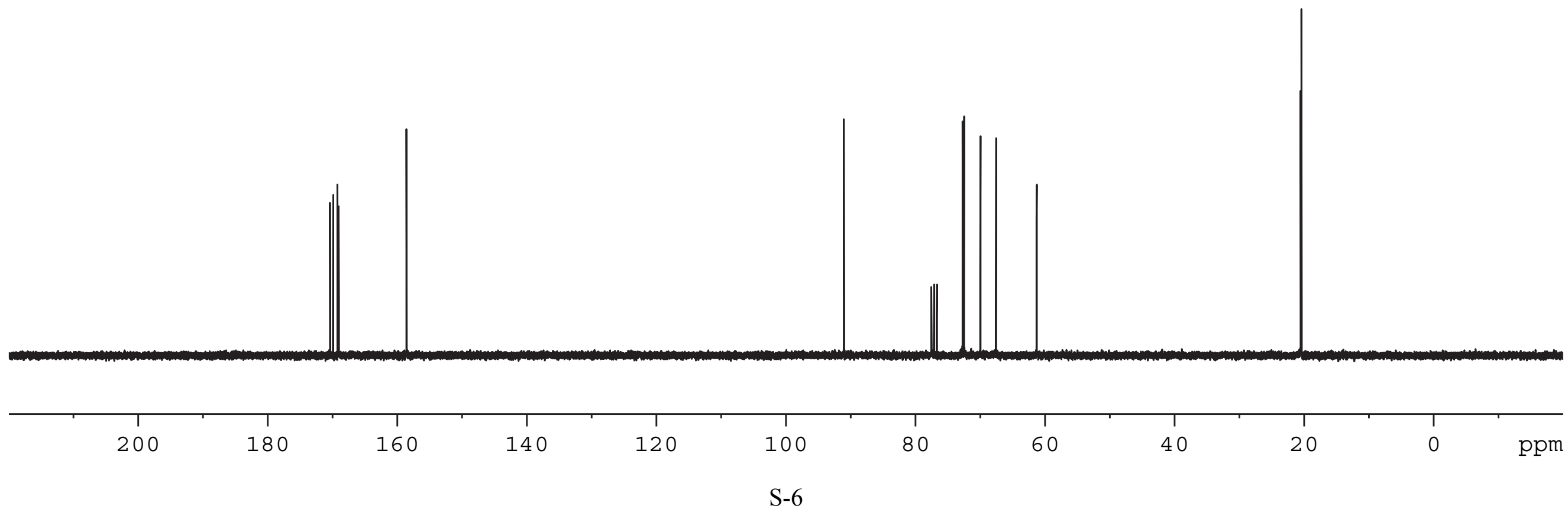




$$
\text { OcO }
$$

$1 b$
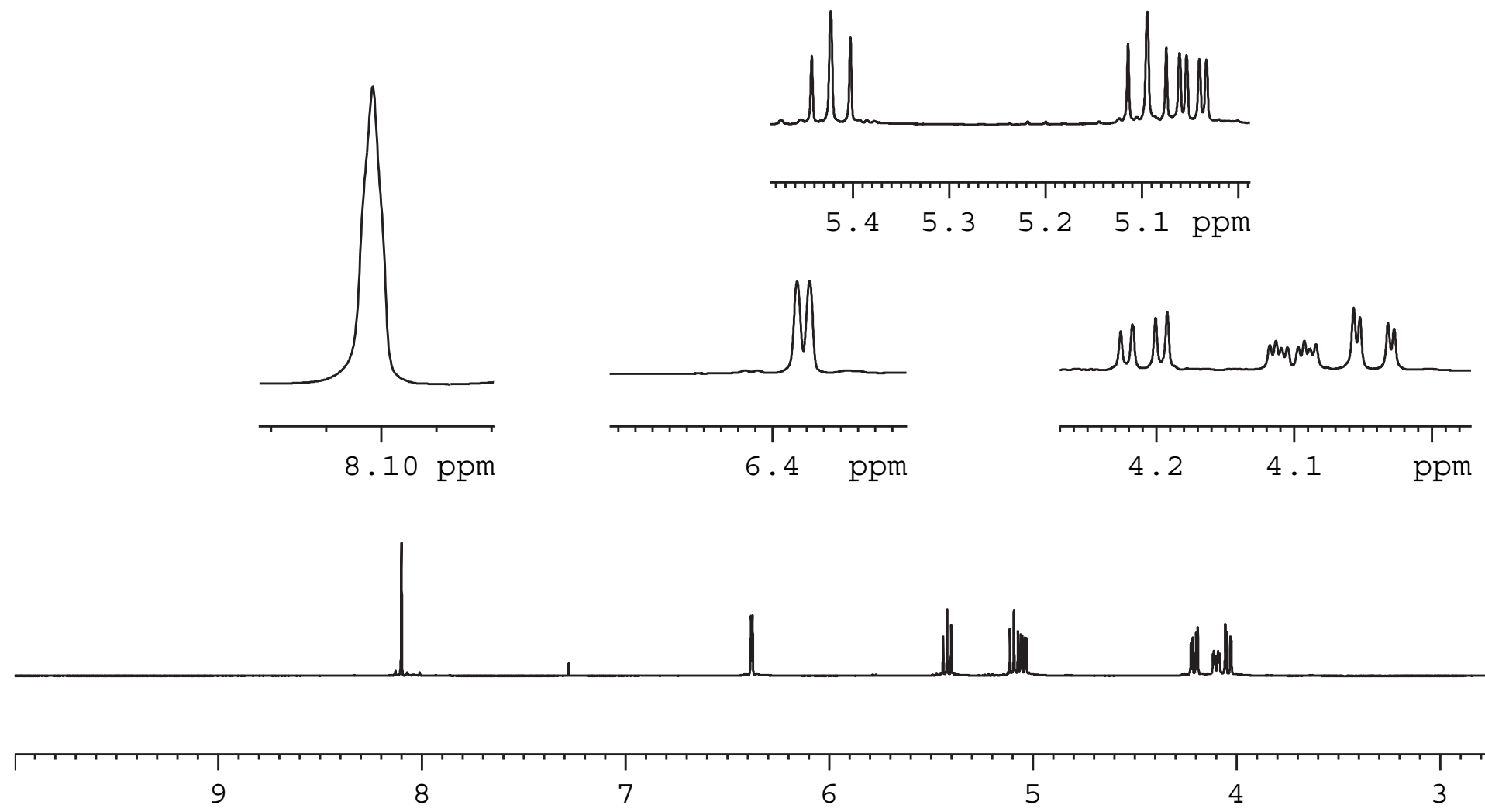

dill

7 

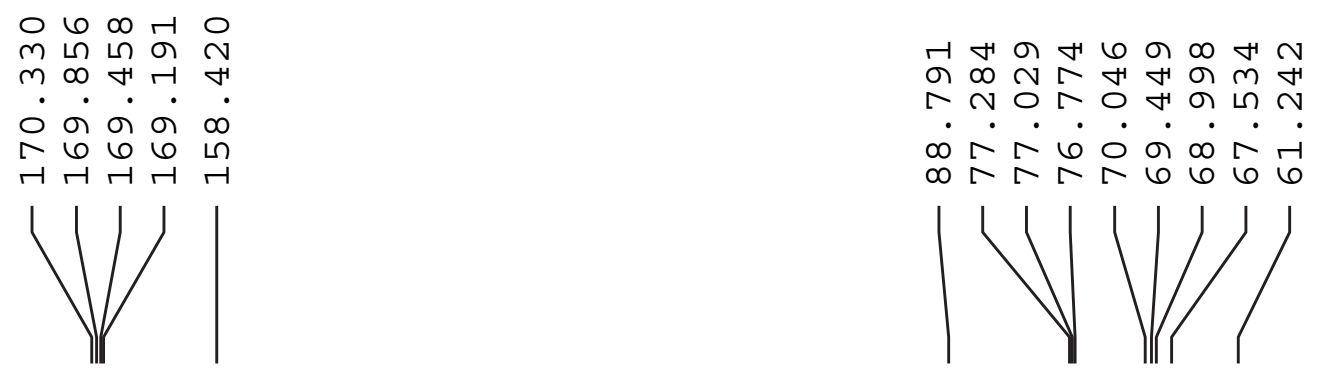

\begin{tabular}{llll}
$\circ$ & $\infty$ & 0 & \multicolumn{1}{c}{} \\
4 & $\infty$ & $\sim$ & $\infty$
\end{tabular} अ $m m$ m

- 0 0 00

$\mathrm{N} N \mathrm{~N}$

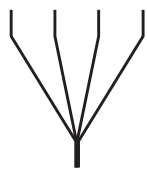

O $\mathrm{O}=\mathrm{O}$

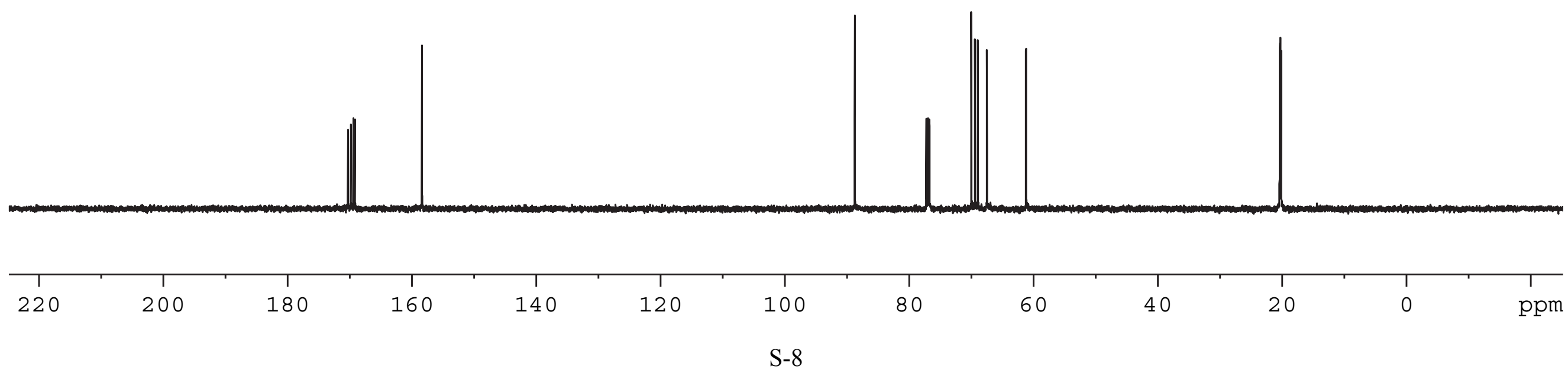



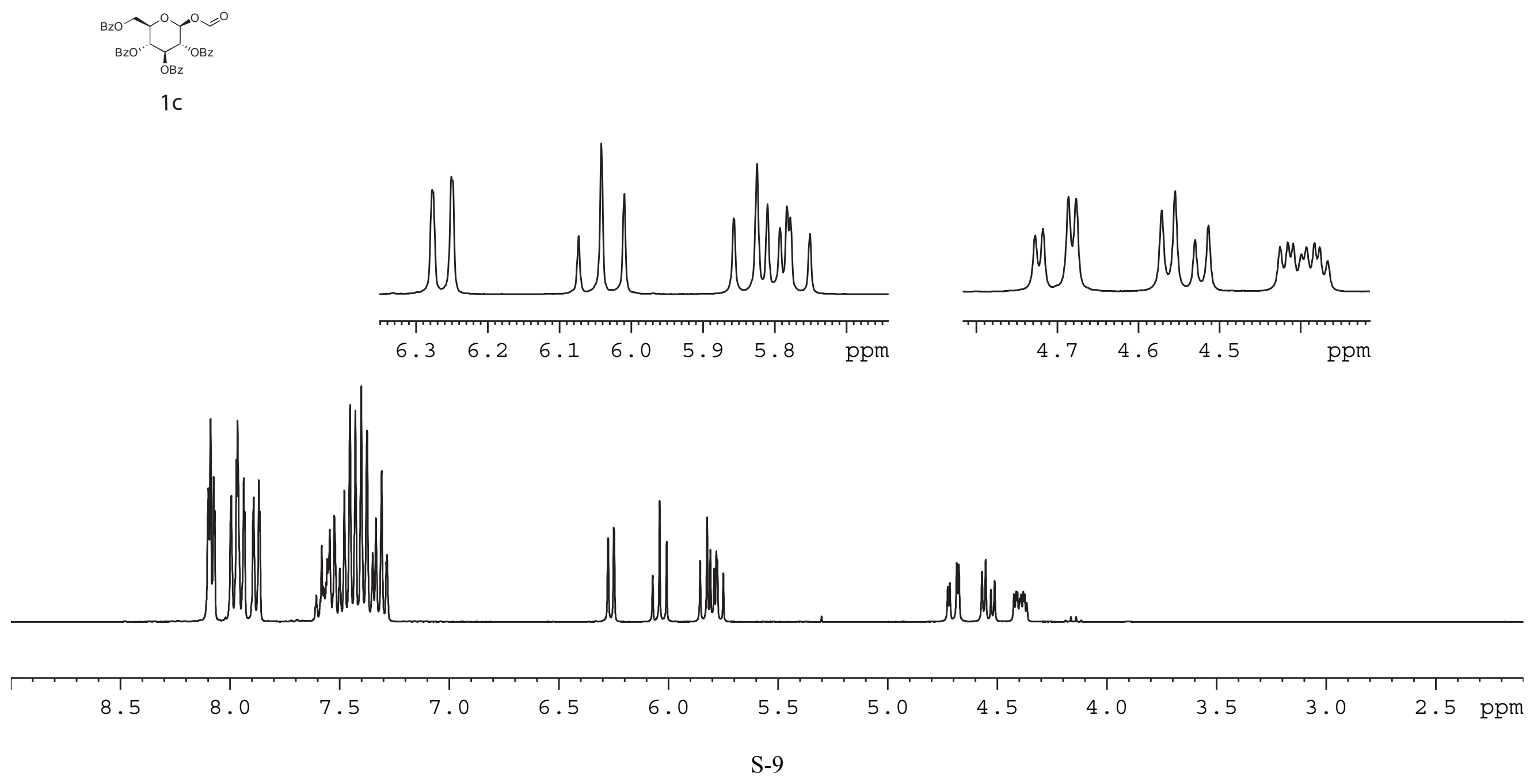

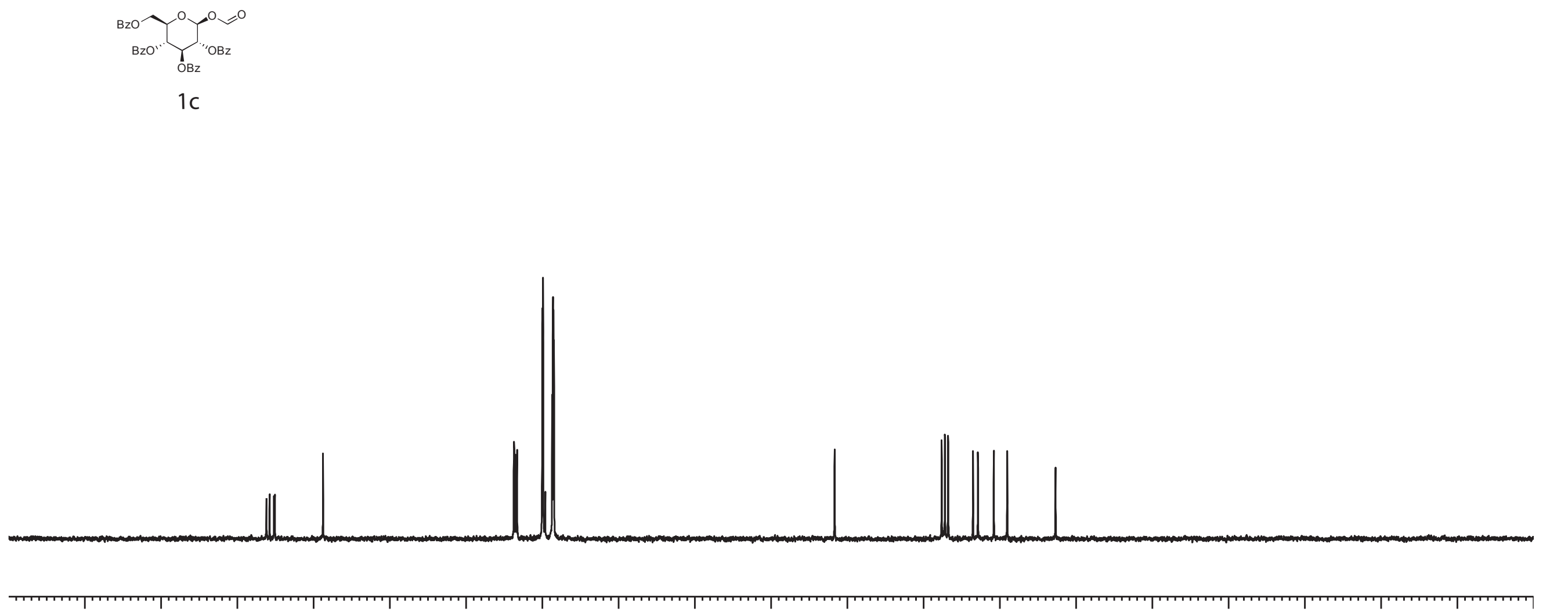

$\begin{array}{rrrrrrrrrrrrrrrrrrrrrrr}190 & 180 & 170 & 160 & 150 & 140 & 130 & 120 & 110 & 100 & 90 & 80 & 70 & 60 & 50 & 40 & 30 & 20 & 10 & \text { ppm }\end{array}$




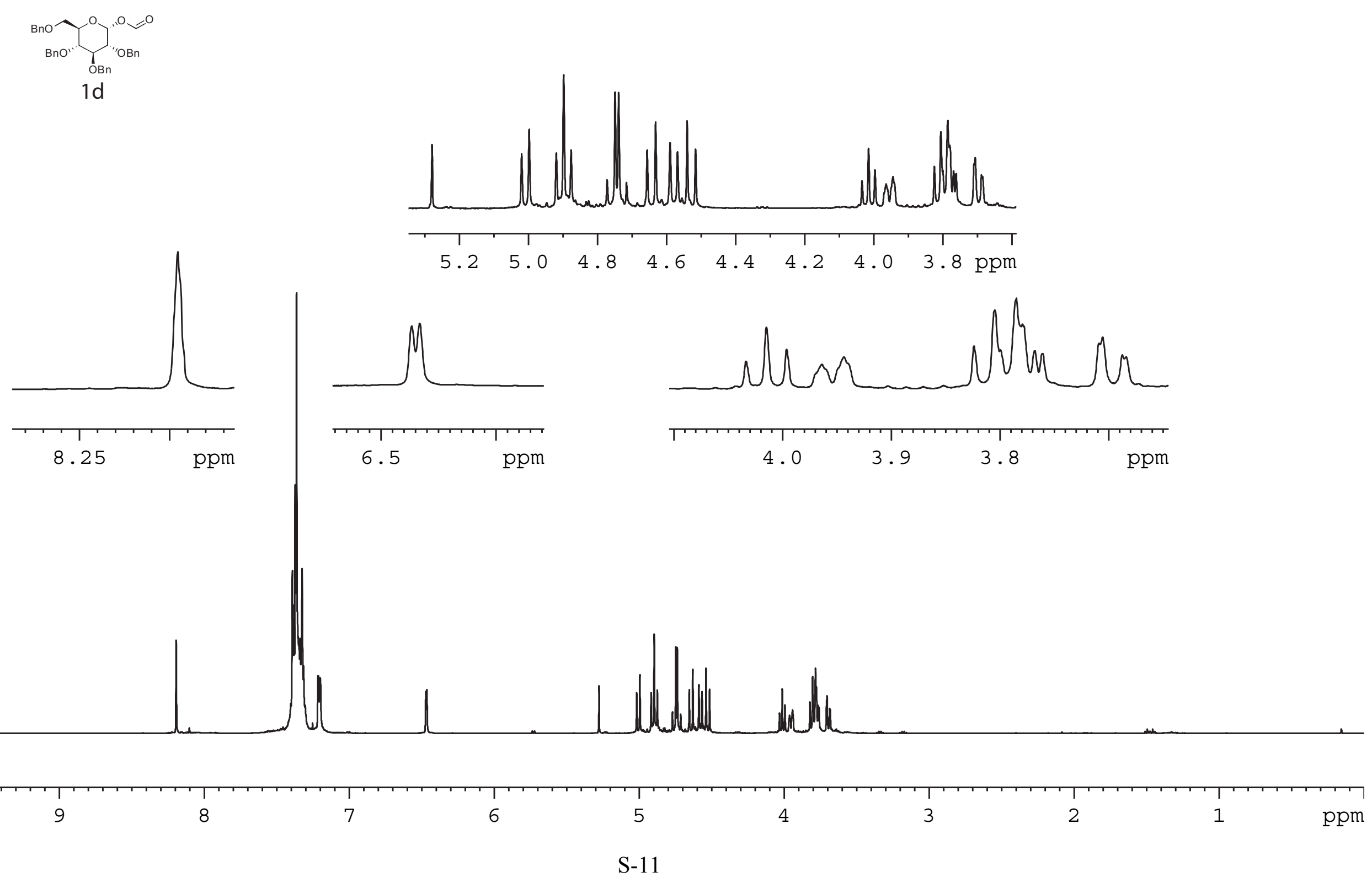


$\underbrace{\mathrm{O} O \mathrm{OBn}}_{\mathrm{OBn}}$

$1 d$

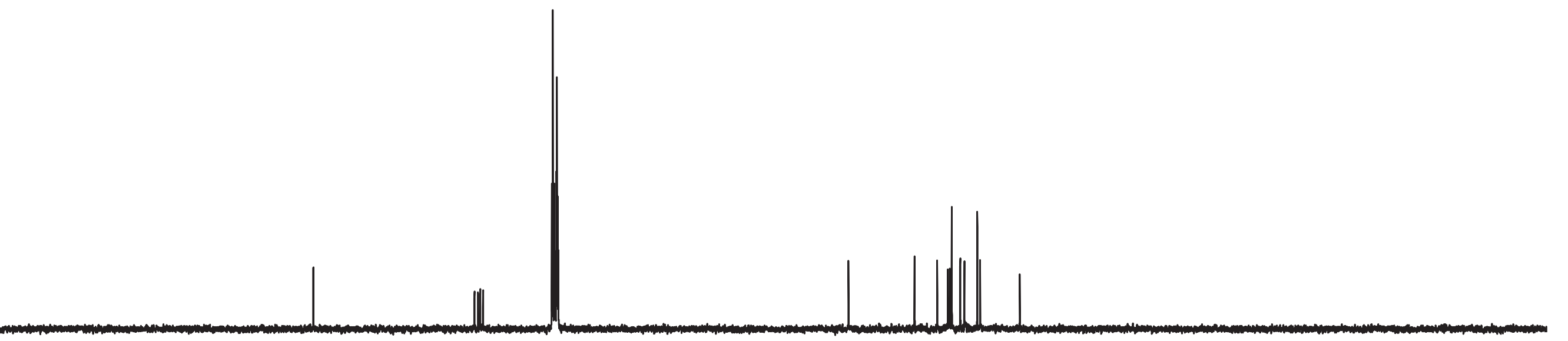



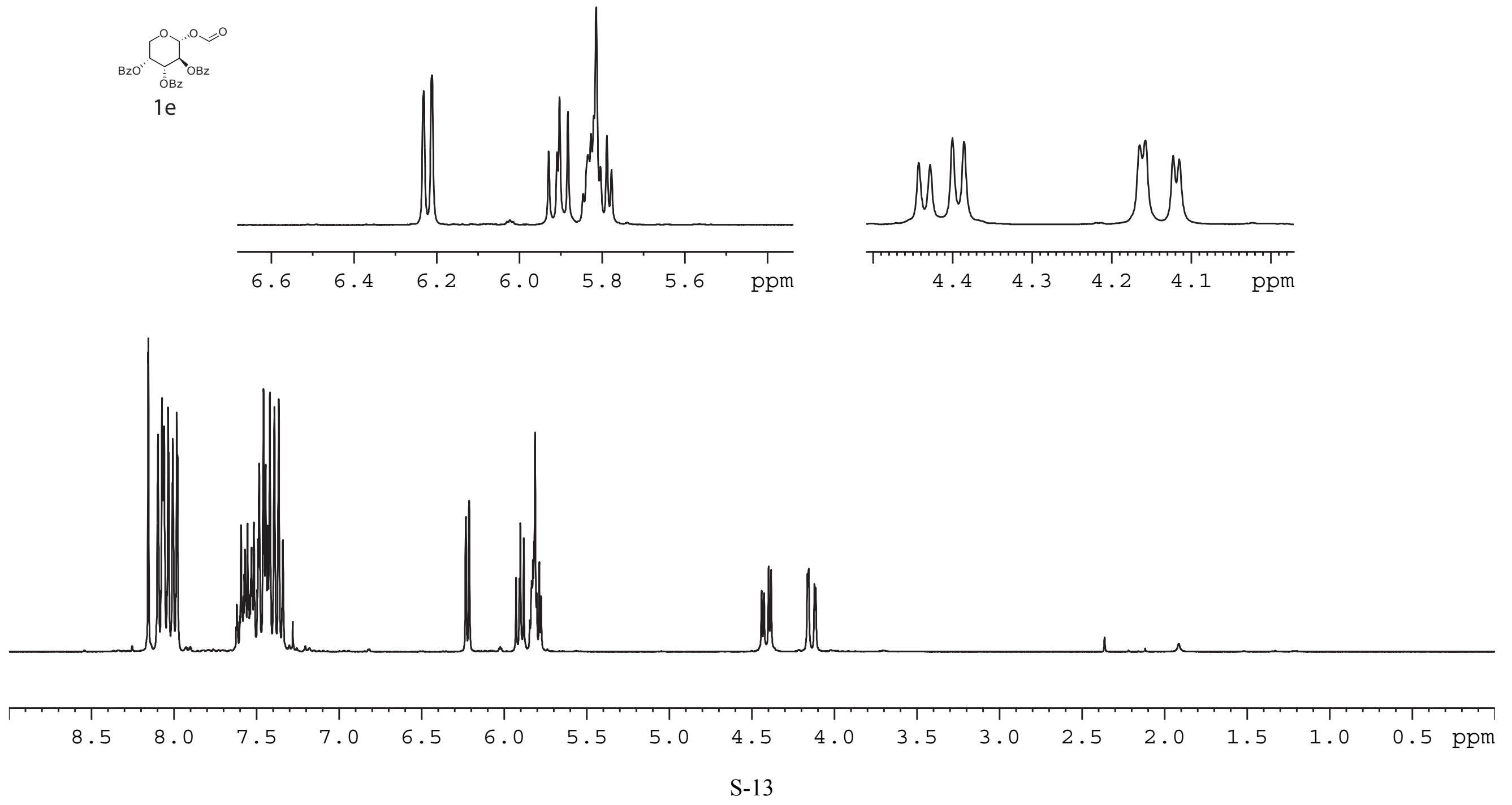


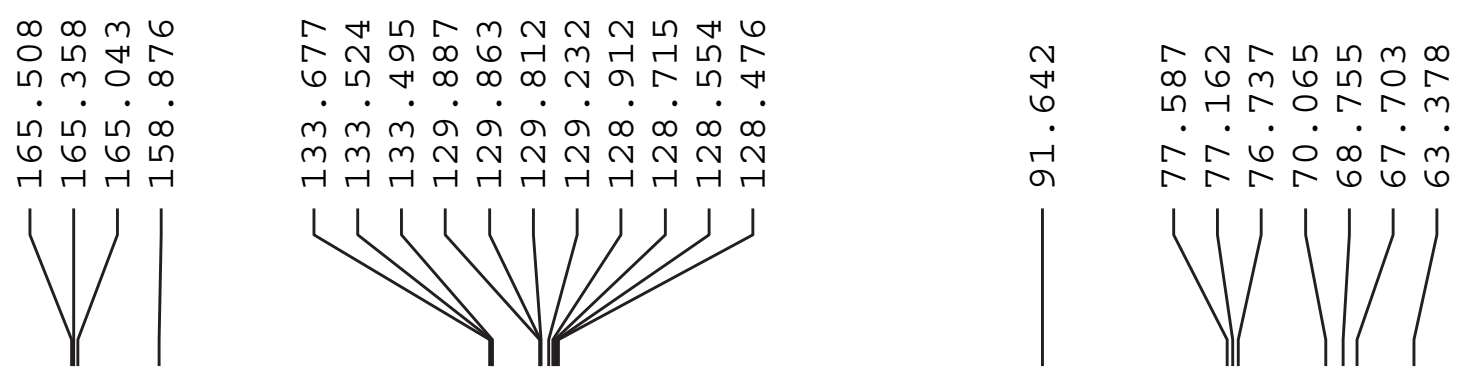

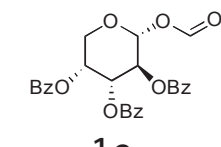

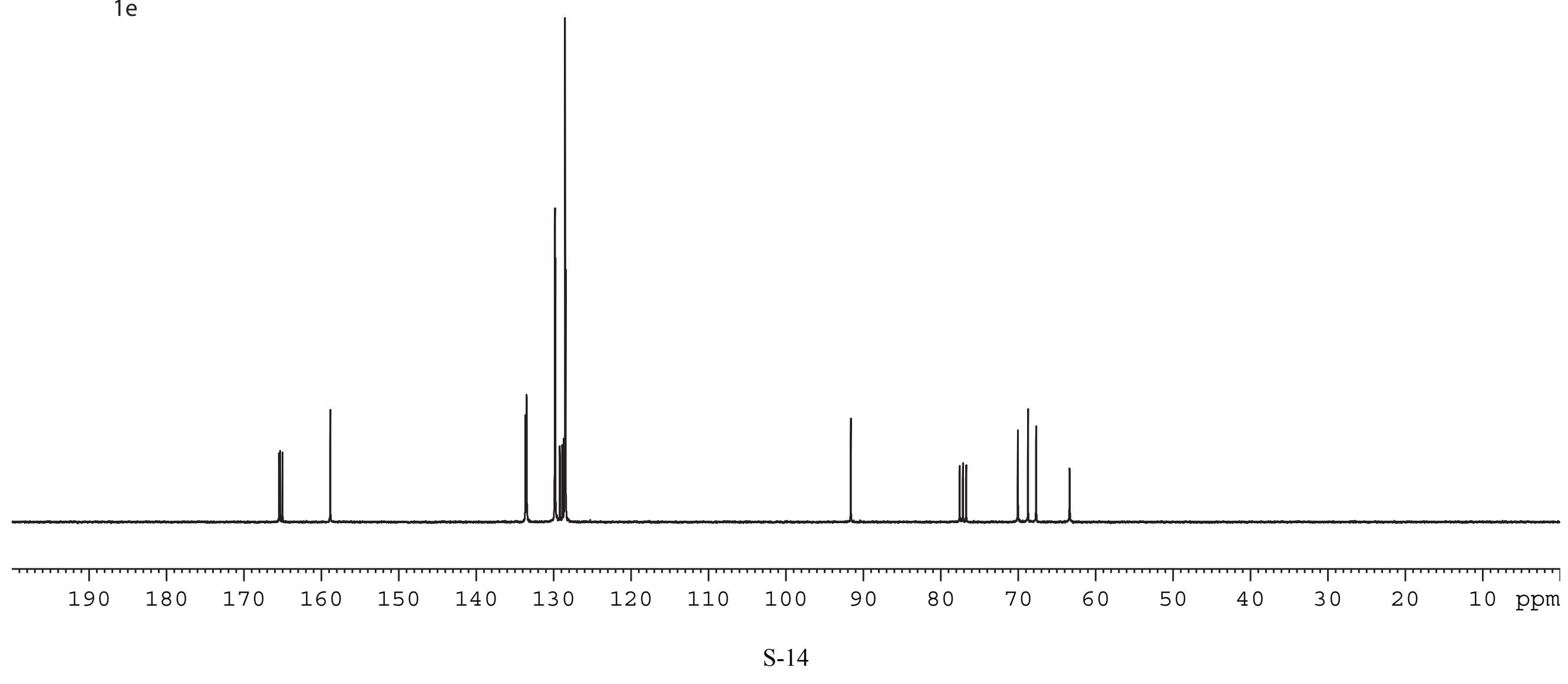



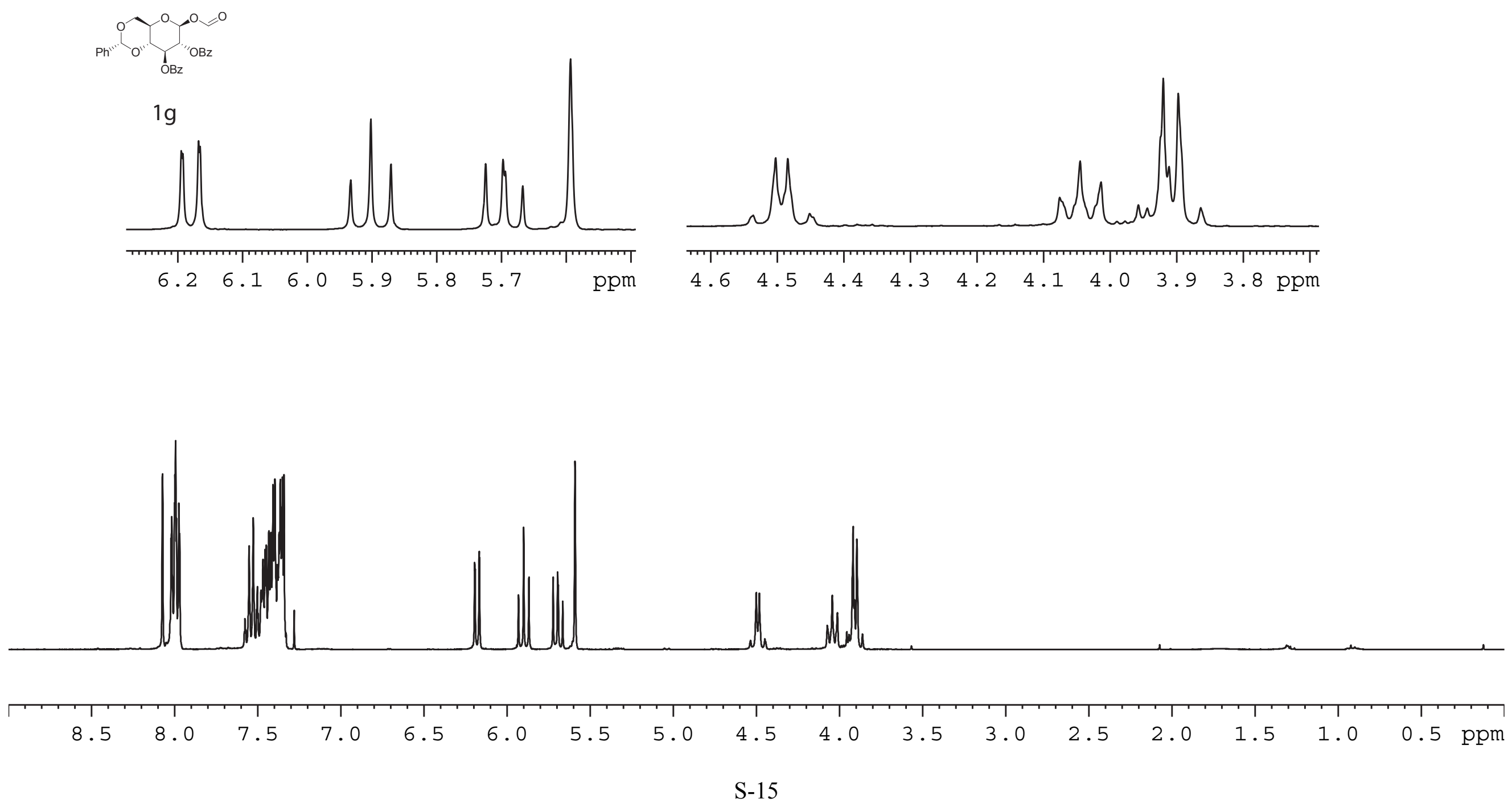


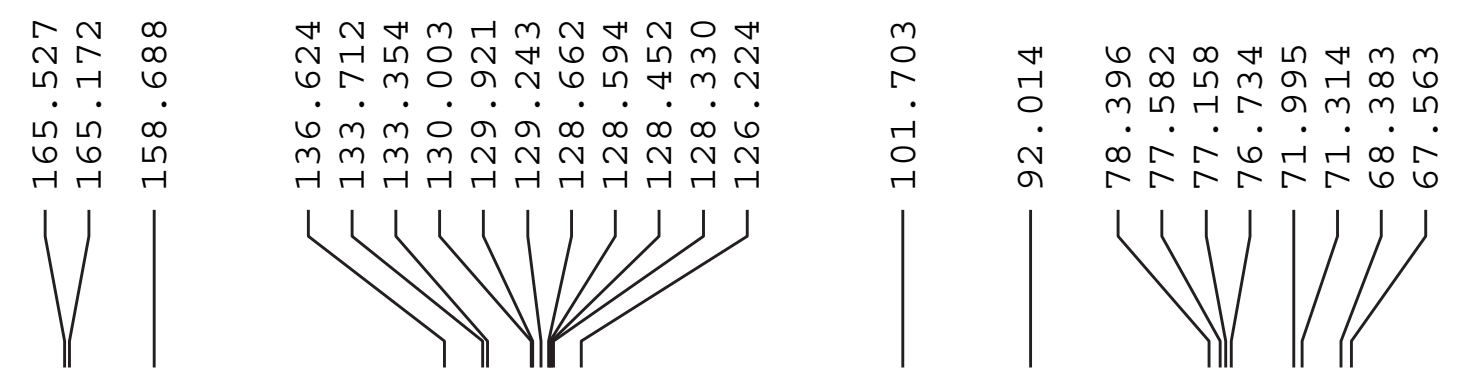

$\mathrm{Ph}_{\mathrm{OBz}}^{\mathrm{O}=\mathrm{OBz}}$

$1 \mathrm{~g}$

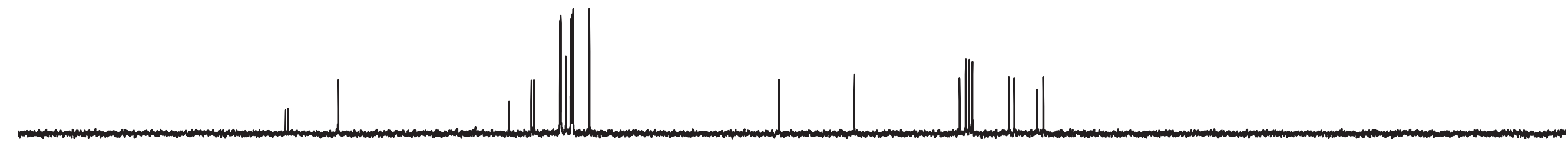



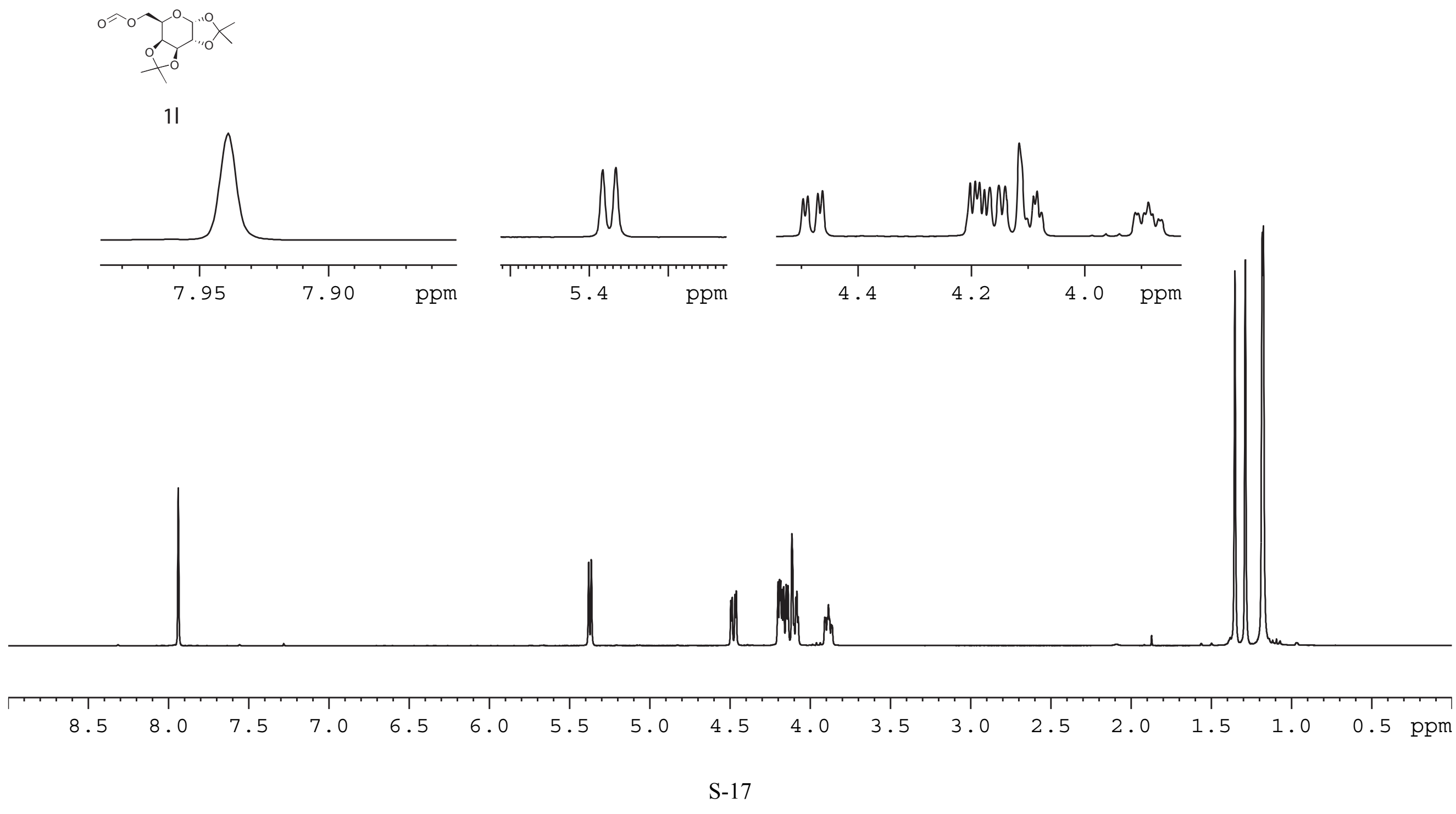


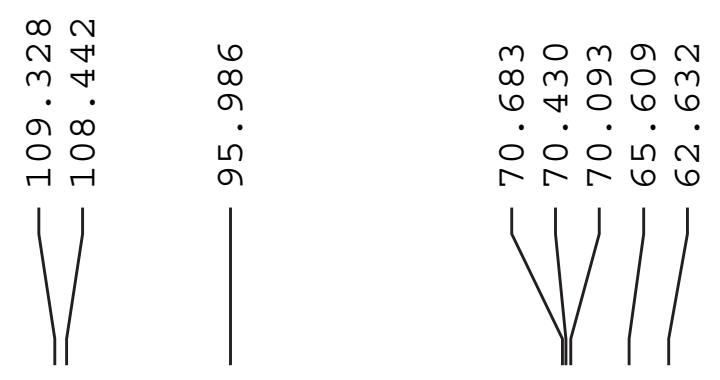

HN ติธิ㇒日勺 मن. $\stackrel{\sim}{\sim} \stackrel{\mathrm{N}}{\mathrm{N}}$

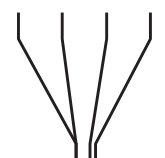

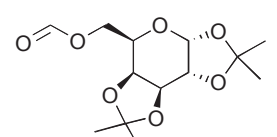

11

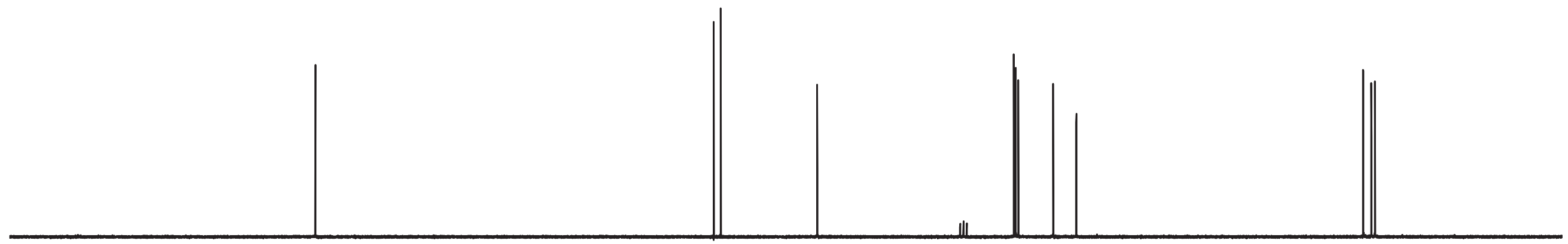



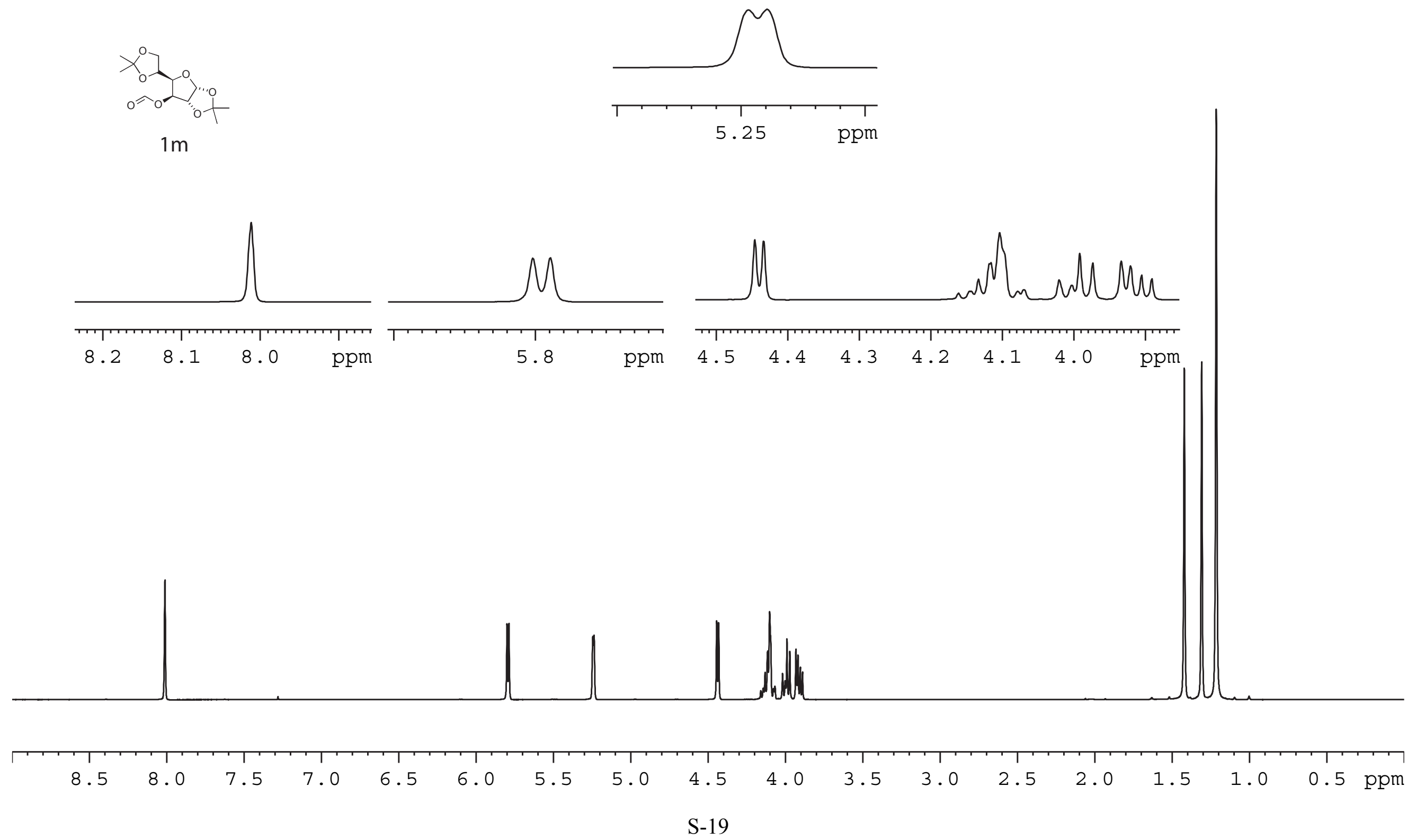


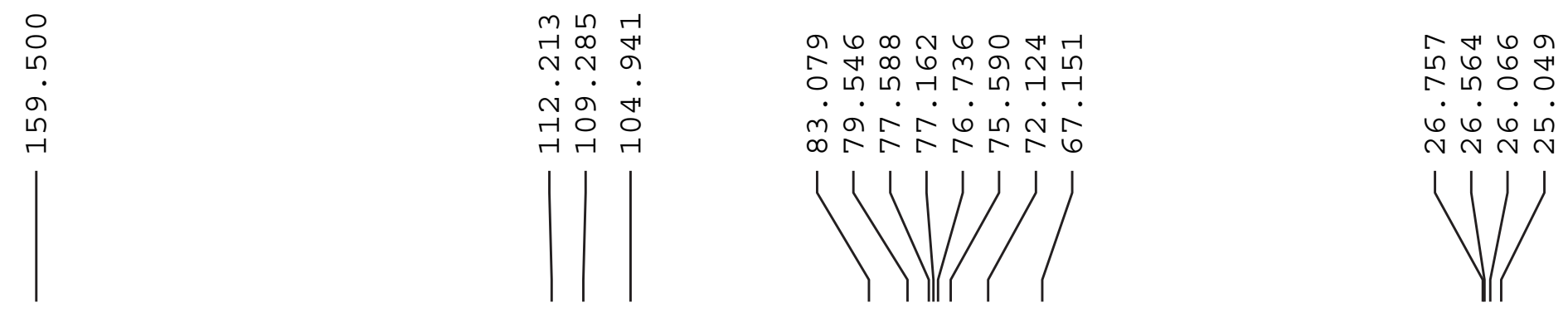

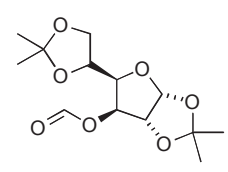

$1 \mathrm{~m}$

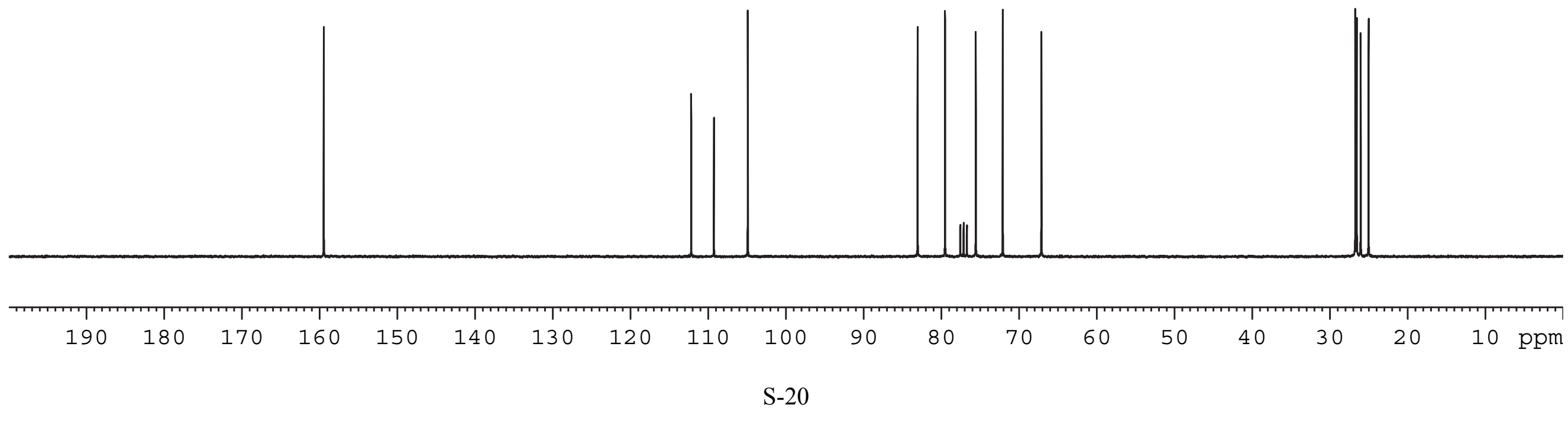




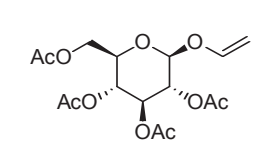

$2 \mathrm{a}$
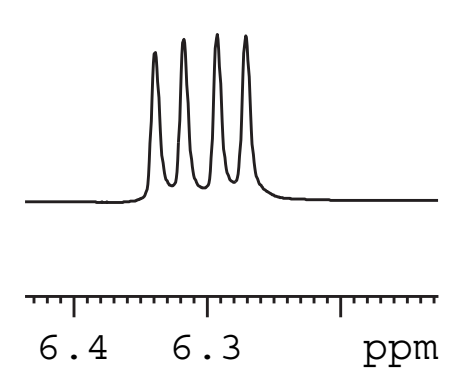
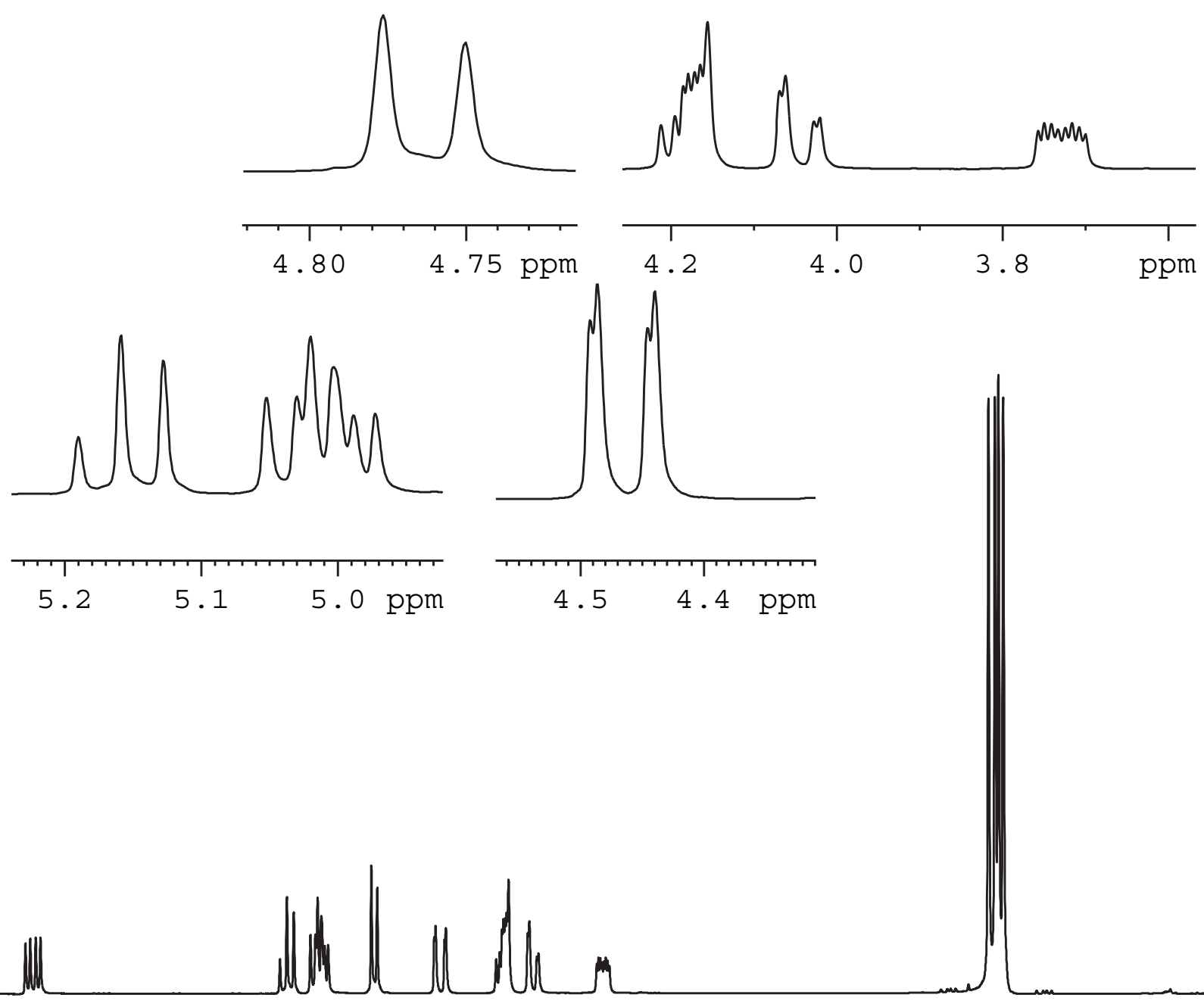

8.5

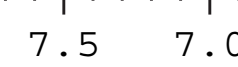

6.5

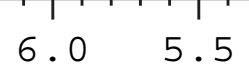

5.0

4.5
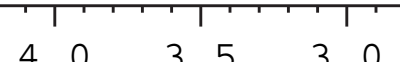

2.5

2.0

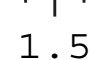

1.0

0.5 ppm 


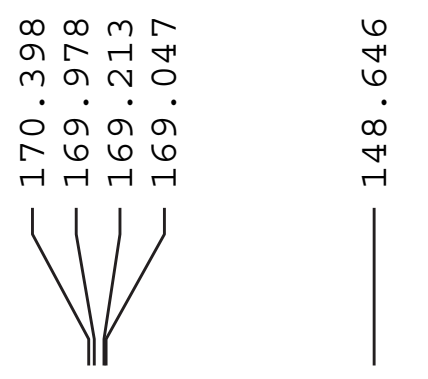

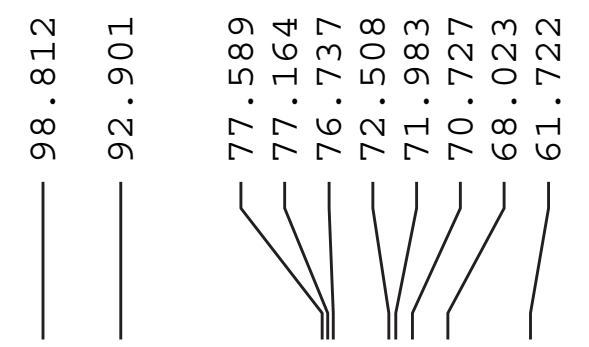

06 다

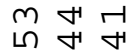

$\dot{0} \dot{0} \dot{0}$ $\sim \sim N$

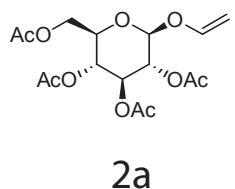

$2 a$
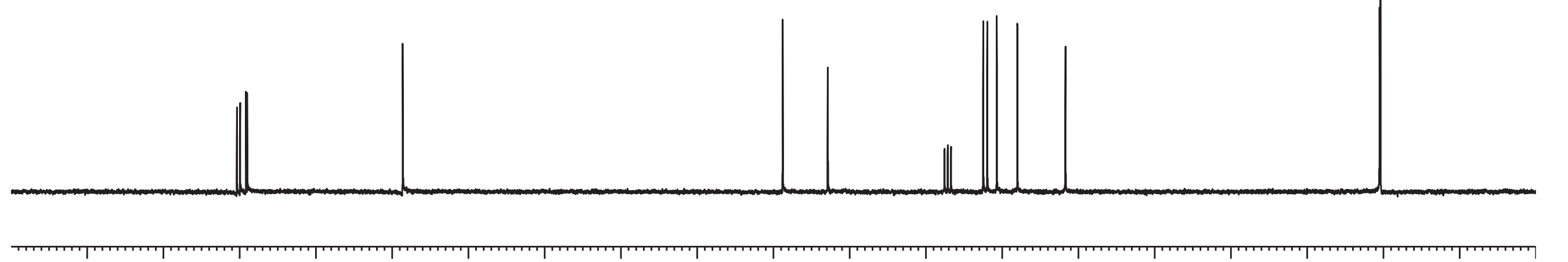

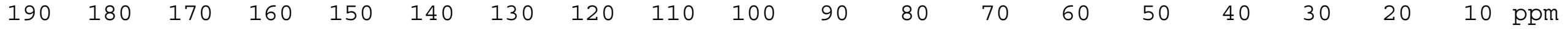



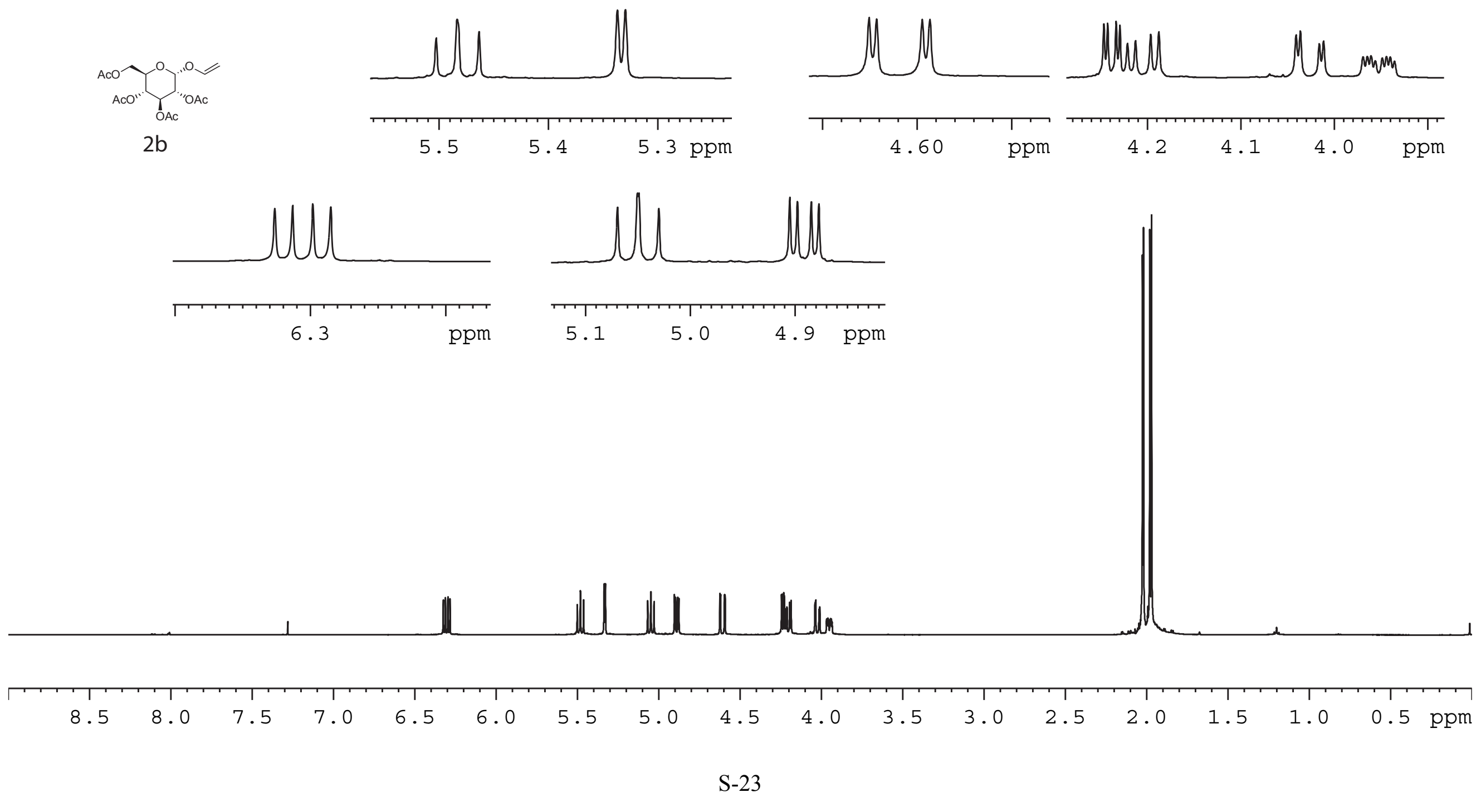


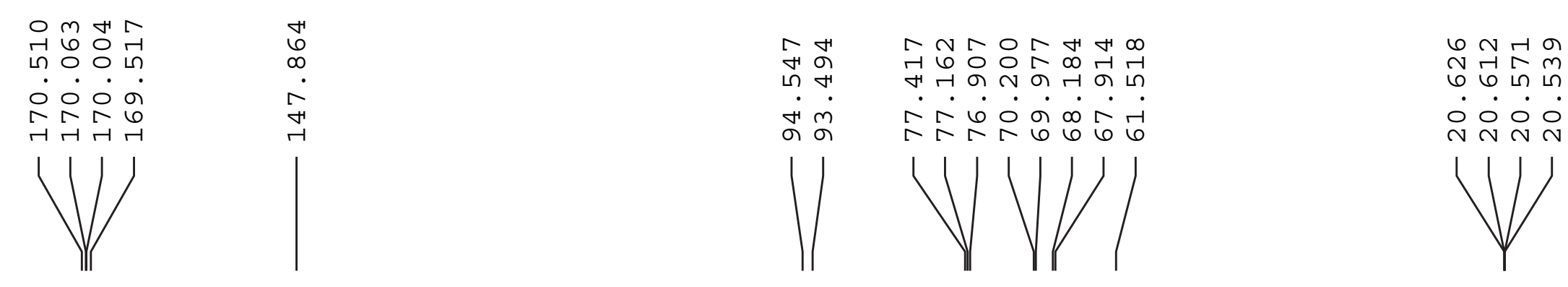

(1)

$2 b$

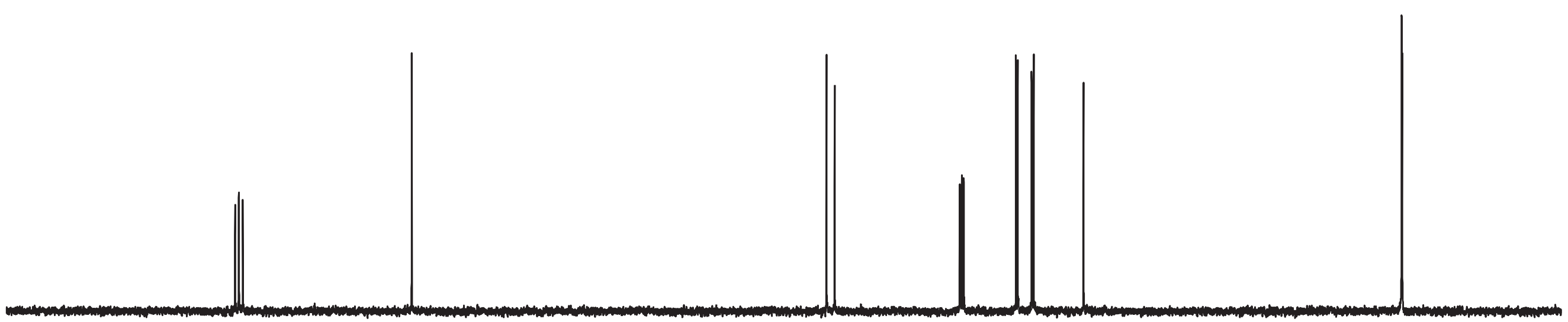



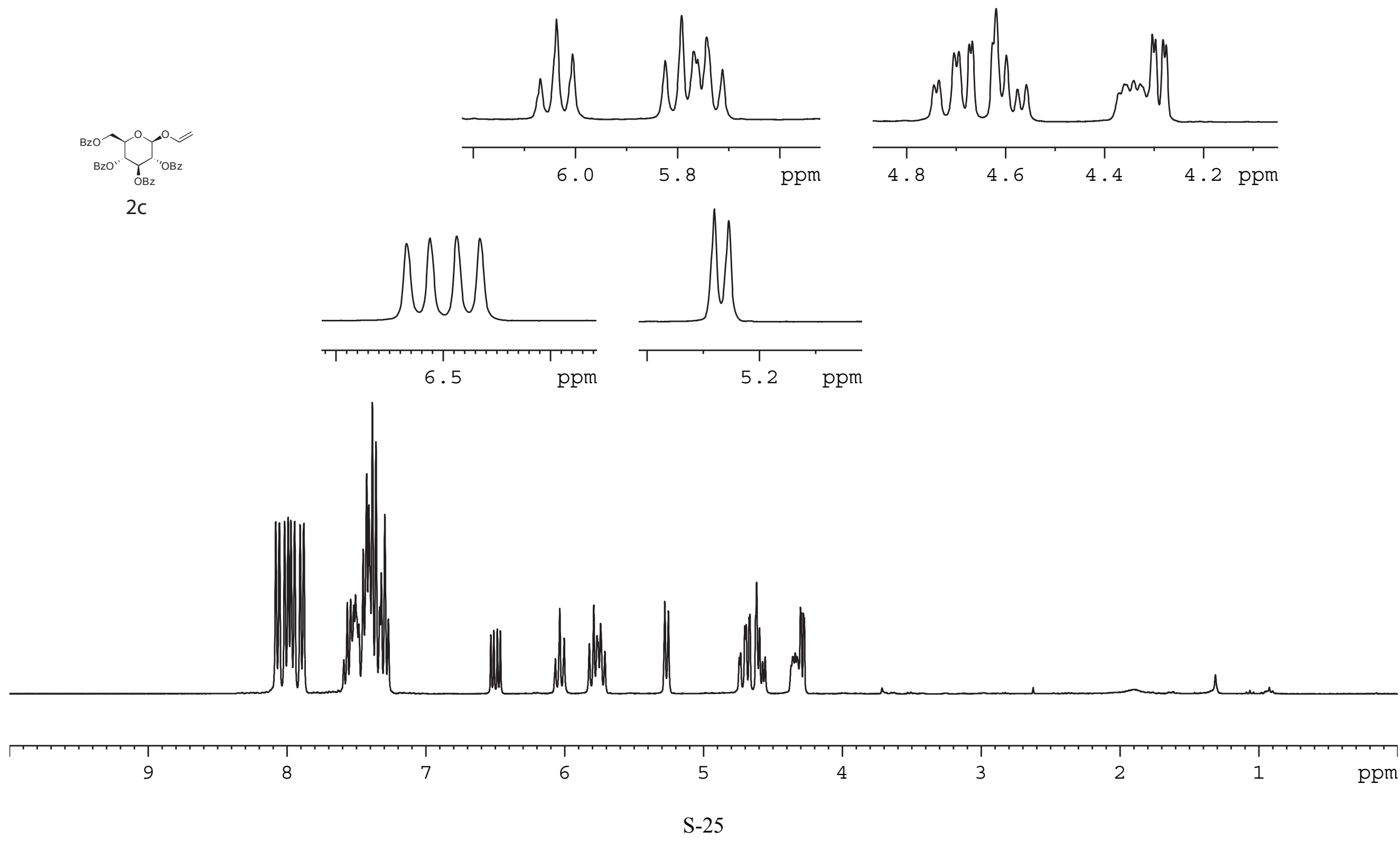
$\infty$ ๓ $\infty$ न

स 20 त

두 $\infty$

$\begin{array}{lll}0 & 0 & 0\end{array}$

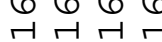

ก $m \sim \infty \Gamma$ ก

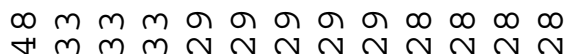

$\infty \quad 0 \quad$ n

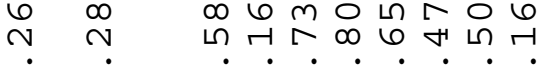

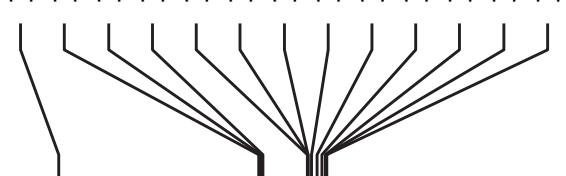

๙

กิ

(1)
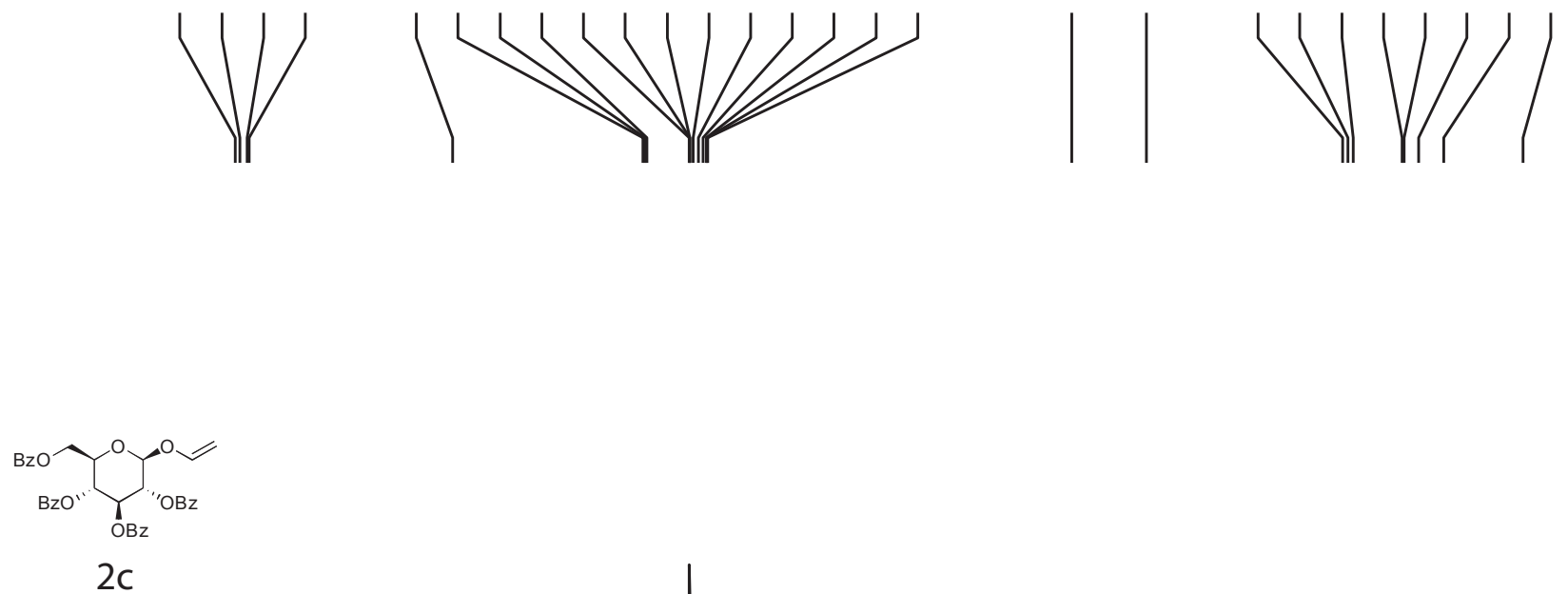

$2 \mathrm{C}$

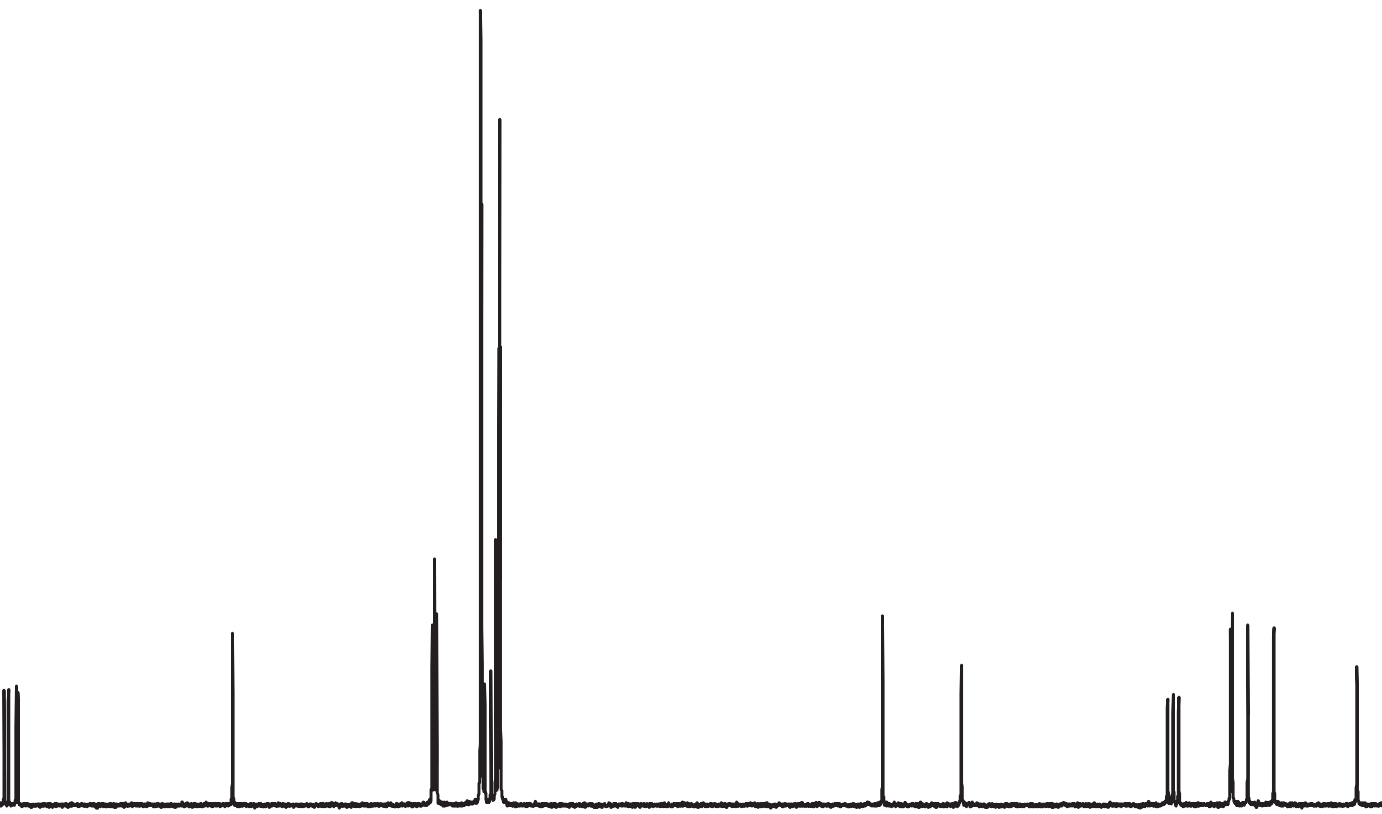

190

180

170

160

150

140

130

120

110

100

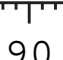

80

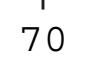

60

50

40

$30 \quad 20 \quad 10$ ppm 

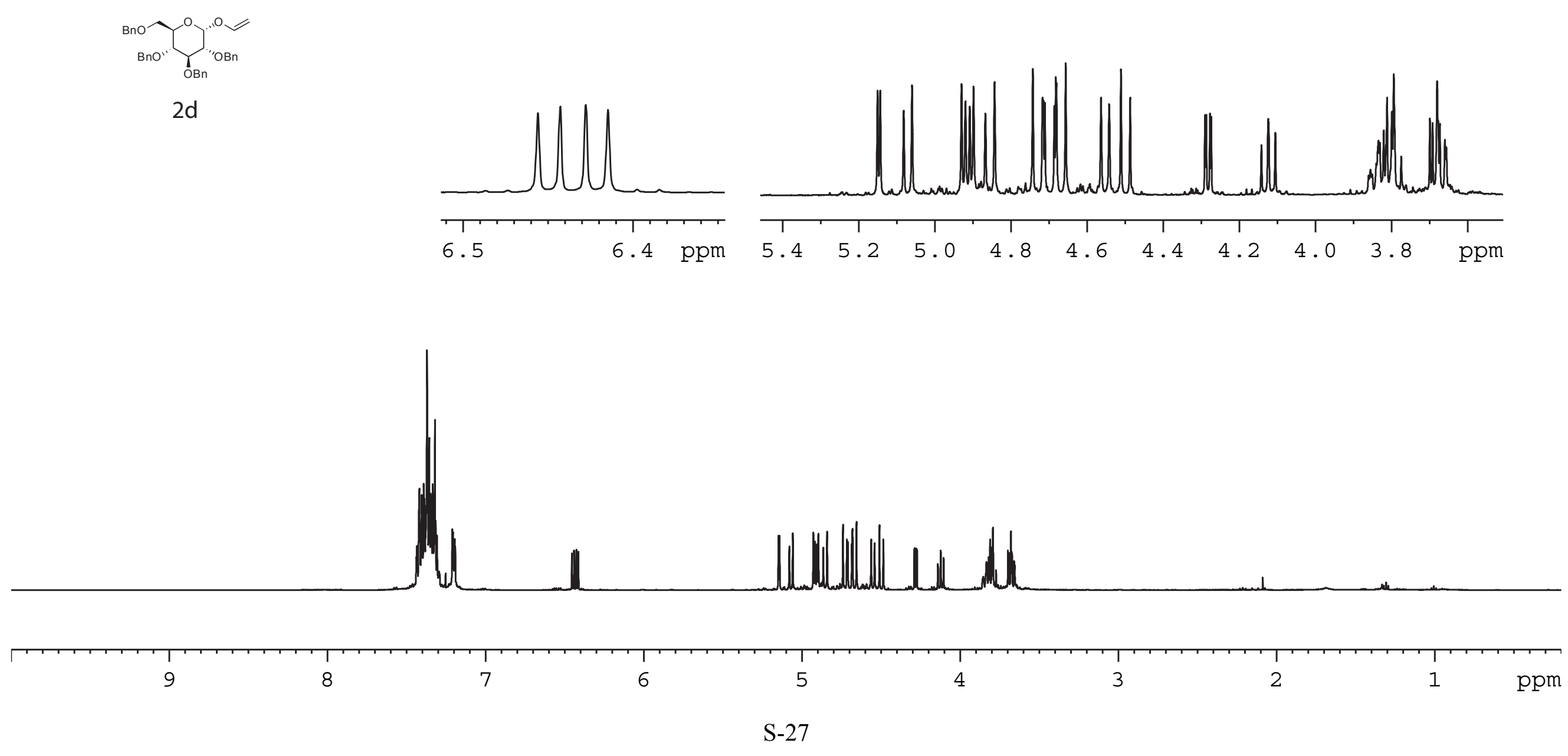


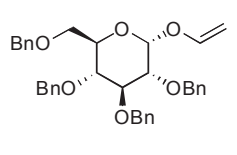

$2 d$

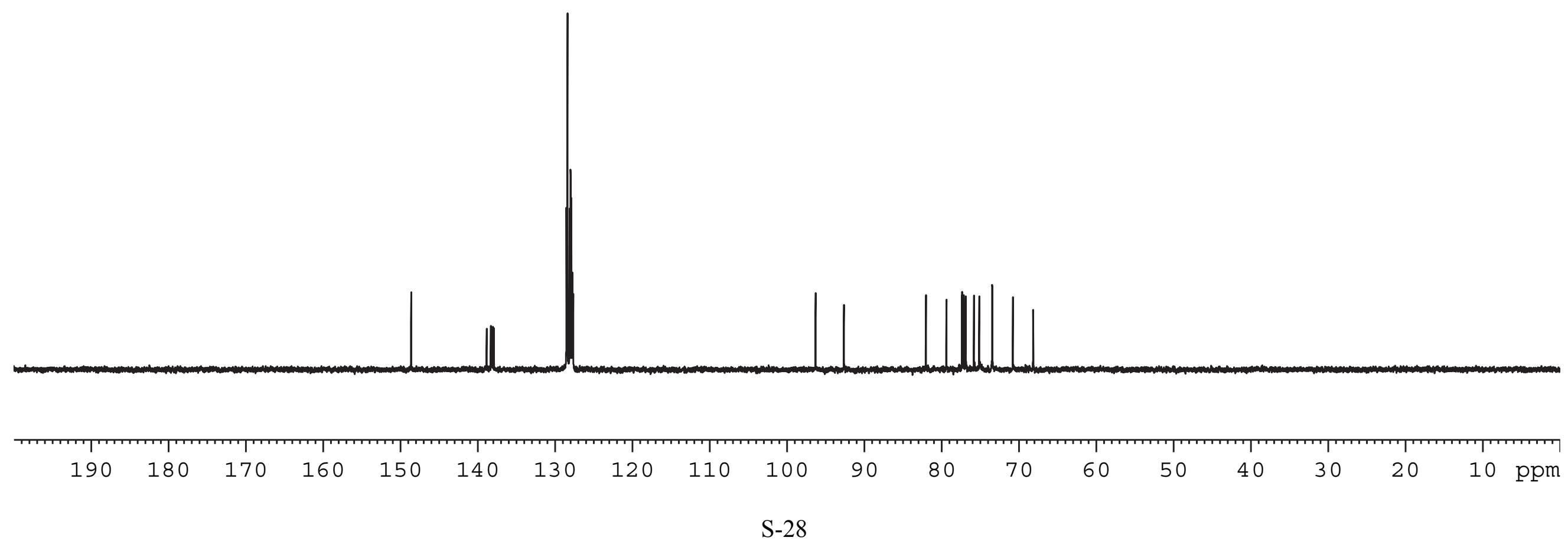



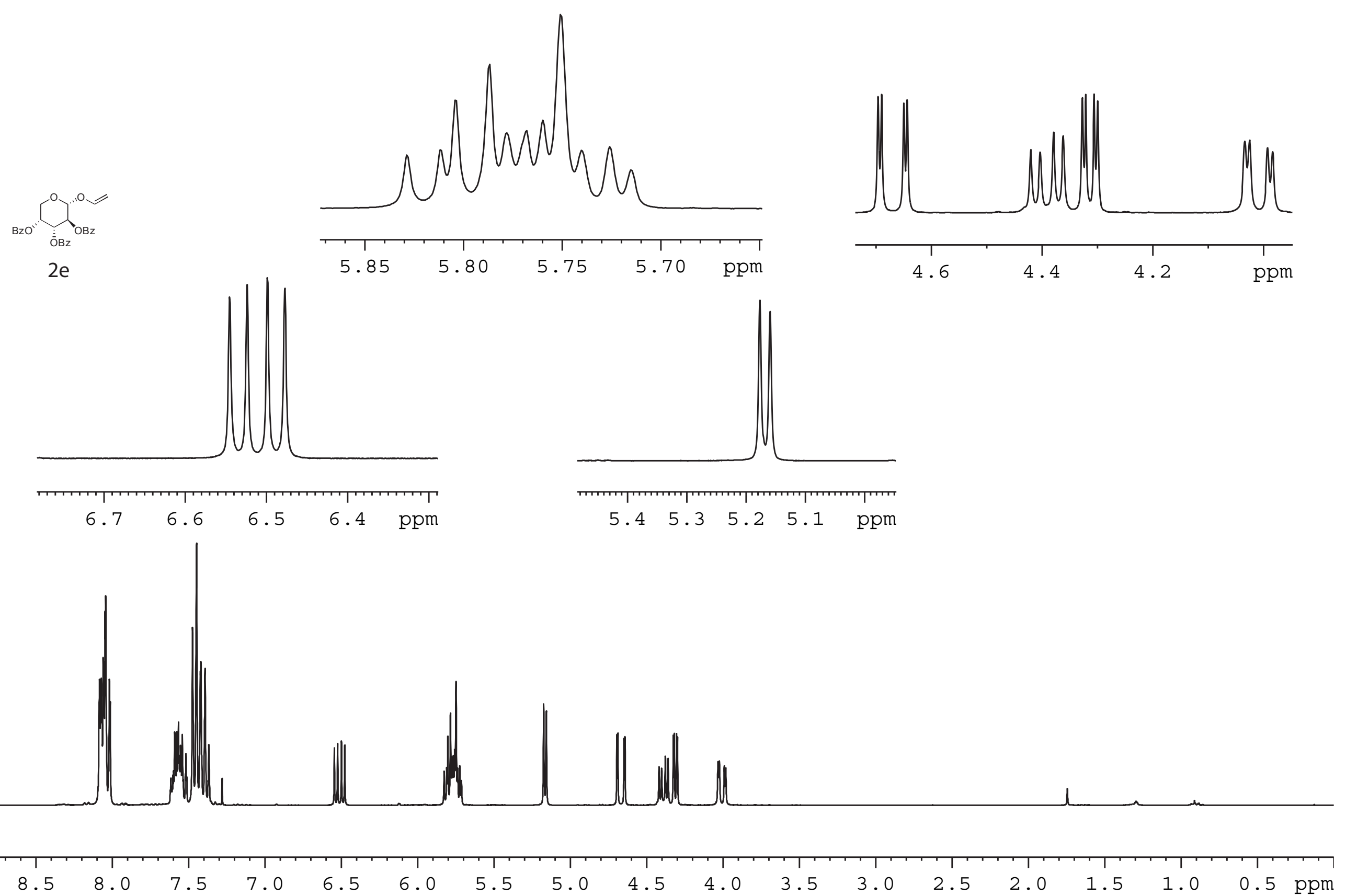

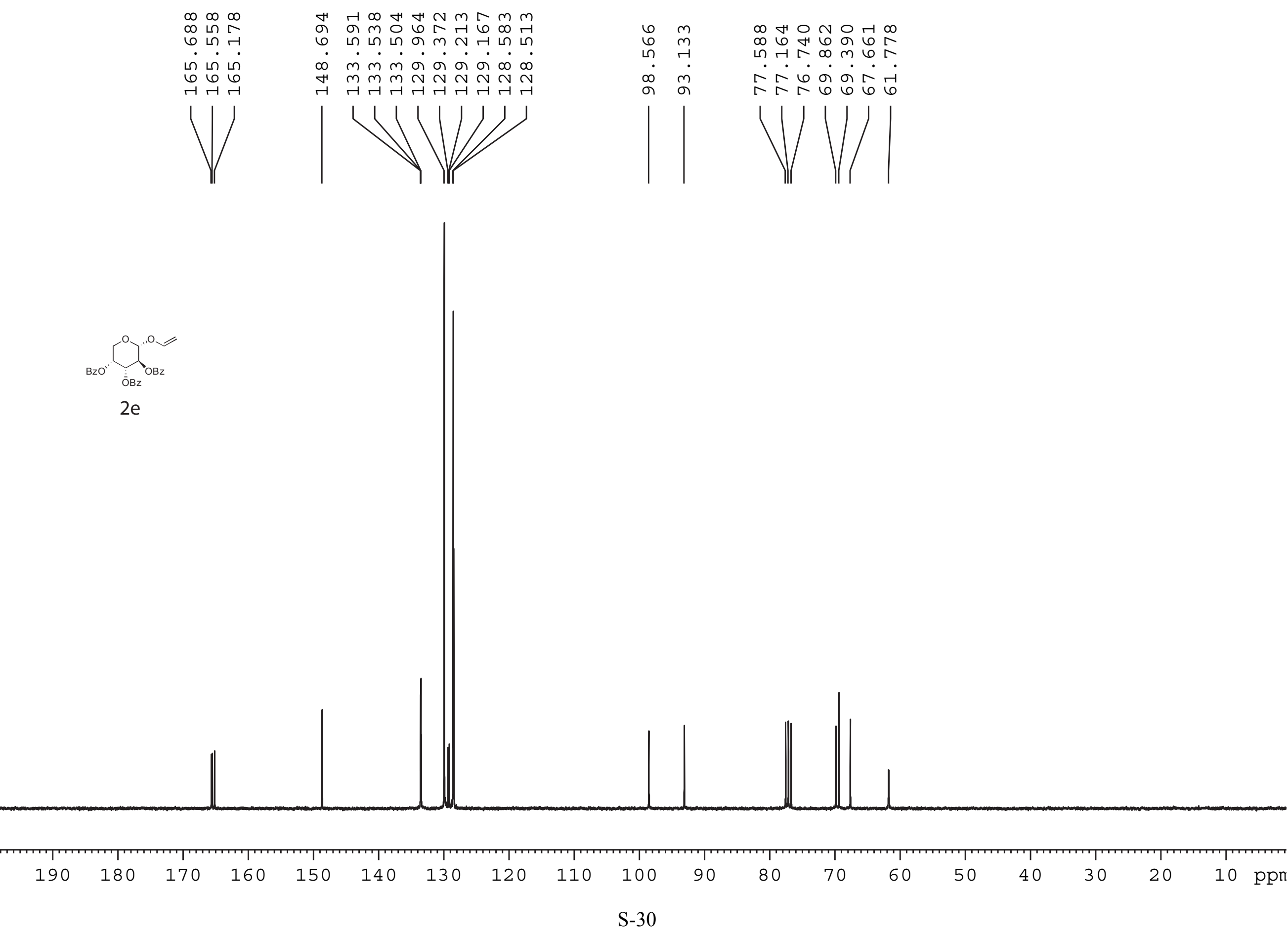

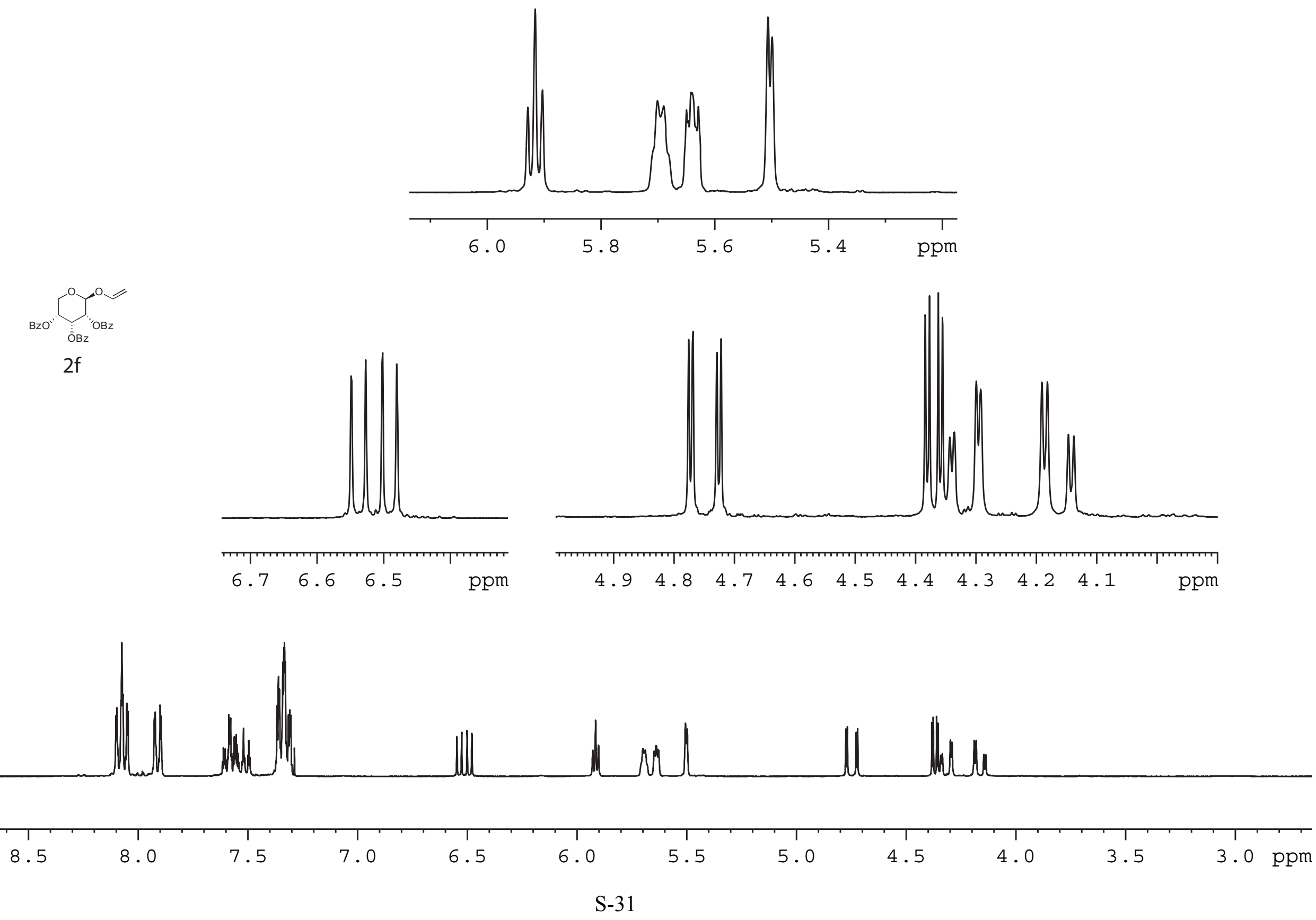

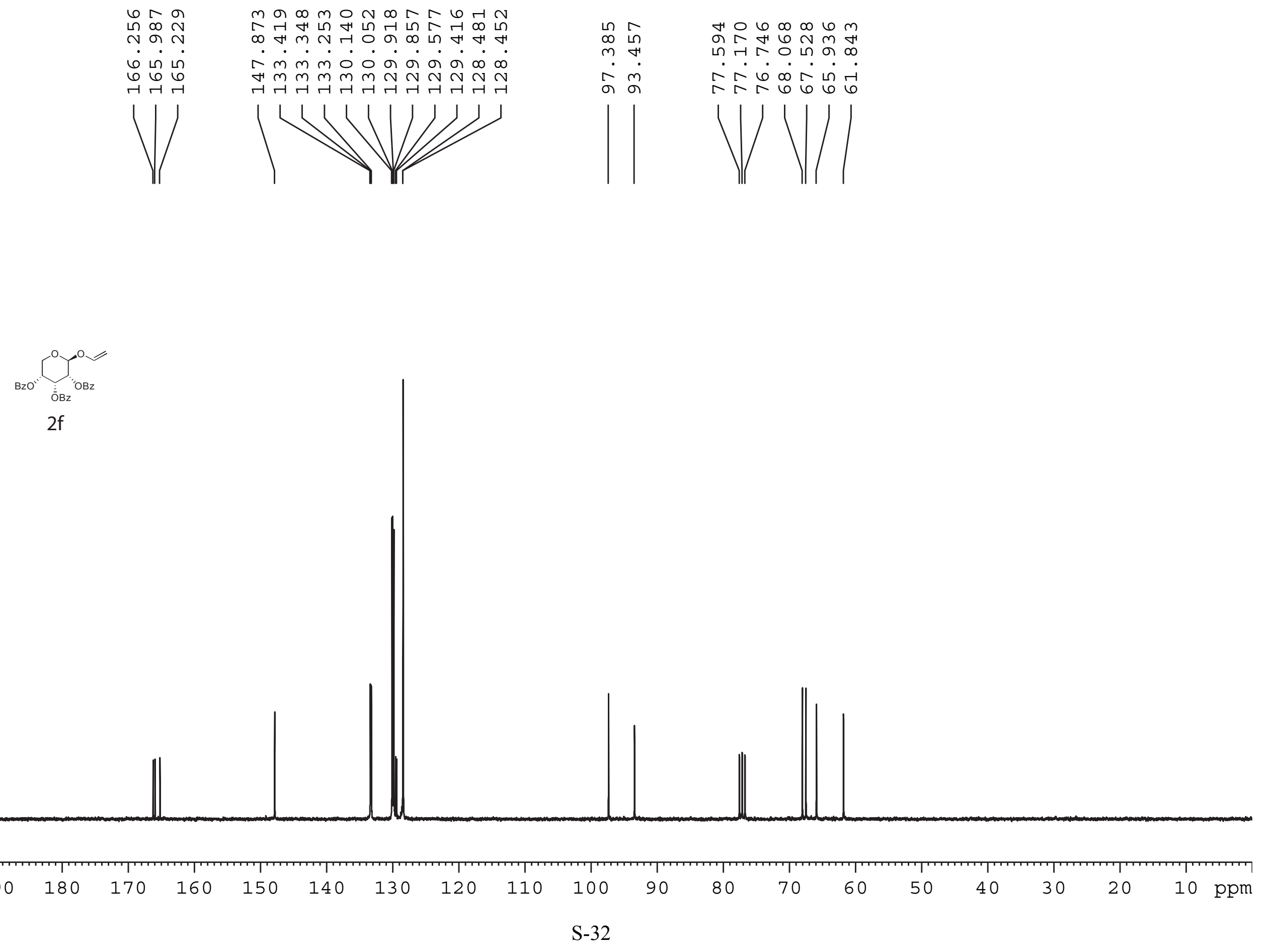


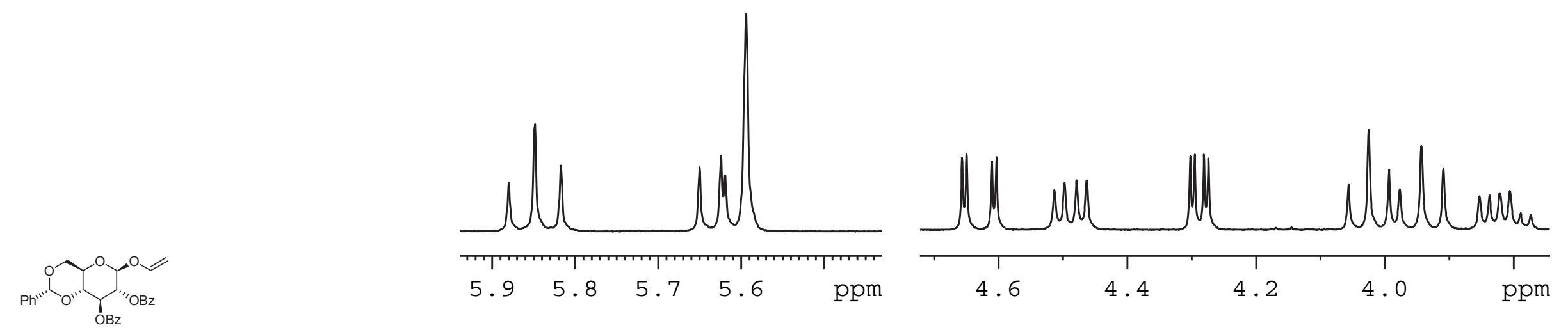

$2 \mathrm{~g}$
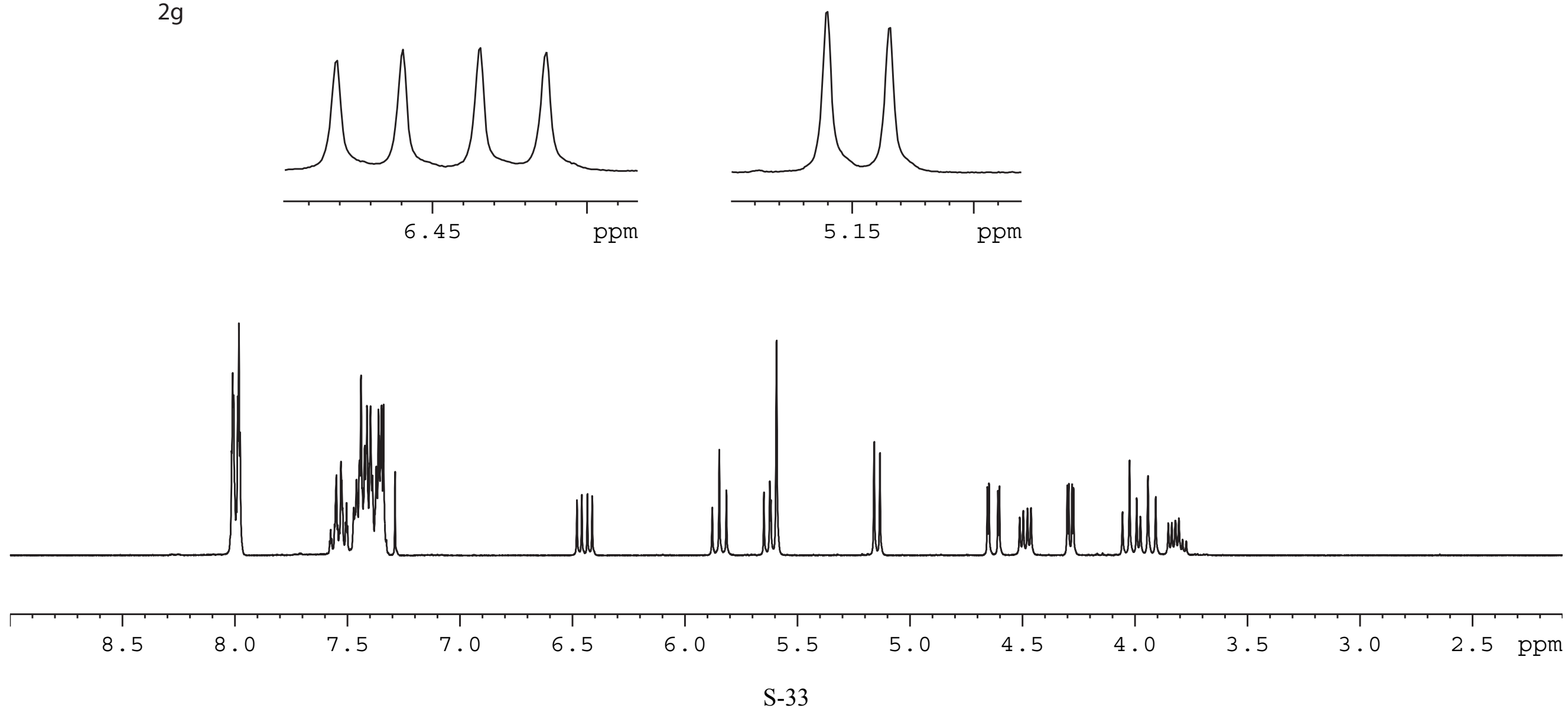

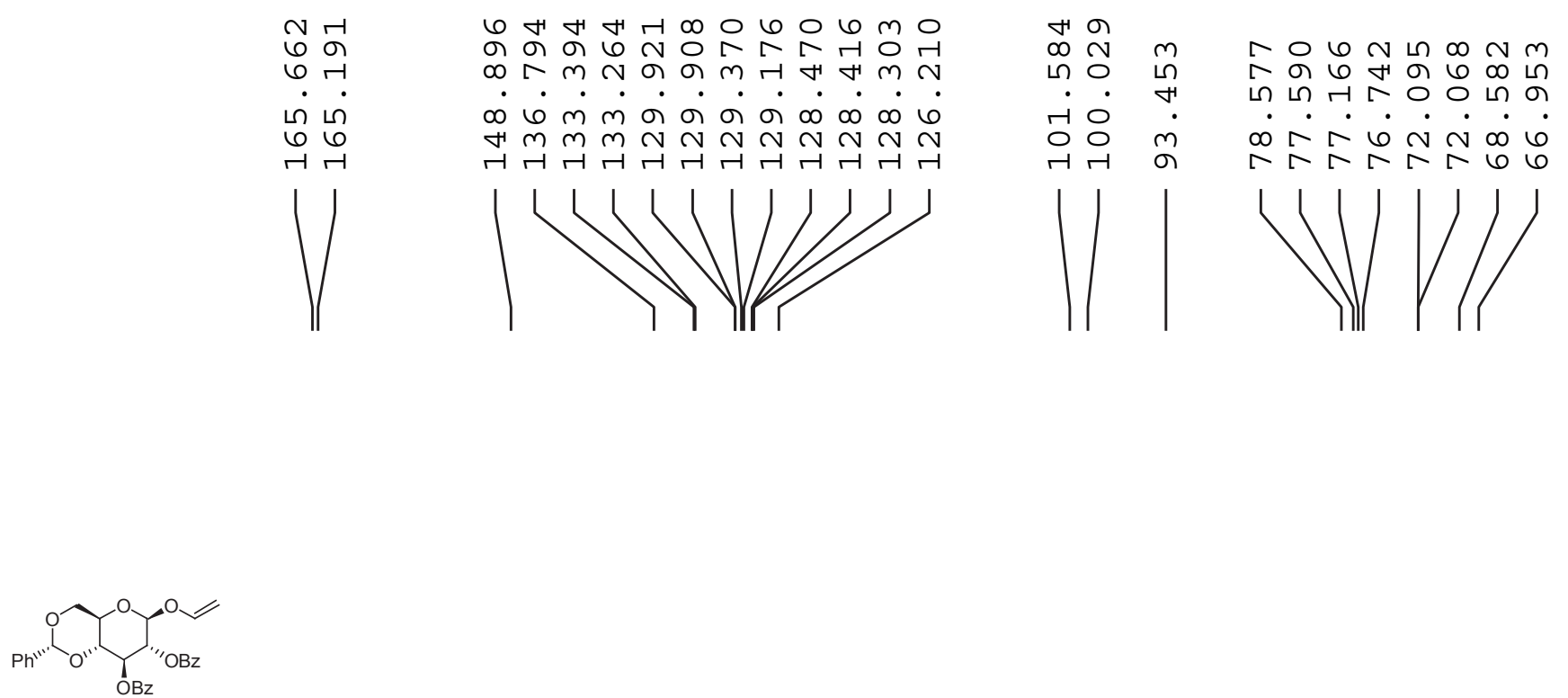

$2 \mathrm{~g}$

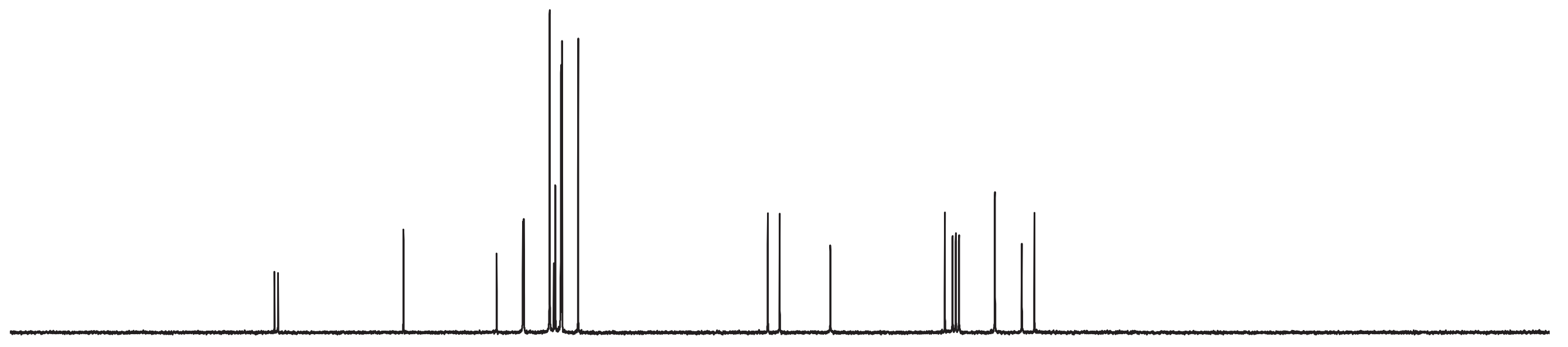



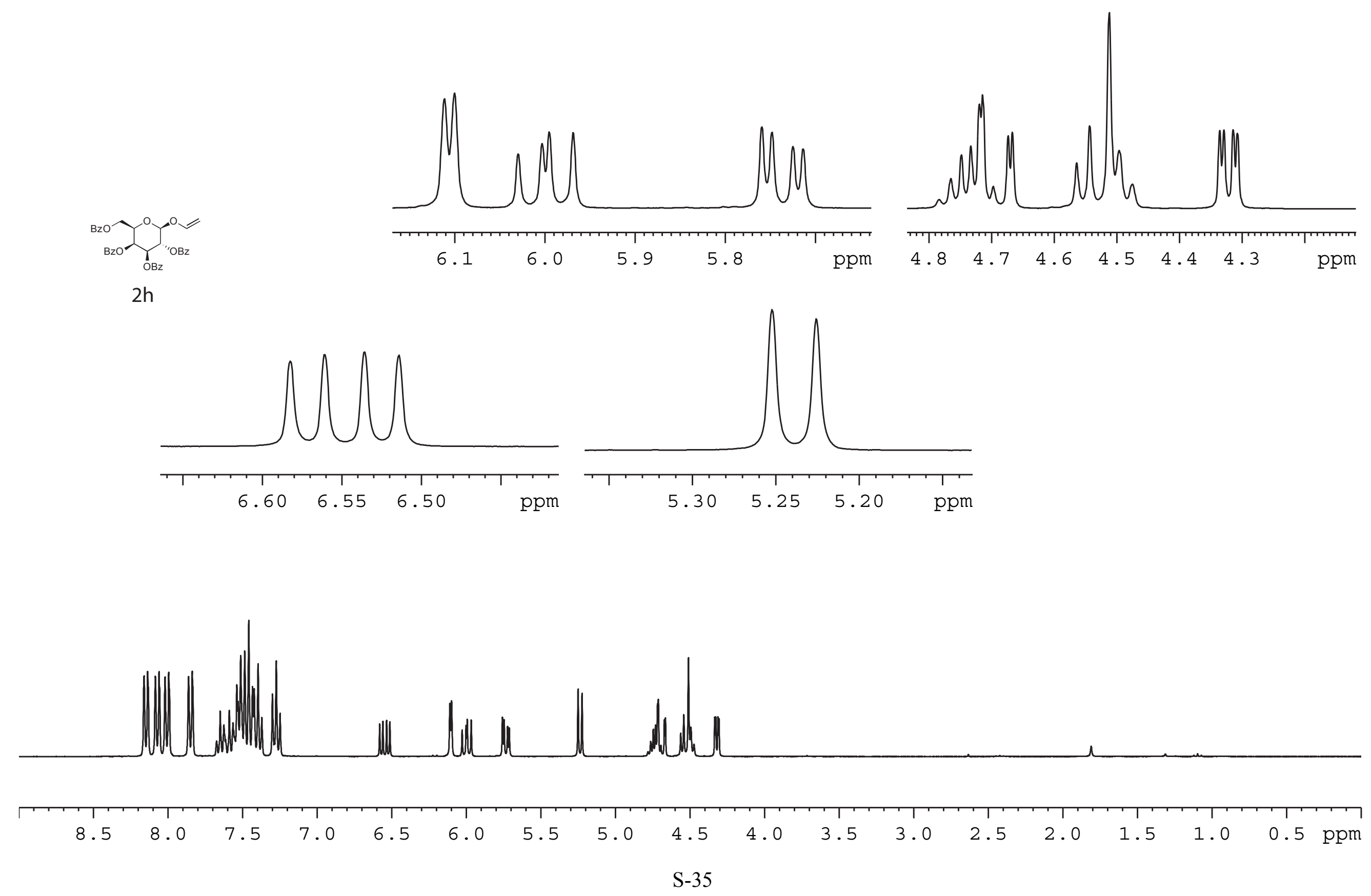

음
๓ $\infty$ ก $m \circ \infty m$ न बर
○ เก เก
$\dot{\infty} \dot{m} \dot{0} \dot{\sigma} \dot{\sigma} \dot{\infty} \dot{\infty} \dot{\infty} \dot{\infty} \dot{\infty}$
6 เ 6666

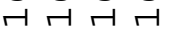

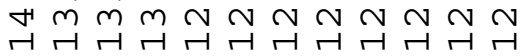
$6 \sim \infty \quad 6$ ब이
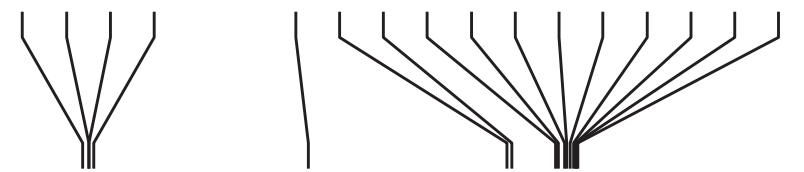
的닫다.

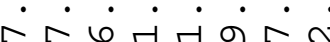

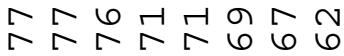

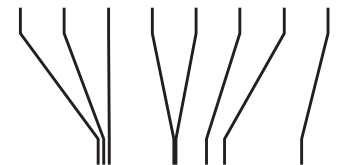

(OBBz

$2 \mathrm{~h}$
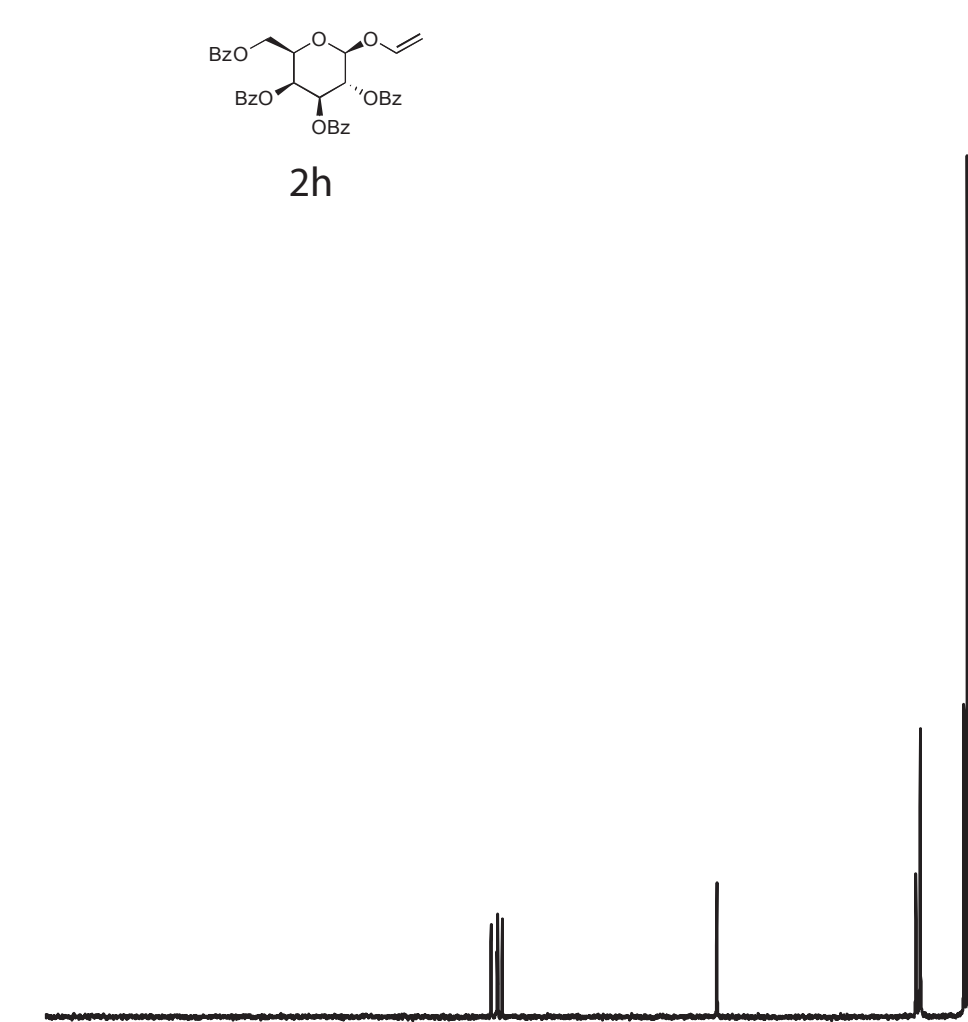

190

180

170

160

150

140

130

120

110

10

\section{S-36}



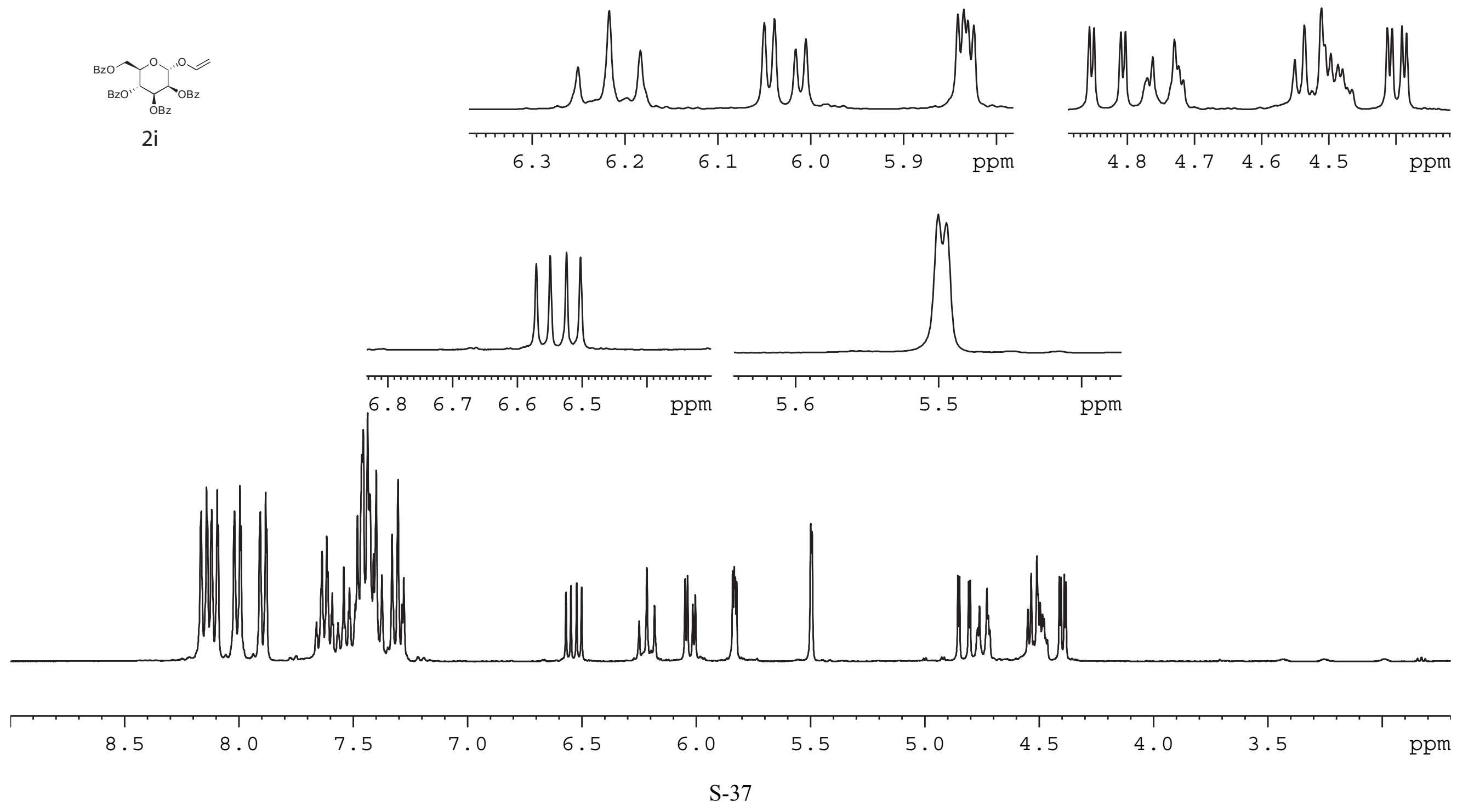
당다

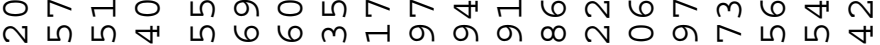
$\dot{0} \dot{n} \dot{m} \dot{m} \dot{m} \dot{\sigma} \dot{\sigma} \dot{\sigma} \dot{\sigma} \dot{\sigma} \dot{\infty} \dot{\infty} \dot{\infty} \dot{\infty}$ $6666+m m m m N N N \sim N N N$ H
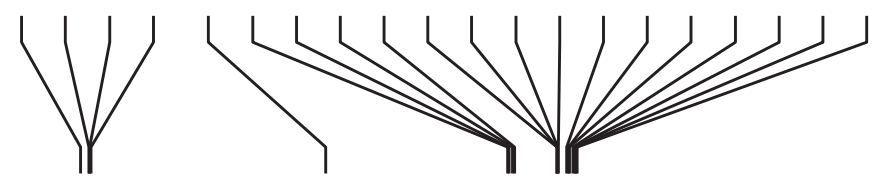

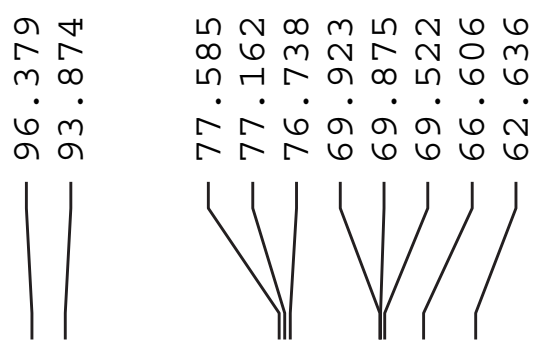
ம ก
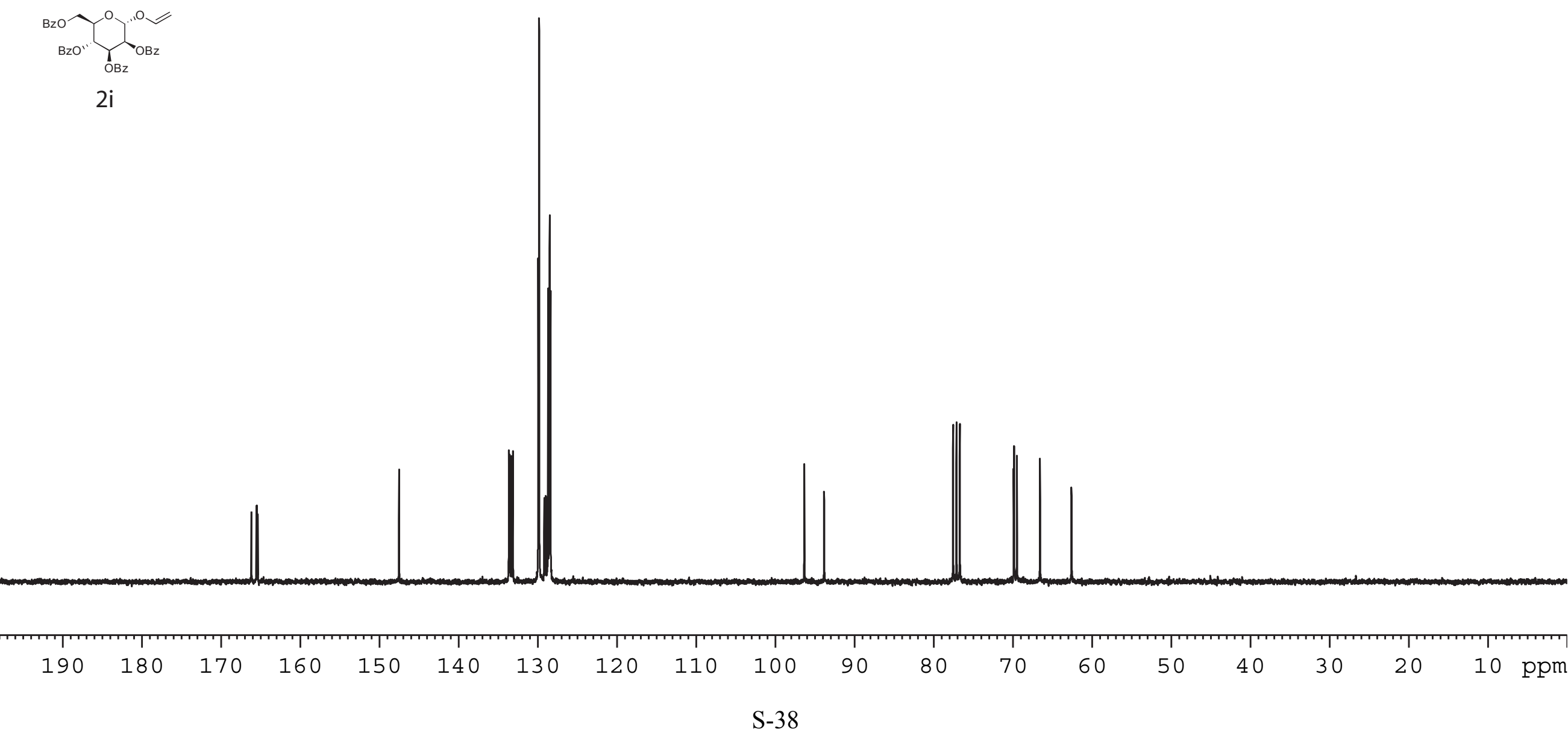


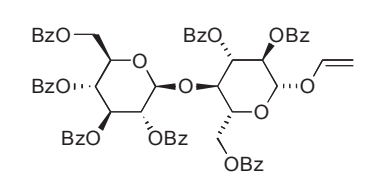

$2 \mathrm{k}$
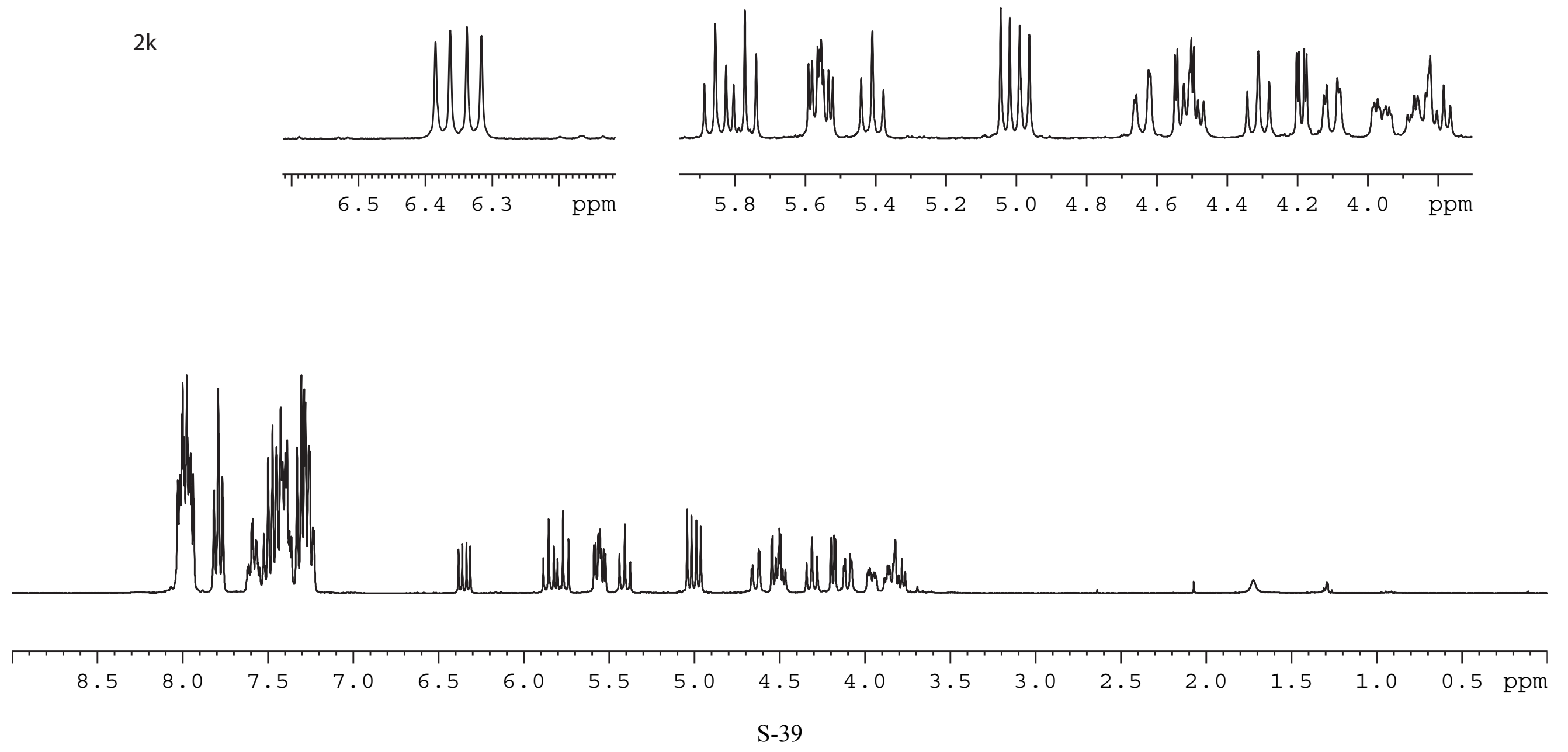


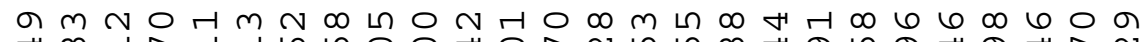

Ho

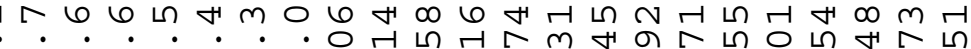

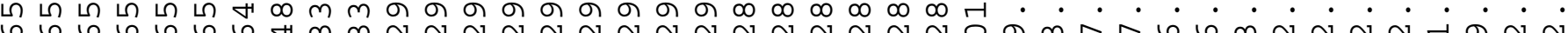

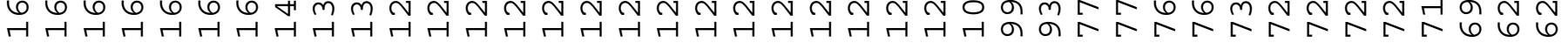
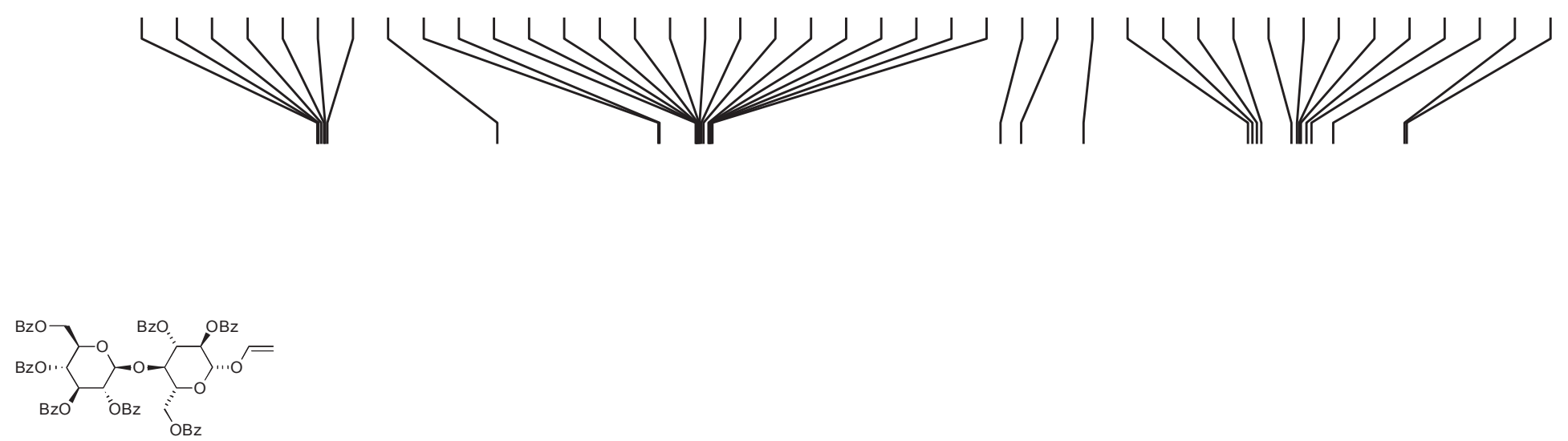

$2 \mathrm{k}$
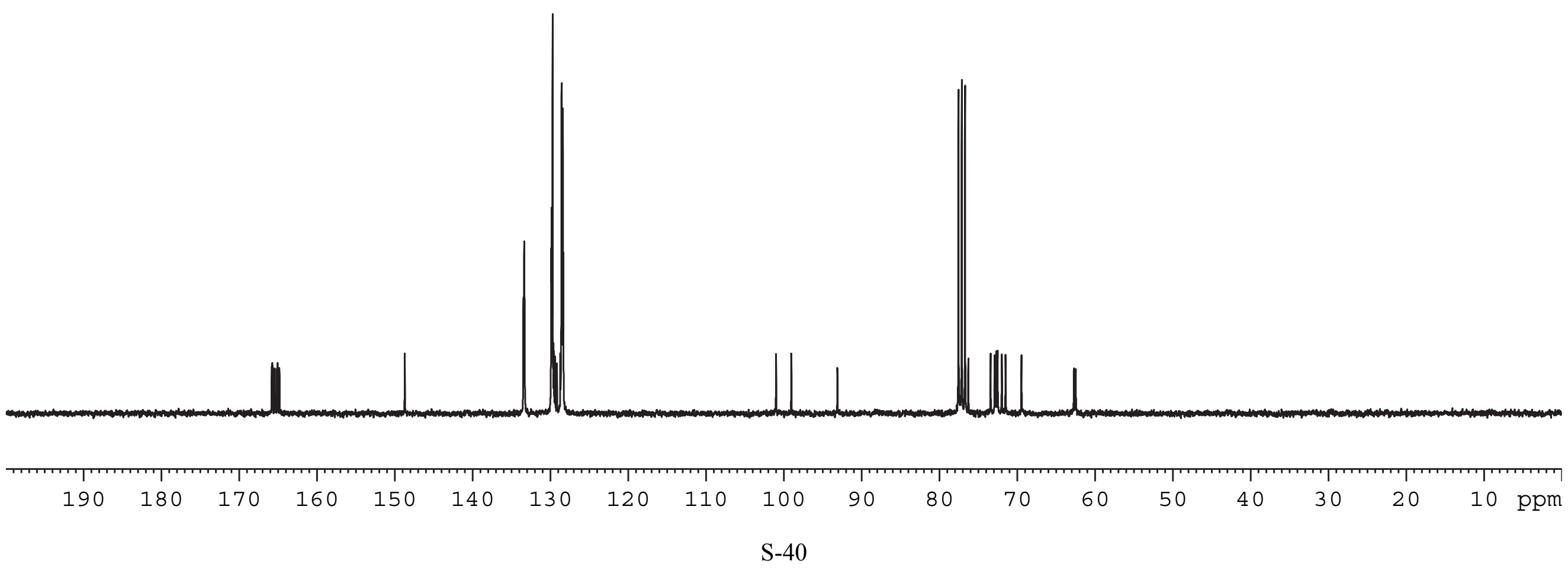

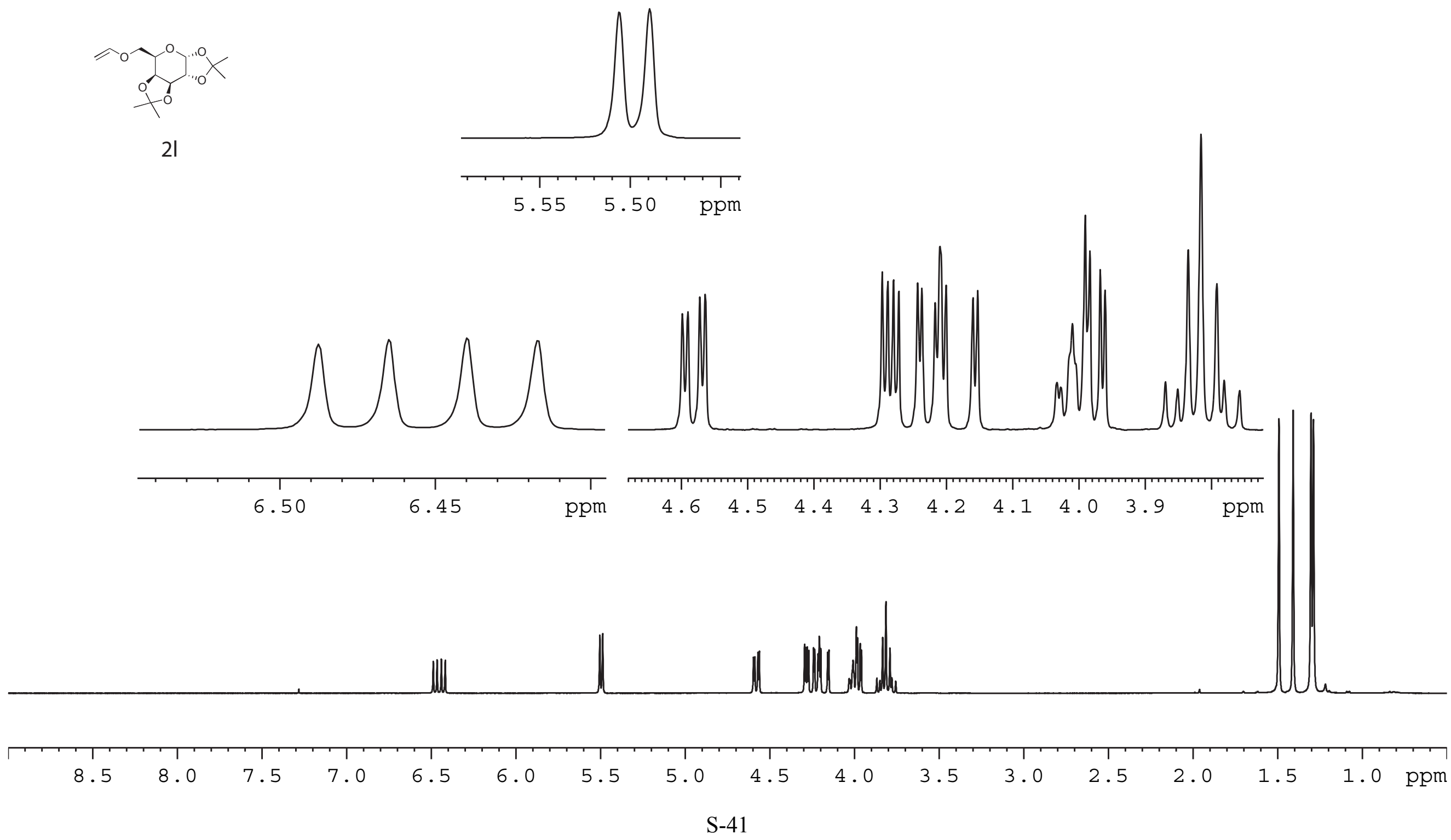

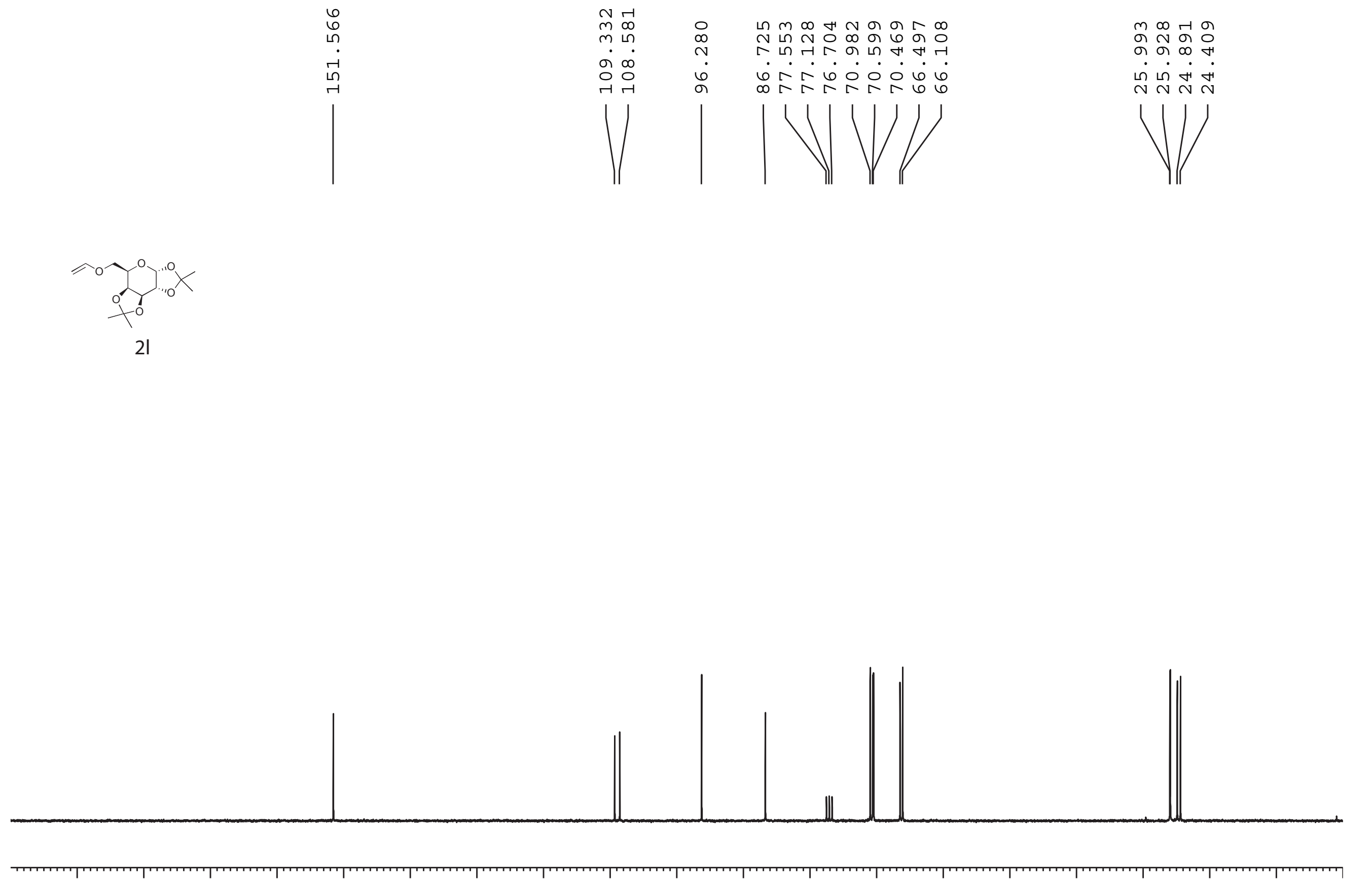

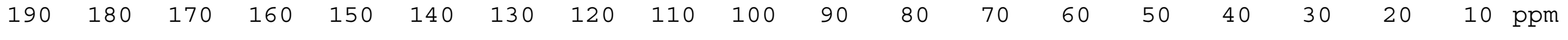



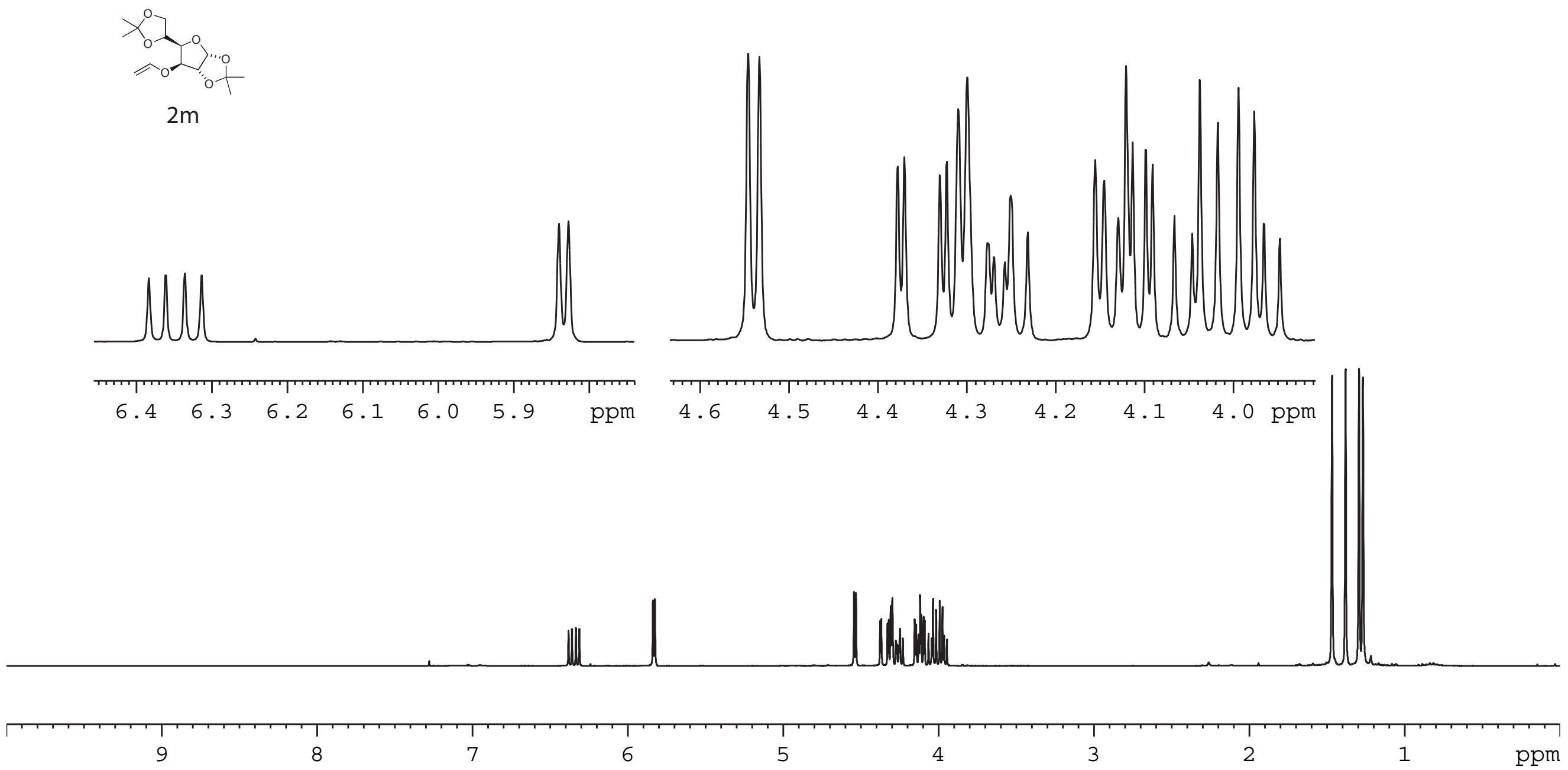

S-43 


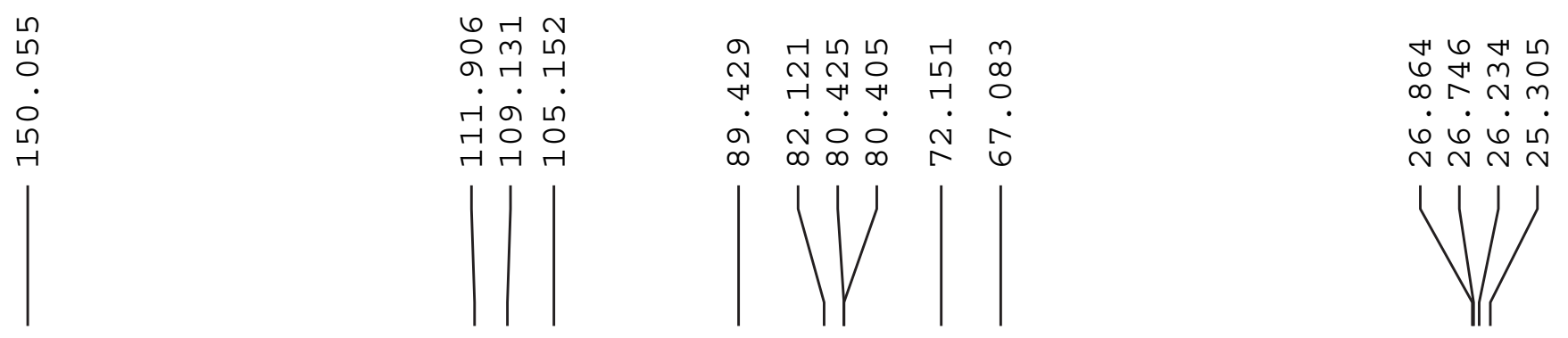
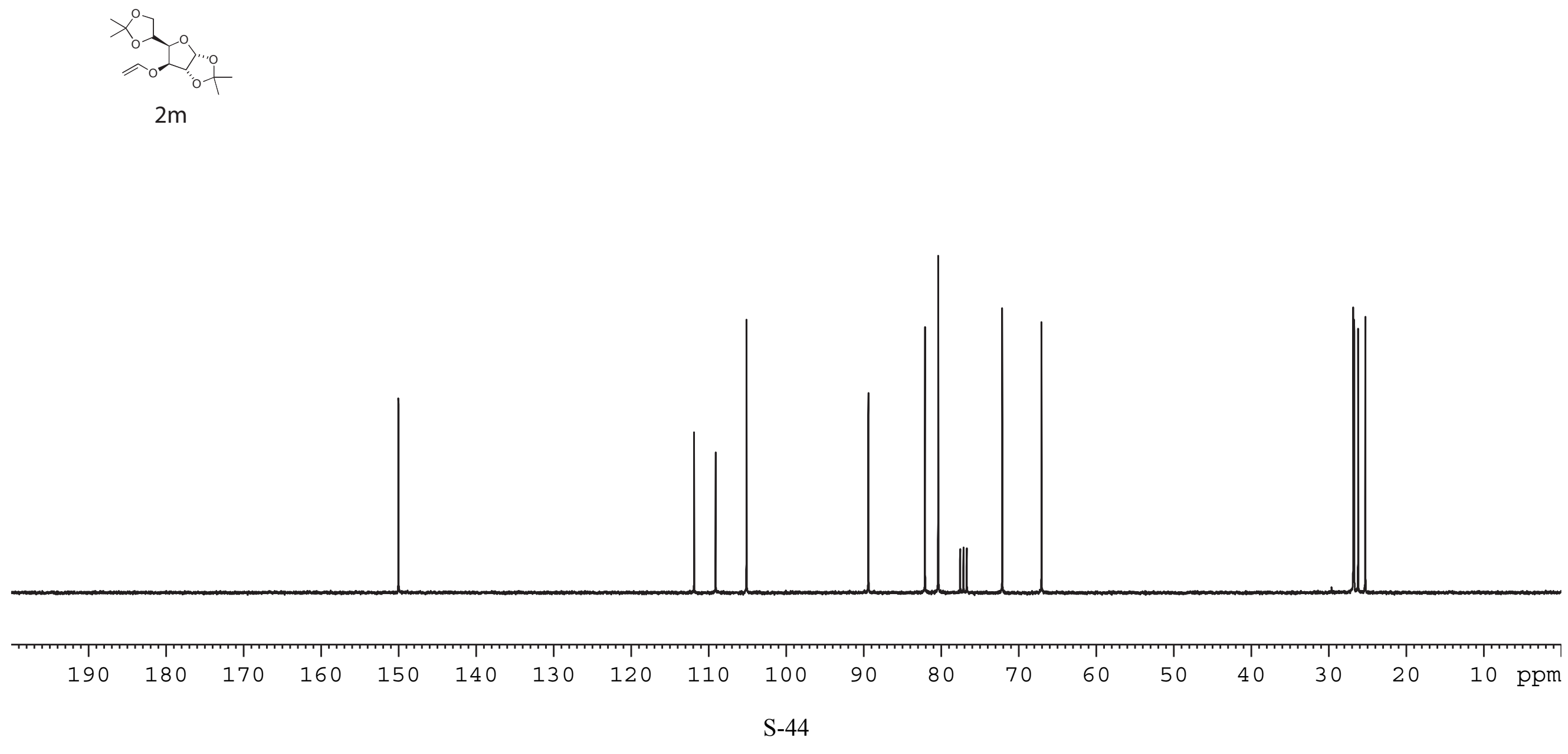


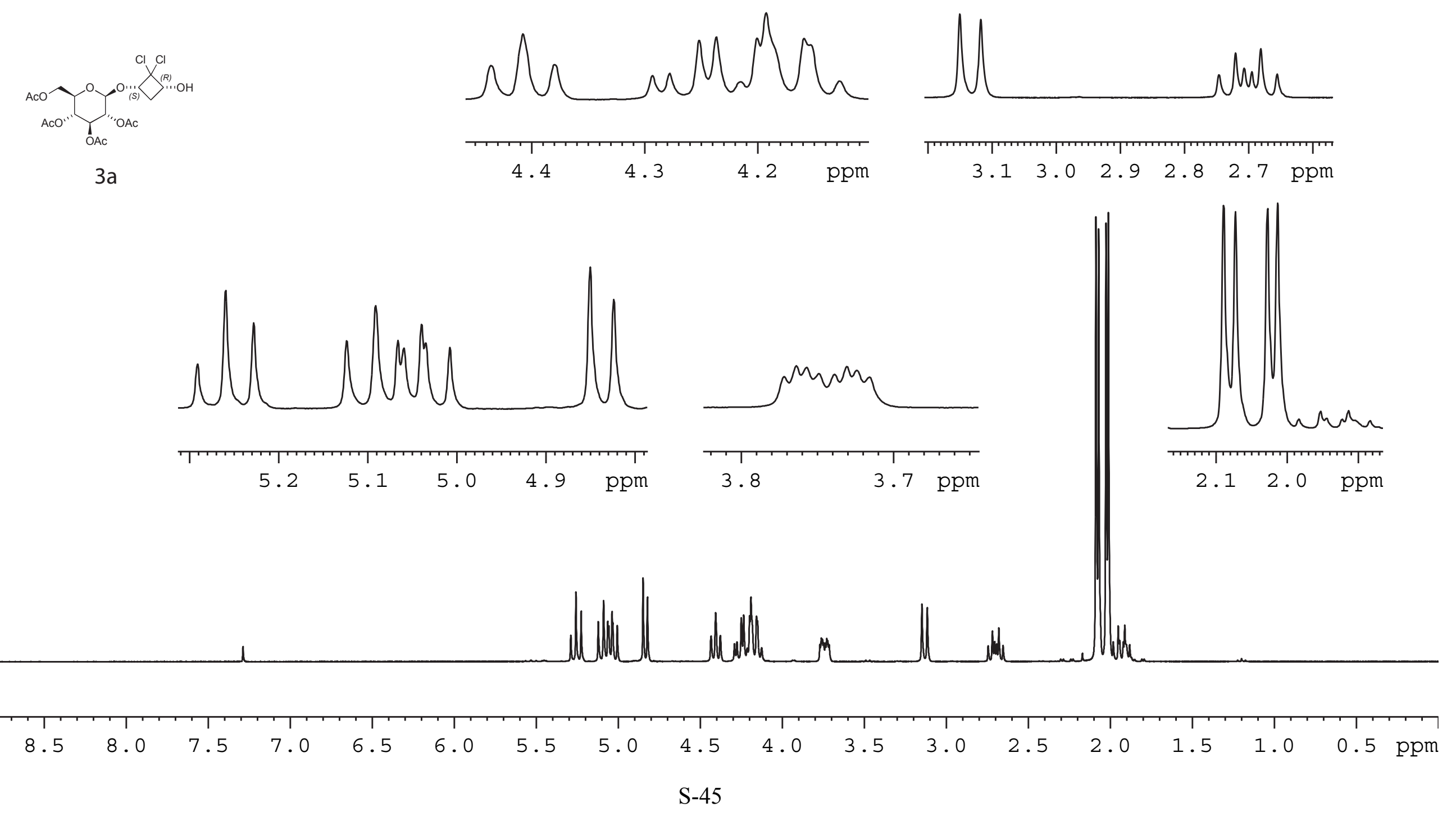



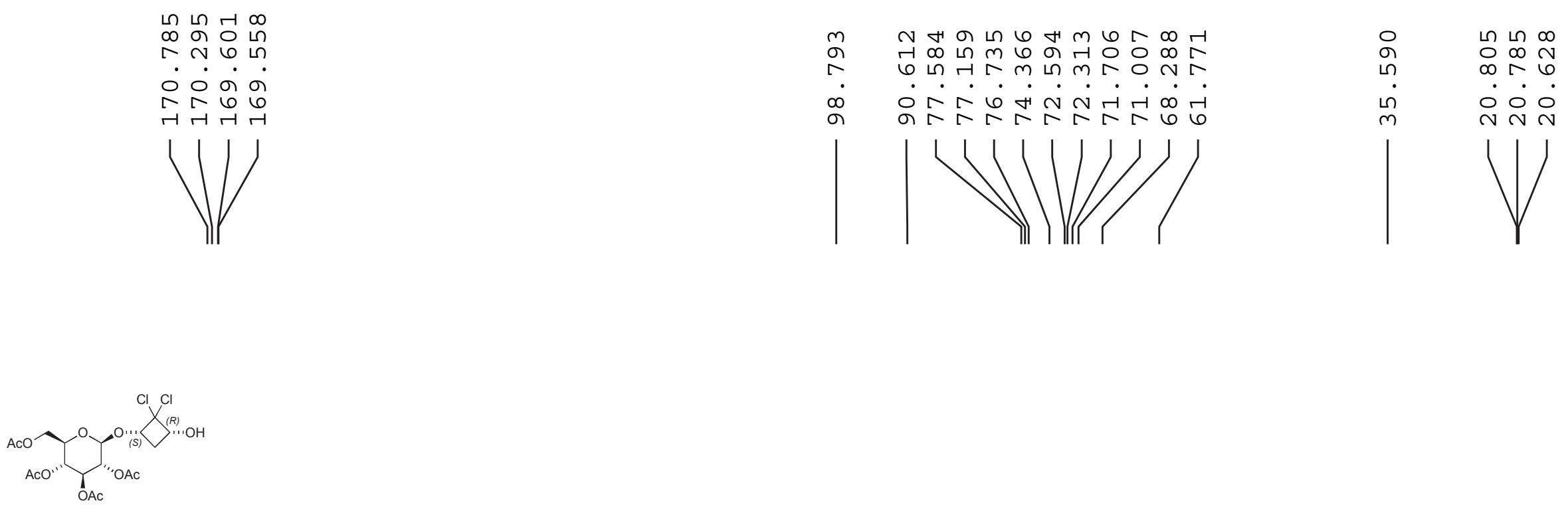

$3 a$
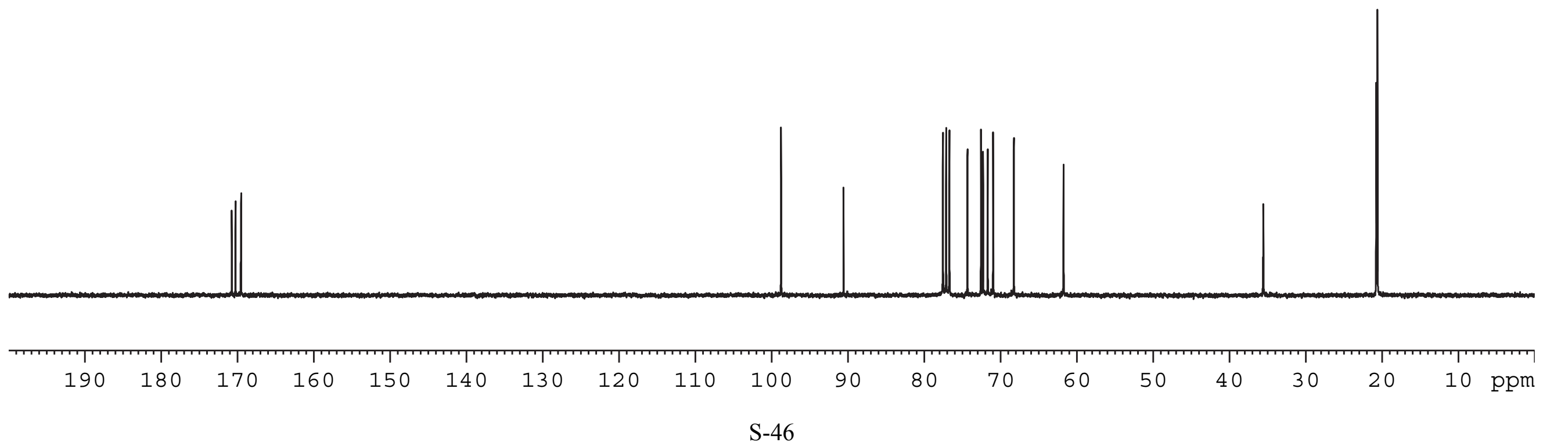

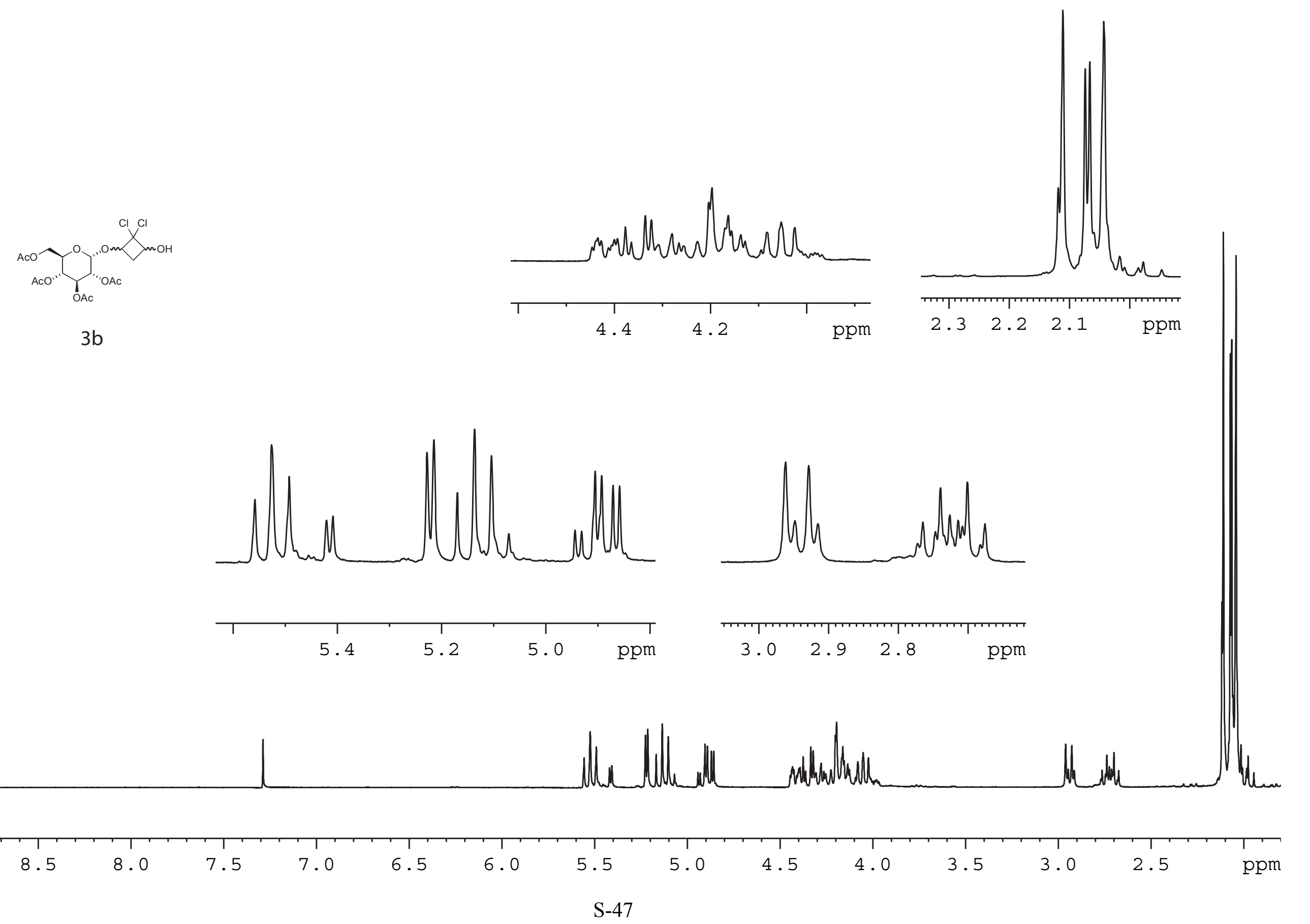
Nก 요대 $\infty$ ก ல் 다잉
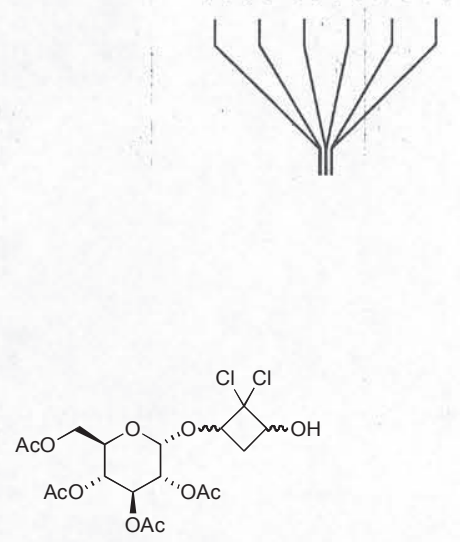

$3 b$
अ

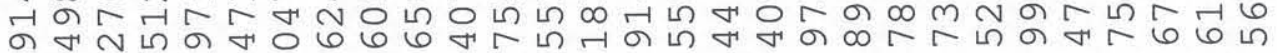
$\dot{0} \dot{0} \cdot \dot{0} \dot{0} \dot{0} \dot{0} \dot{0} \dot{0} \dot{0} \dot{0} \dot{0} \dot{0} \dot{0} \dot{0} \dot{0}$ б̆

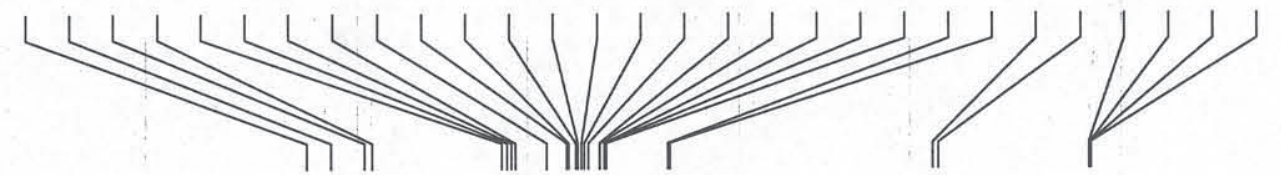

(a) 


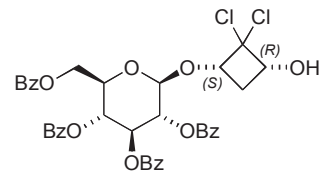

$3 c$

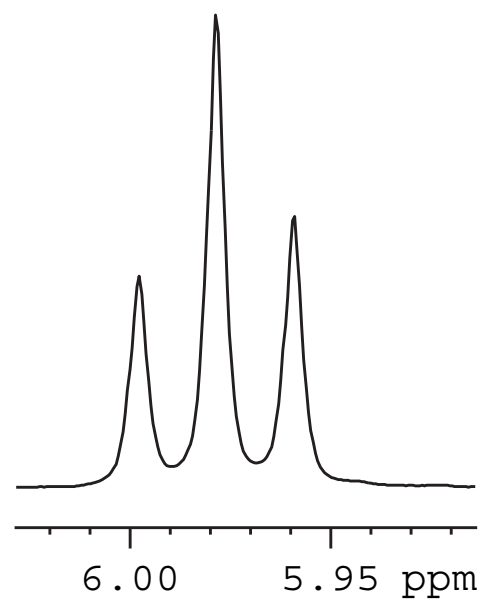

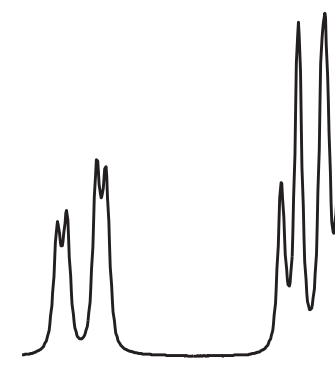

$\begin{array}{lllllll}4.6 & 4.5 & 4.4 & 4.3 & 4.2 & \text { ppm }\end{array}$

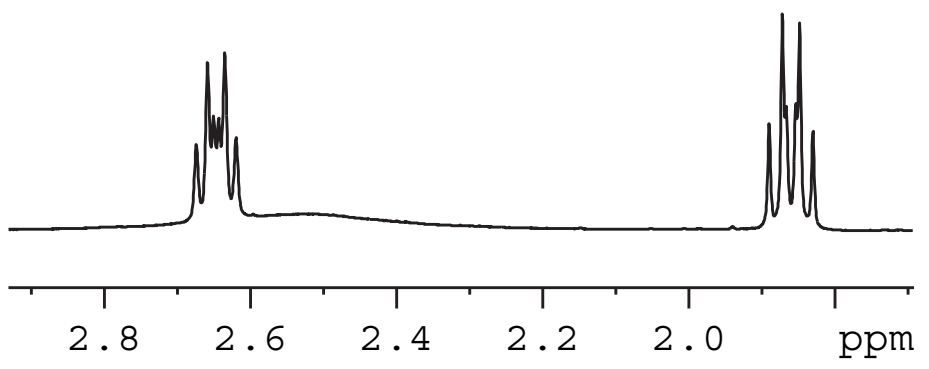

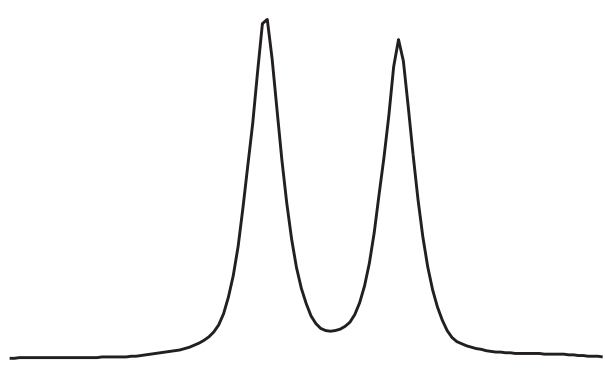

\begin{tabular}{llll}
\hline .26 & 5.24 & 5.22 & ppm
\end{tabular}

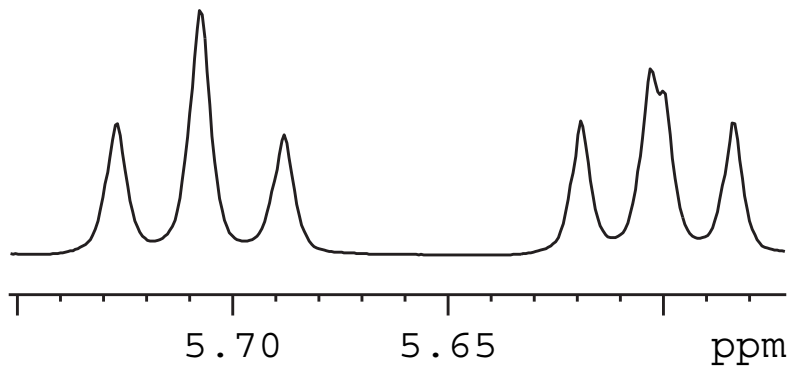


윰ำ $\sim \infty \mathrm{m}$ in 6666 다 $-1+1$

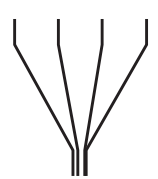
6 म $m m m \infty \propto \infty \propto \infty \infty \infty \infty \infty \infty$

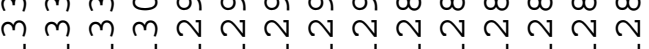

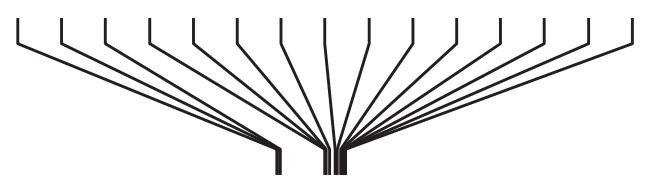

Gा

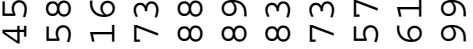
ब
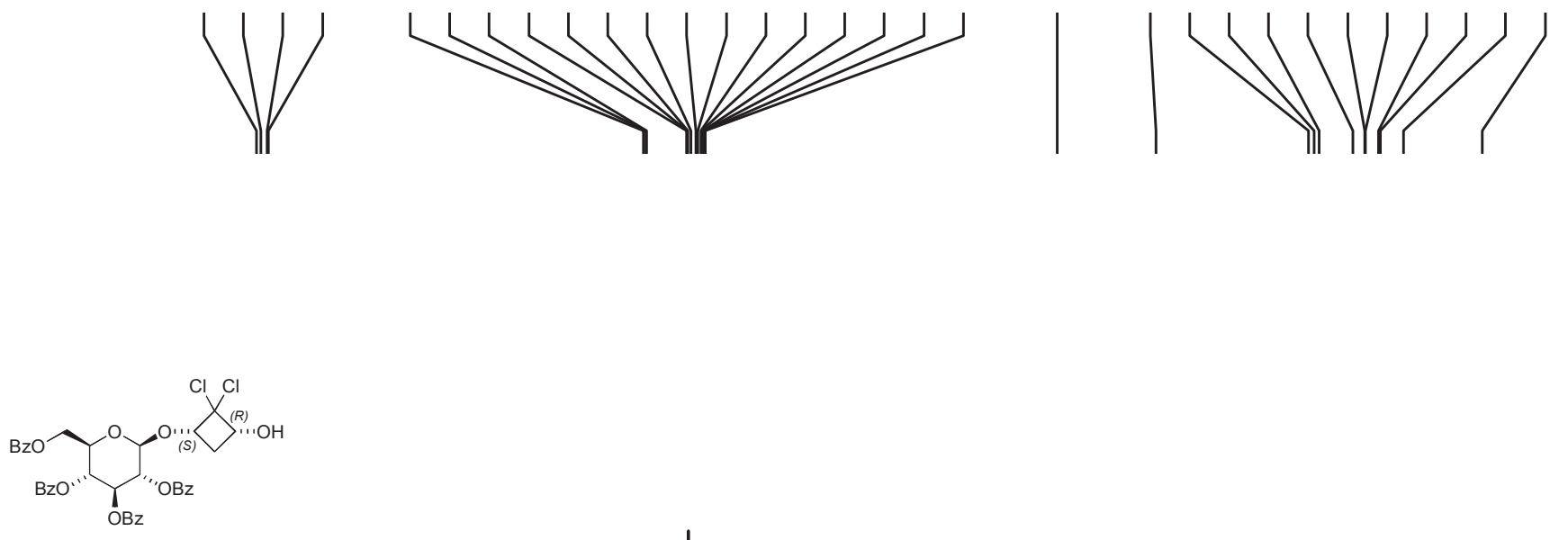

$3 c$ 

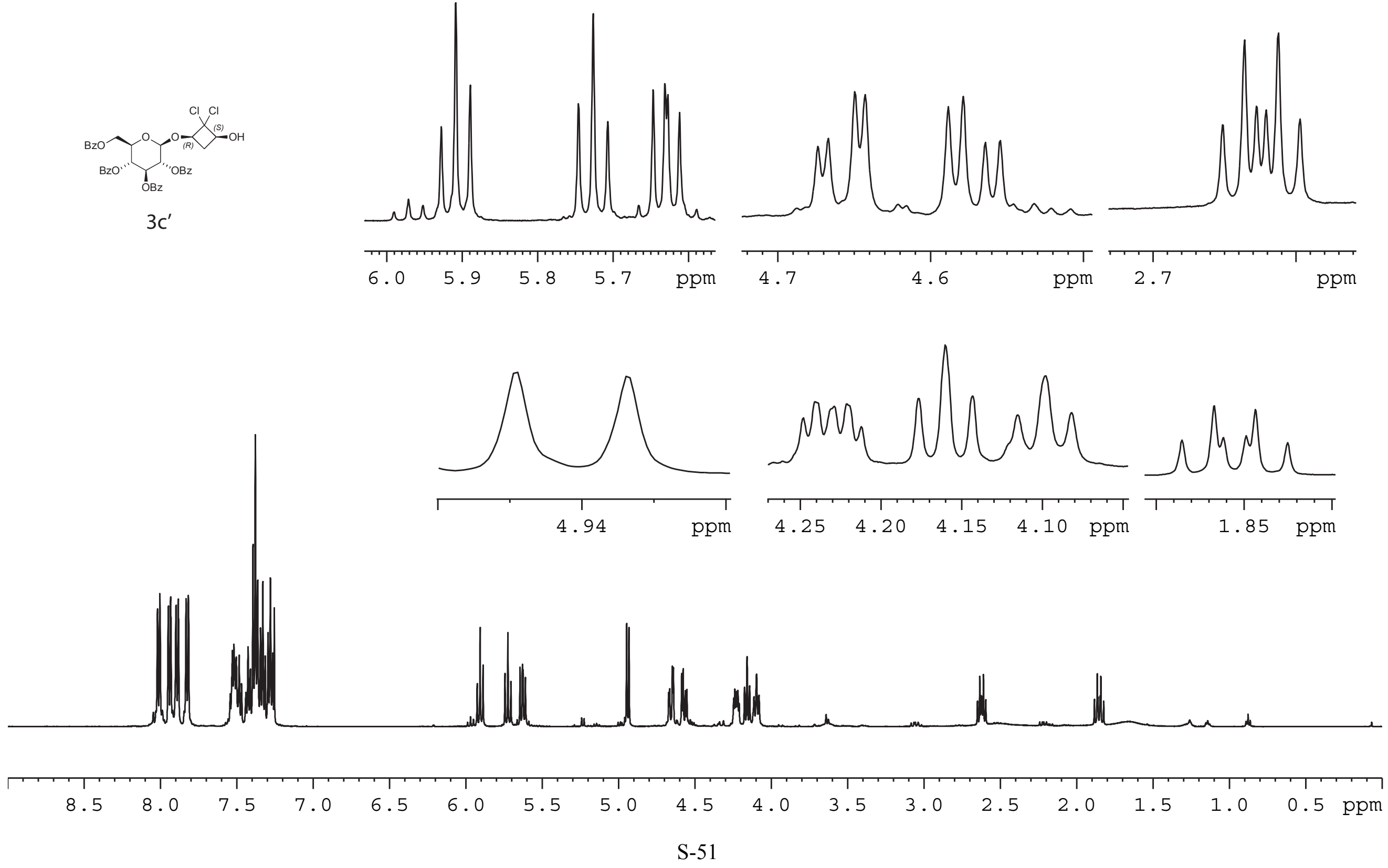


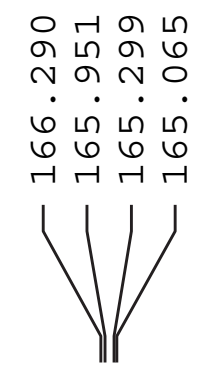

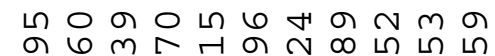

ถึ

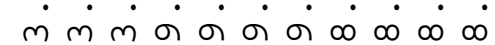

$m m m \sim N \sim N N \sim N N$

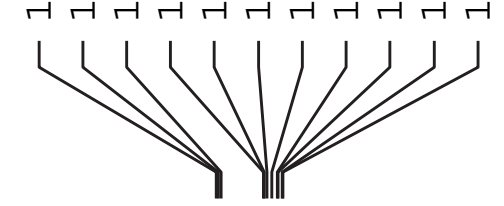

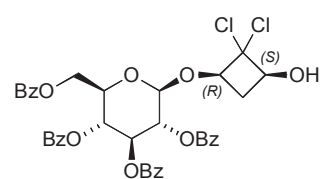

$3 c^{\prime}$
-1
0

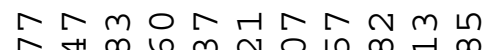

구의

-

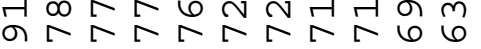

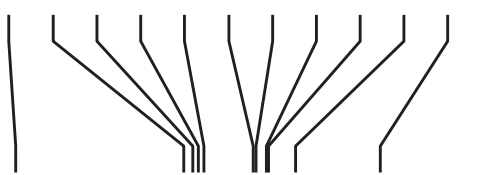

6

เ

m
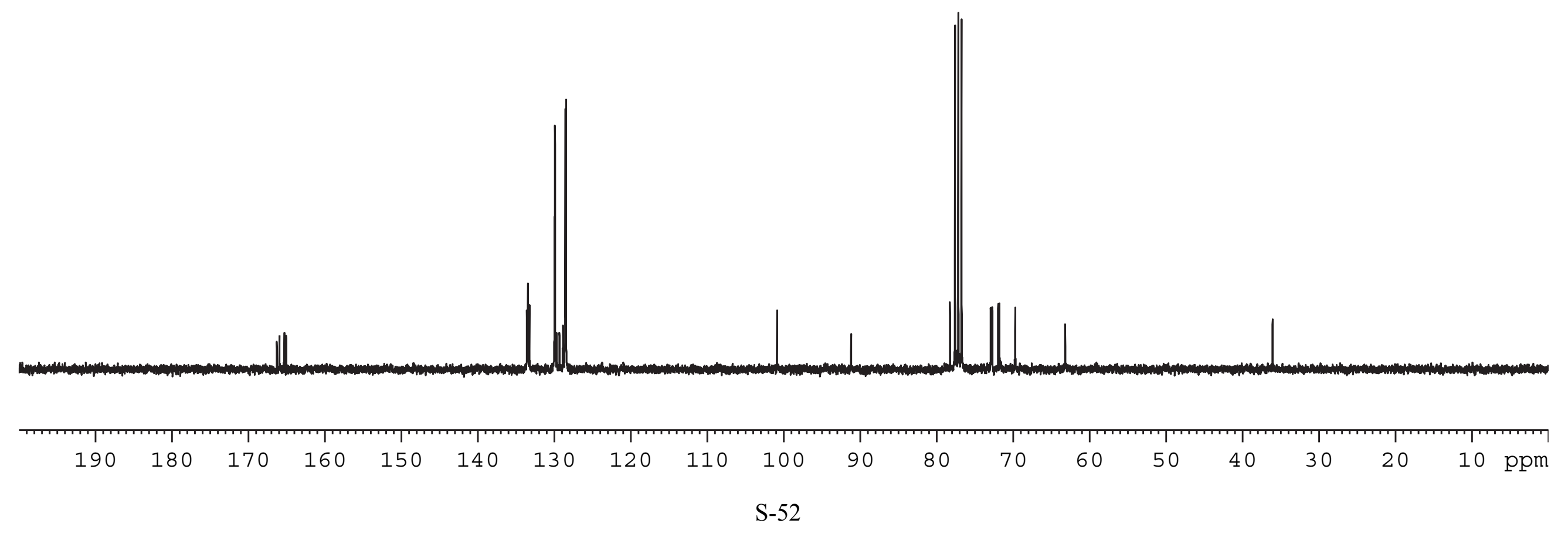


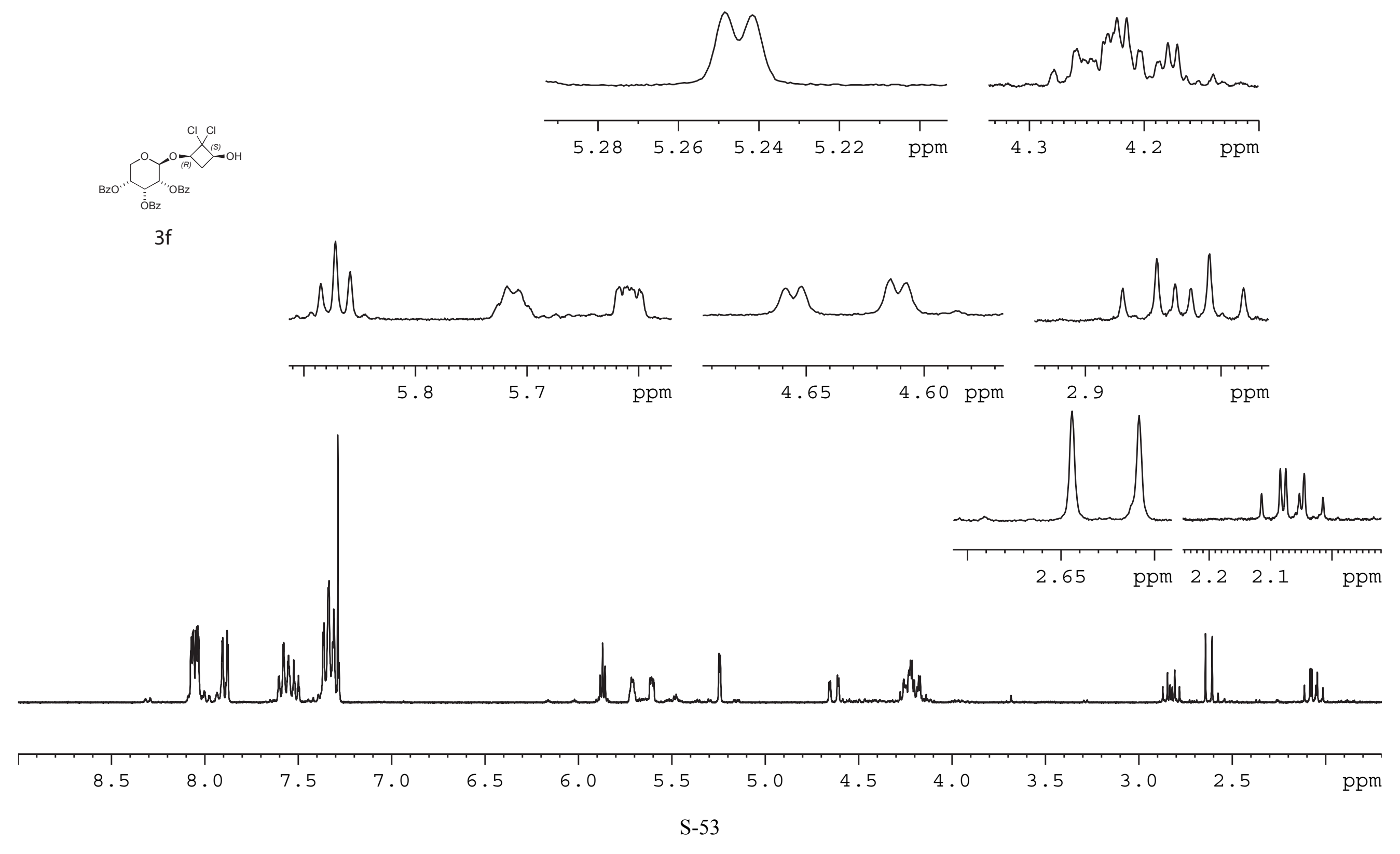




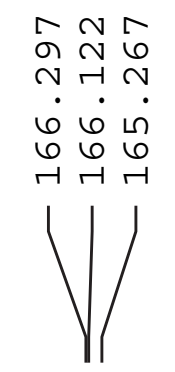

겅 $m$ の

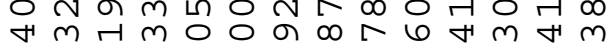
$\dot{m} \dot{m} \dot{0} \dot{0} \dot{\circ} \dot{\sigma} \dot{\sigma} \dot{\sigma} \dot{\sigma} \dot{\infty} \dot{\infty}$

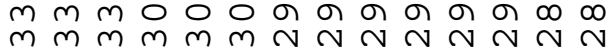

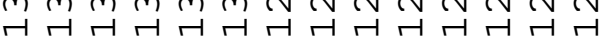

드 เก ด ने

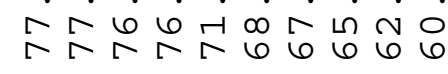

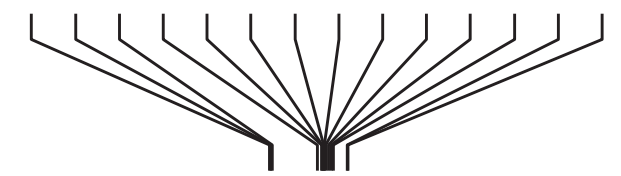

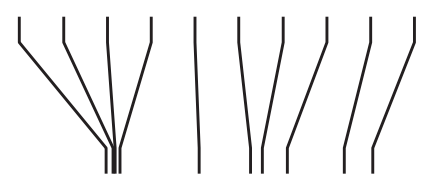

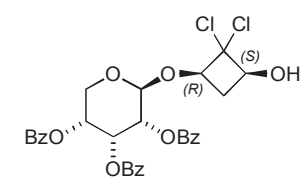

$3 f$
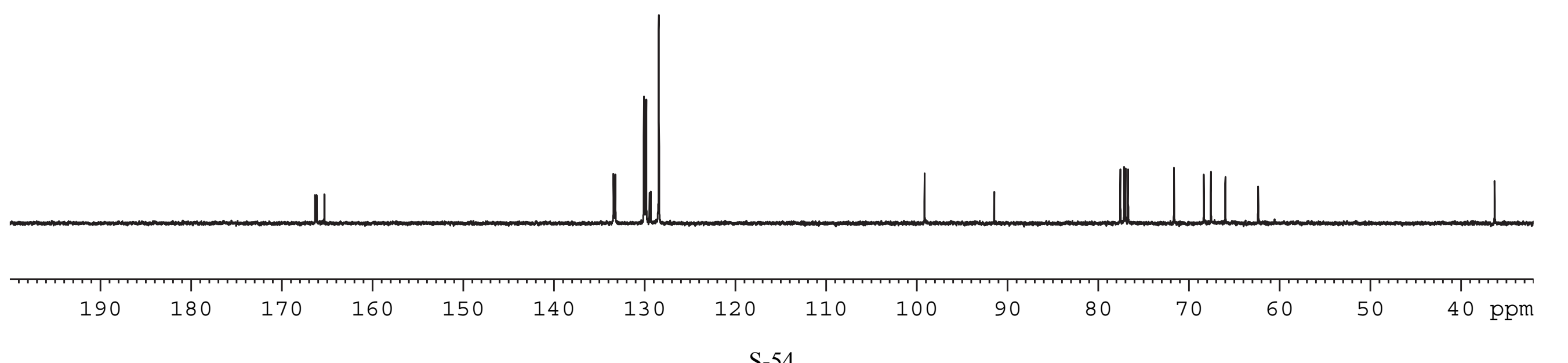


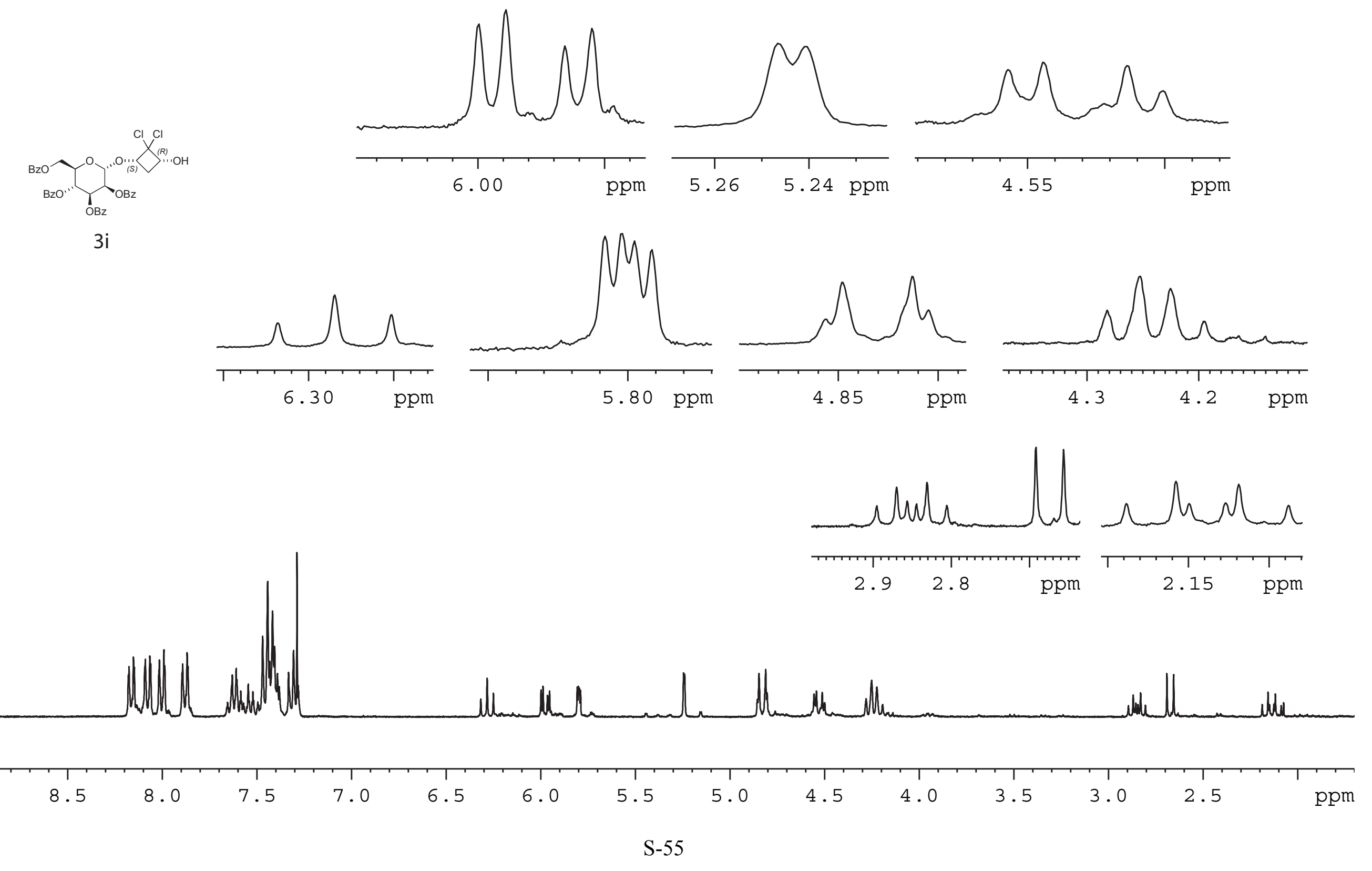


Nล⿵人

$m 6$ เ

$6\llcorner$ เ

666

-

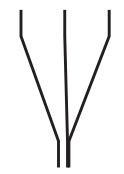

$\checkmark \theta$ म

$m m m \dot{m} \dot{m} \dot{\theta} \dot{\sigma} \dot{\sigma} \dot{\sigma} \infty \infty \infty$

$m m m m m \sim \sim \sim N \sim \sim \sim N$

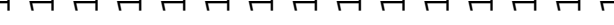

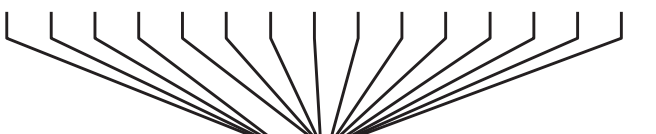

- $\quad 6$ क

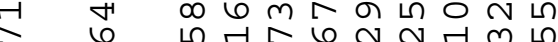

$4 \pi, N N+m$

$\infty$ न

arrarr.ro

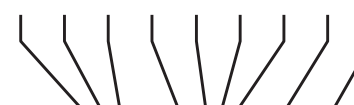

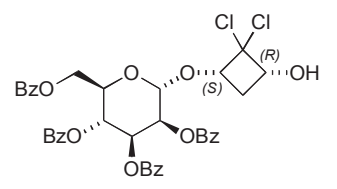

$3 \mathrm{i}$

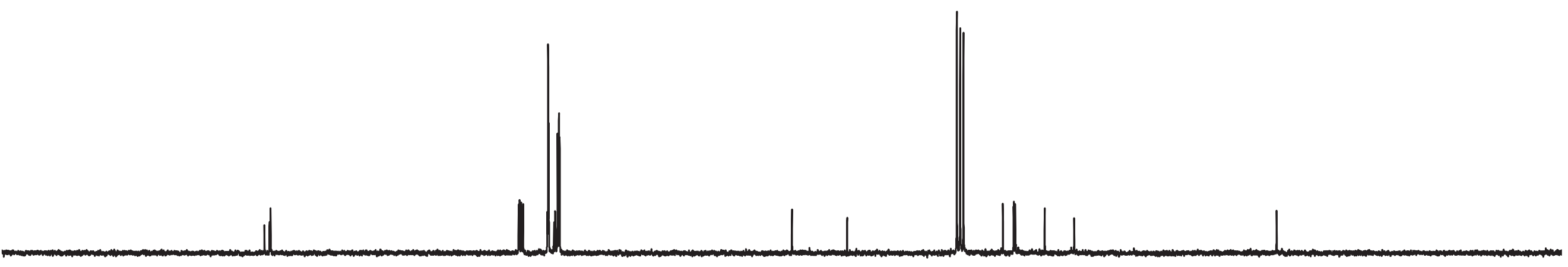



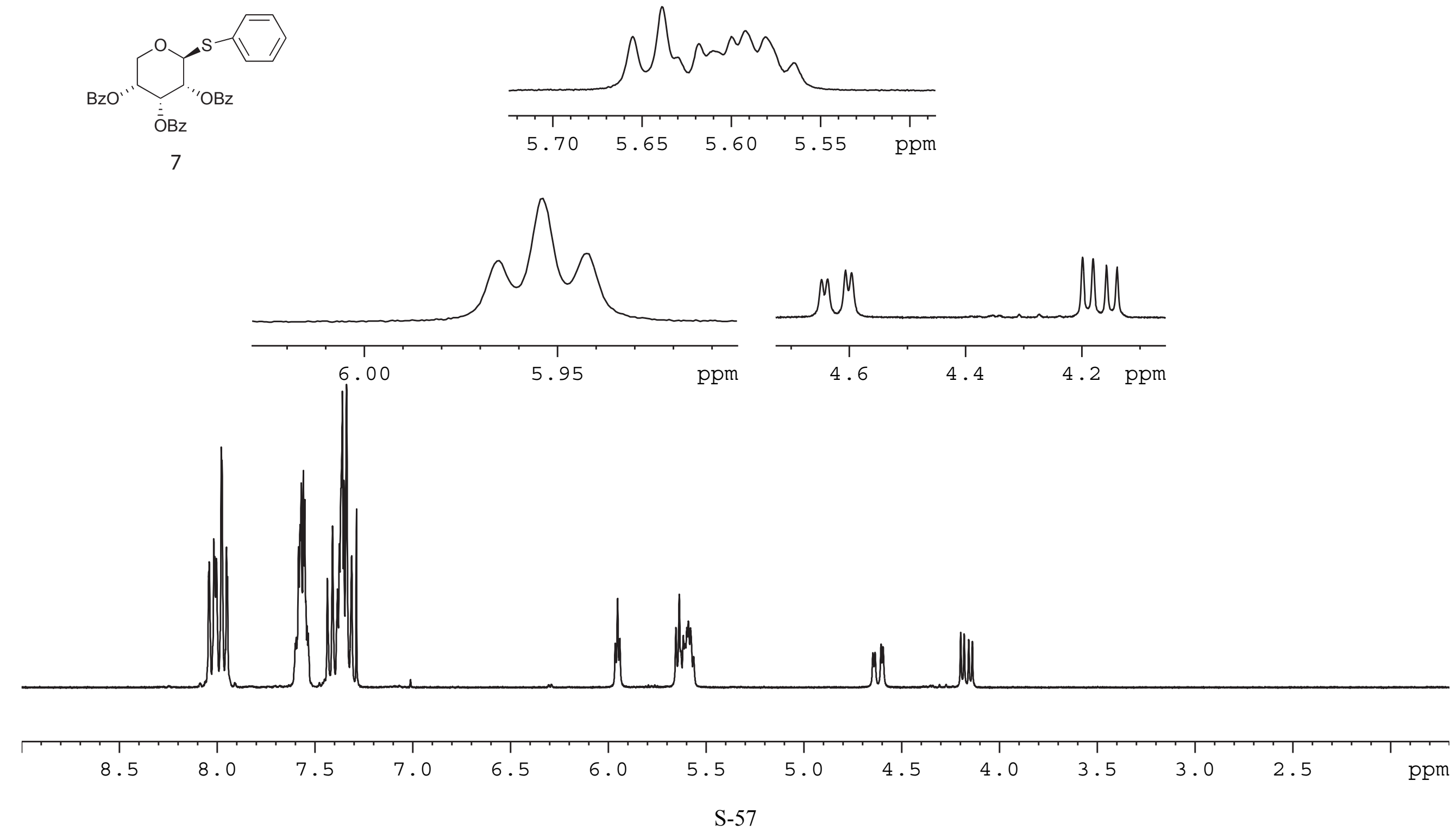
๙

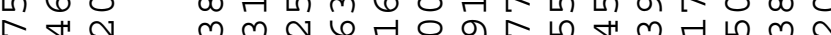

$\cdot \cdot$

เก เก

666

$m m m \sim N \circ$ の

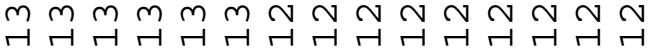

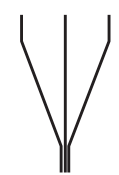

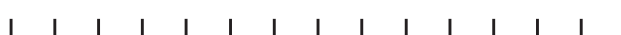

Hin
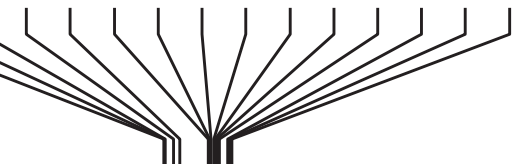

ᄂ $\infty \backsim \sim 6 \pi$

न

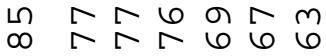
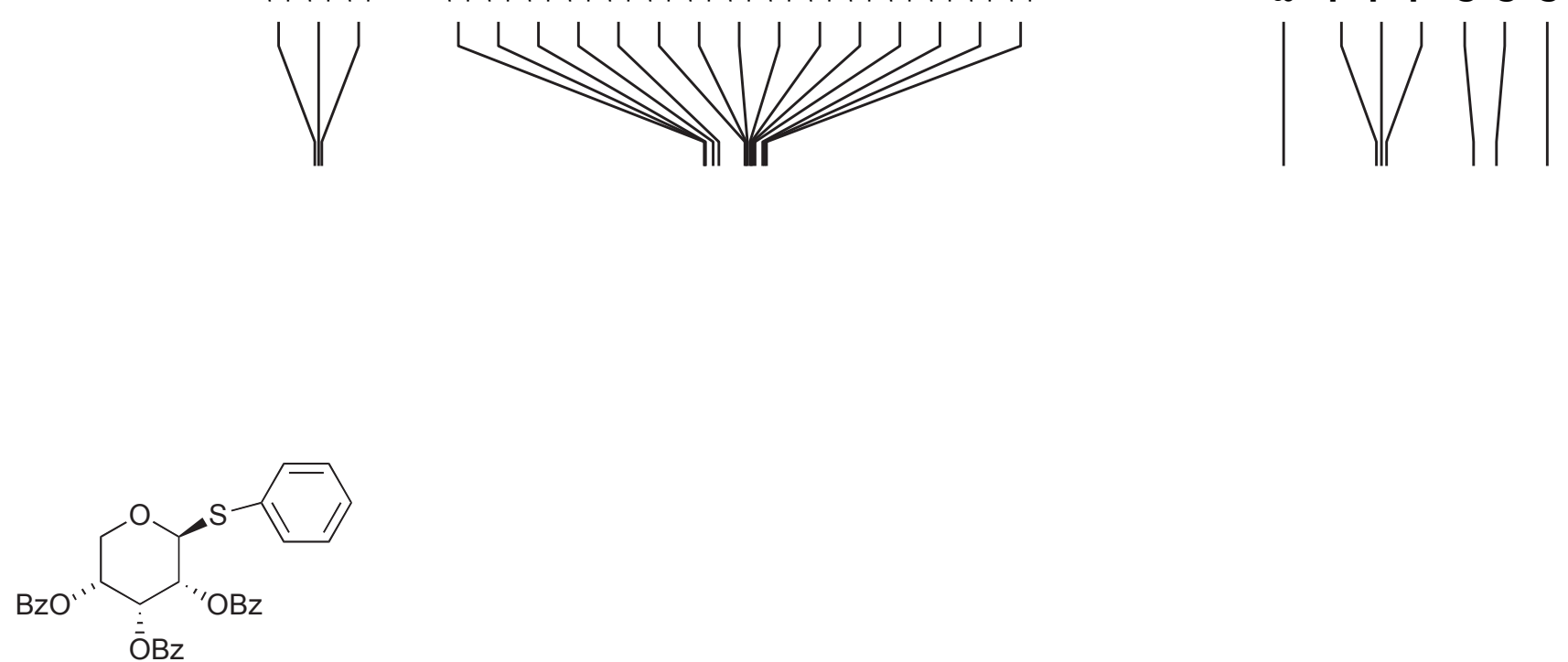

7

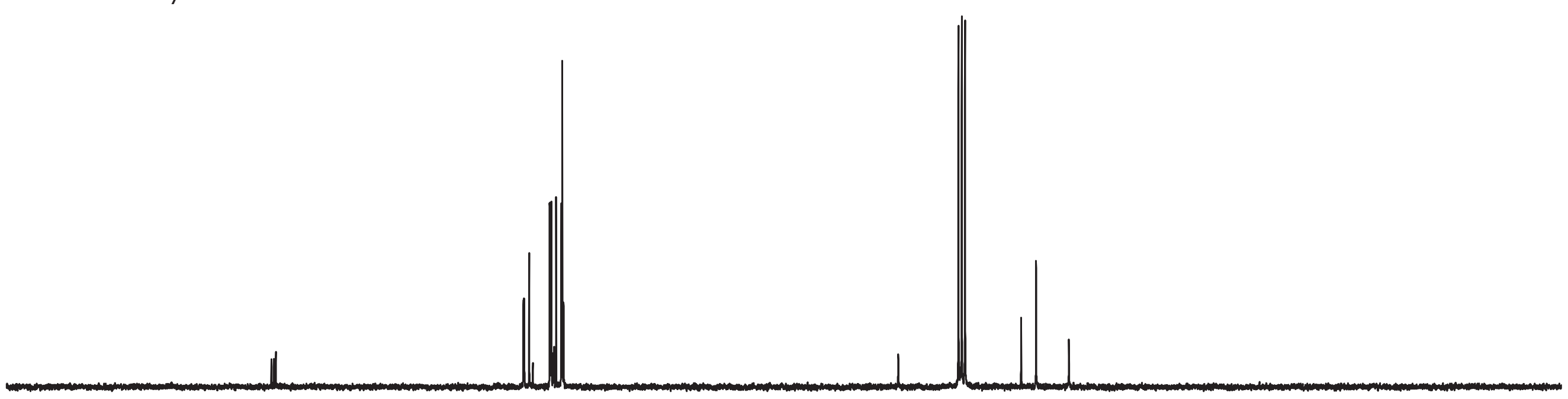

\begin{tabular}{|c|c|c|c|c|c|c|c|c|c|c|c|c|c|c|c|c|c|c|}
\hline T"1 & TाיTा & Tाग & $T$ & 'T" & T" & "T & "Tाיז & 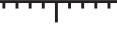 & דיחיד & T"1 & Tाग & Tाי & Tाग & מיד & Tי & $T 11$ & $T$ & דודיודן דוד \\
\hline 190 & 180 & 170 & 160 & 150 & 140 & 130 & 120 & 110 & 100 & 90 & 80 & 70 & 60 & 50 & 40 & 30 & 20 & $10 \mathrm{ppm}$ \\
\hline
\end{tabular}




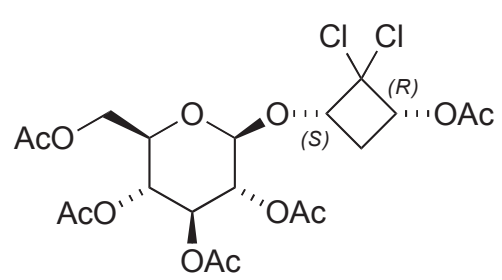

$9 a$
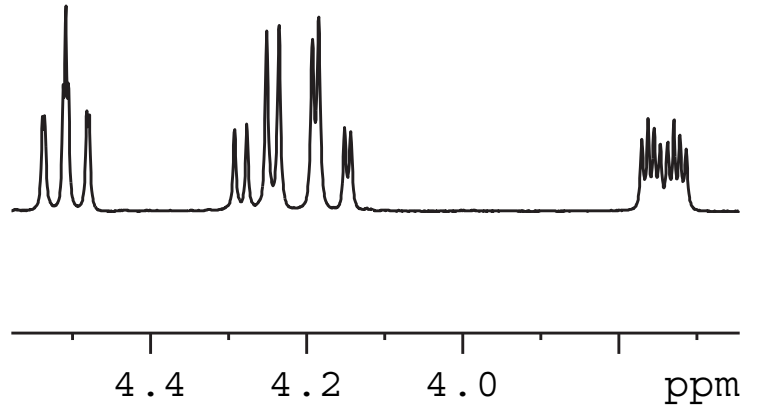
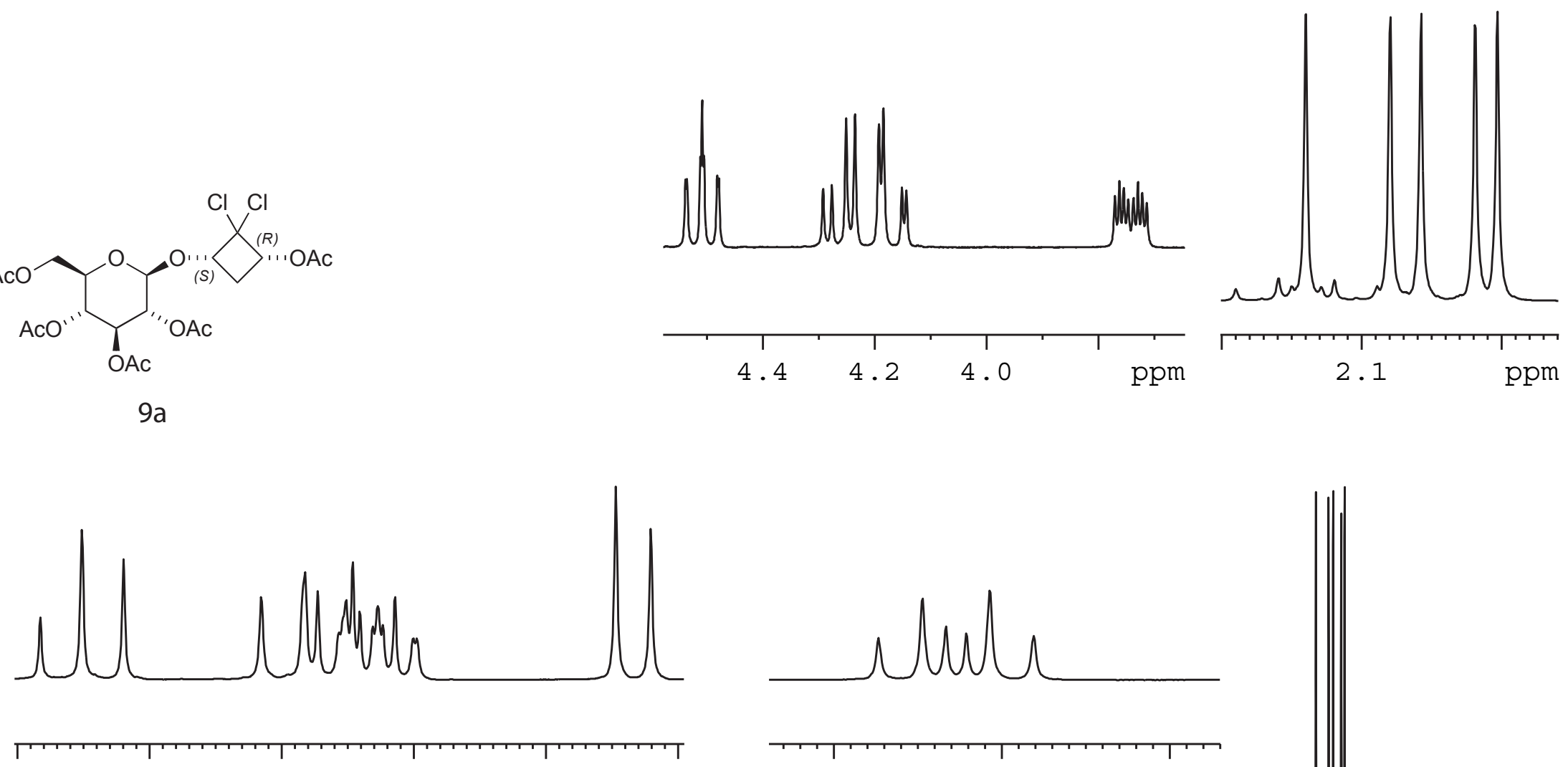

5.2

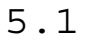

5.0

4.9

ppm

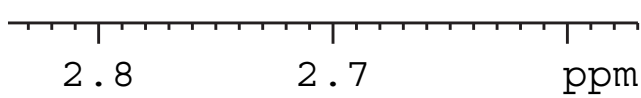

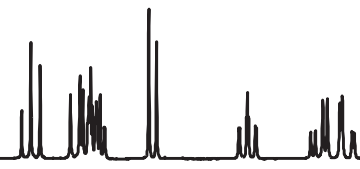
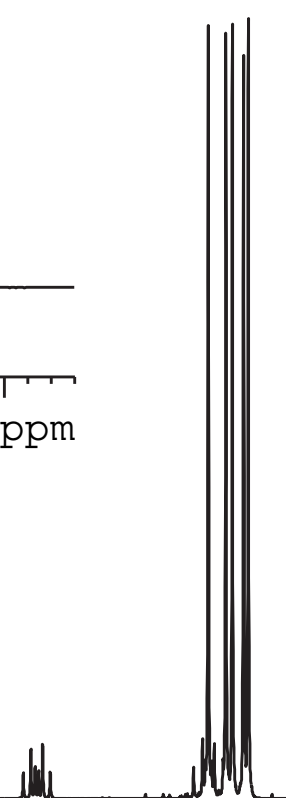

8.58.

7.5

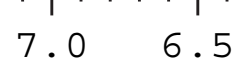

6.0

5.5

5.0

4.5

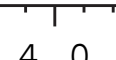

3.5

3.0

2.5

$2.0 \quad 1.5$

$1.00 .5 \mathrm{ppm}$ S-59 
$m \pi \circ \pi m^{4}$

ก

ती 0 म

$\circ \circ \sigma \sigma a$

तત

1111

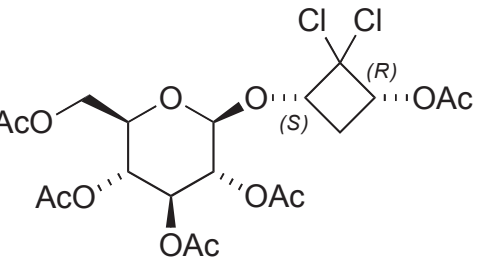

$9 a$ n न

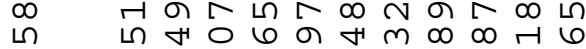

. $\cdot$. $\cdot$. $\cdot$..

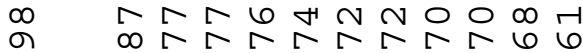

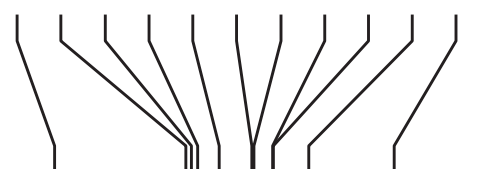

नَ

6 ถึ

问

ำ ㅇํ

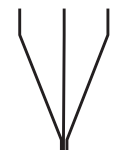



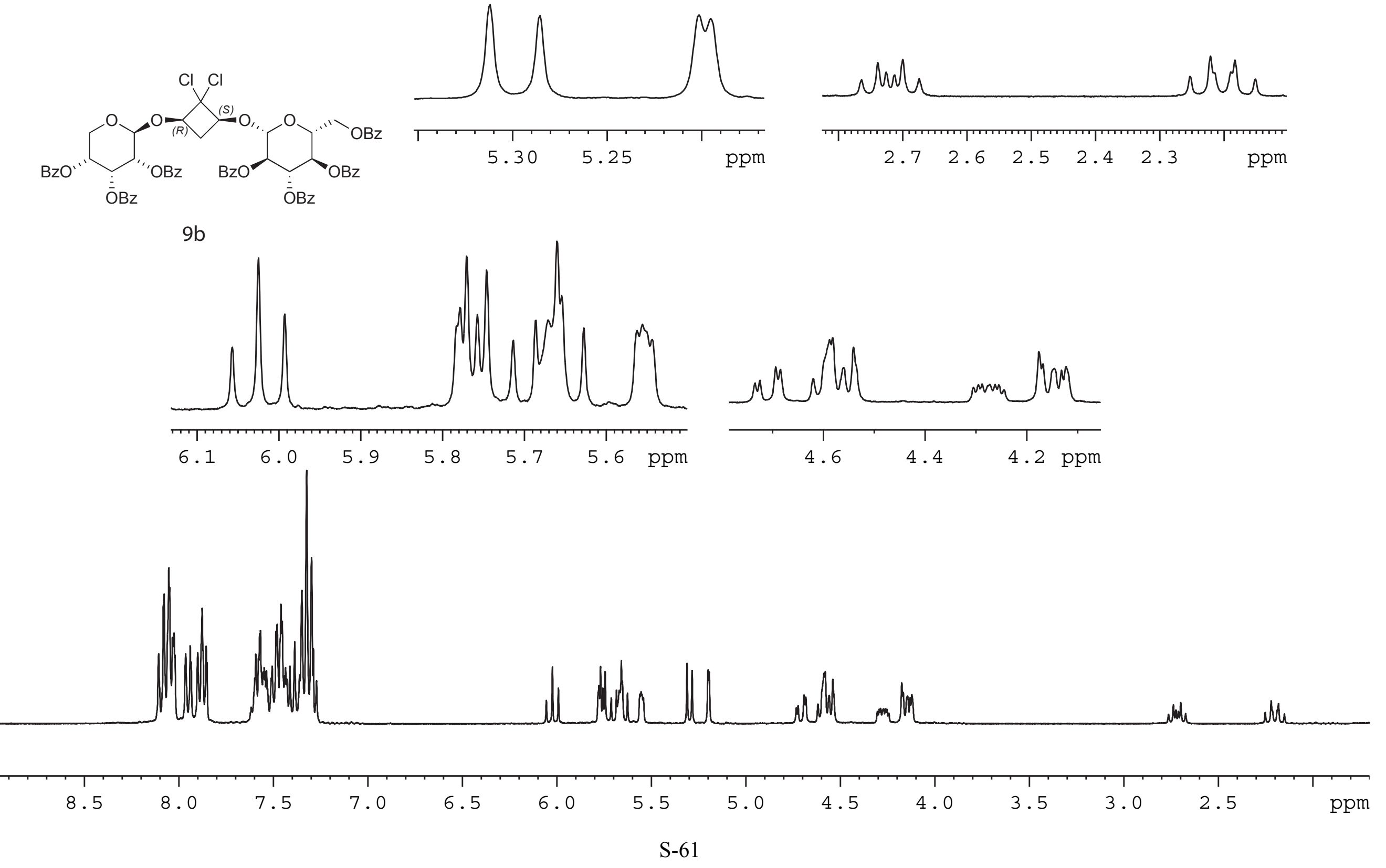
个

$\infty N+10 m+40$ म

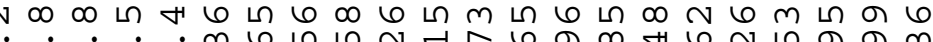
舟

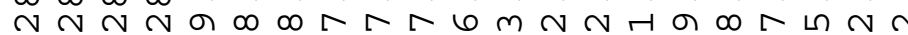
न

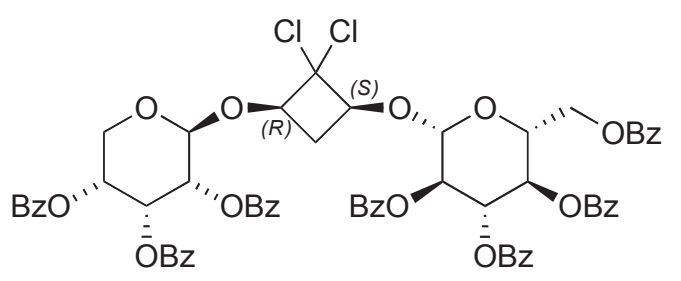

$9 b$
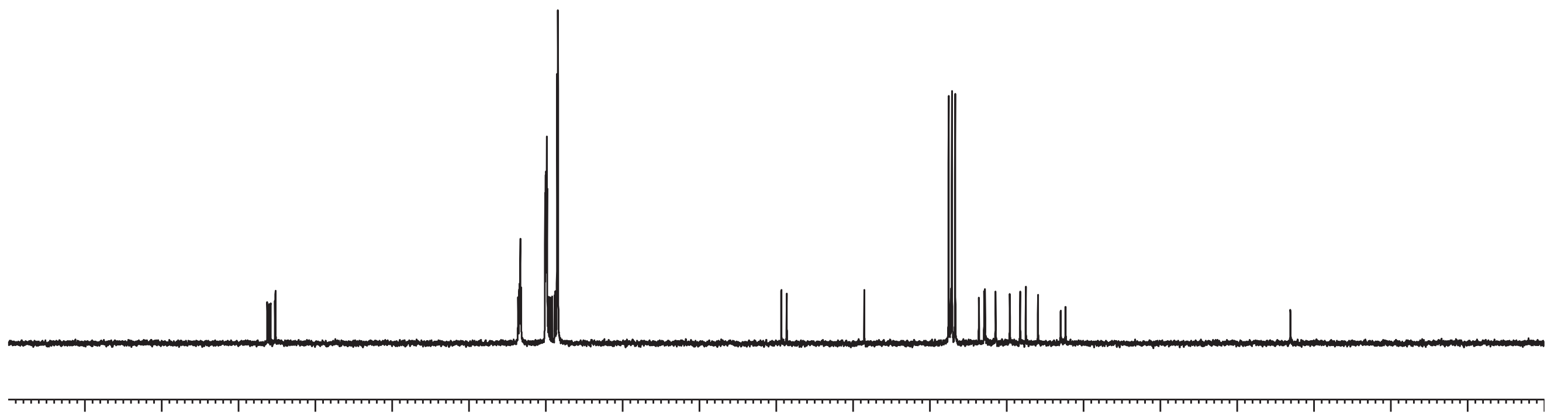

$\begin{array}{llllllllllllllllllll}190 & 180 & 170 & 160 & 150 & 140 & 130 & 120 & 110 & 100 & 90 & 80 & 70 & 60 & 50 & 40 & 30 & 20 & 10 & \text { ppm }\end{array}$



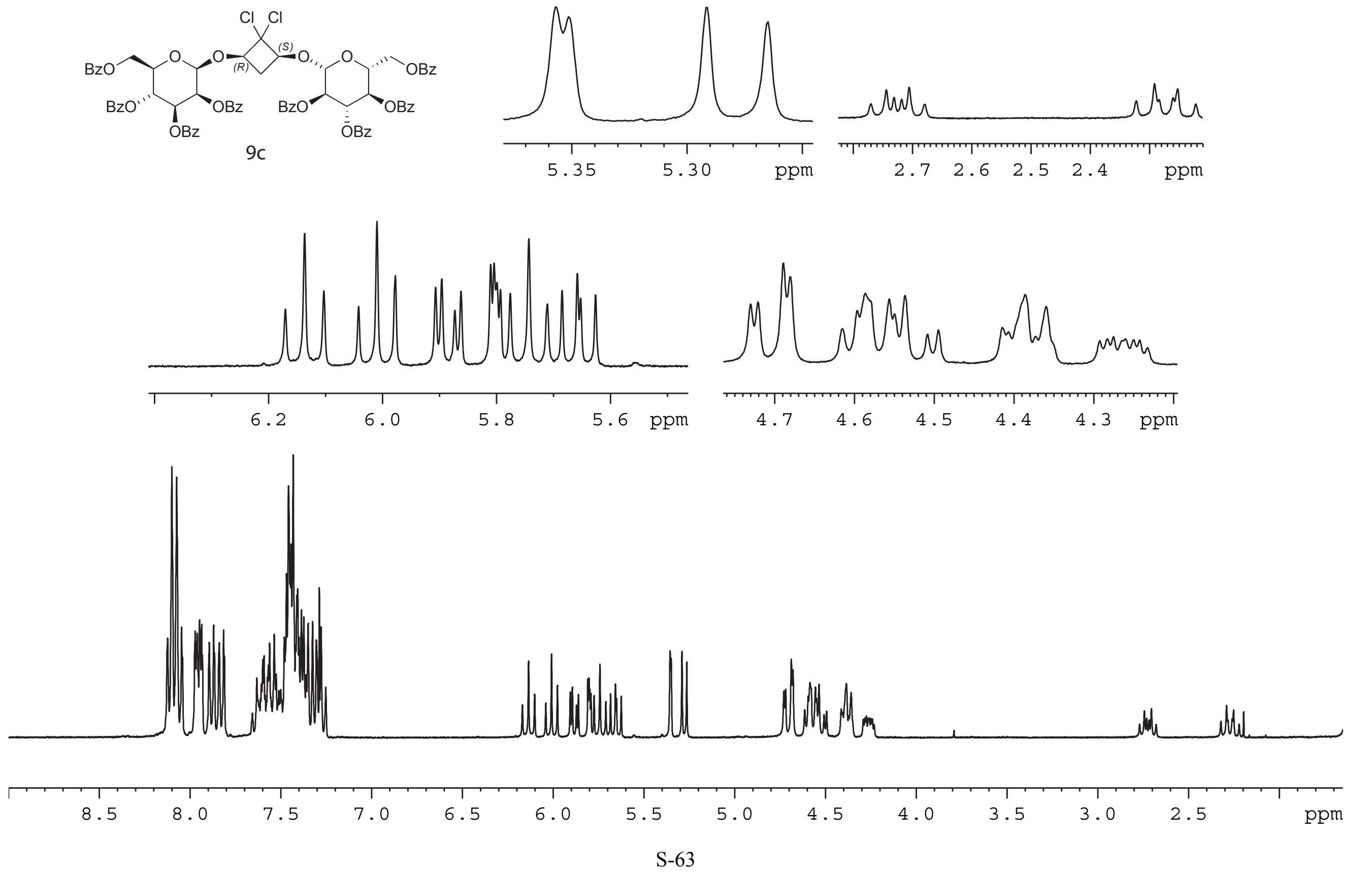


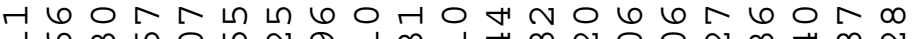

NommoLr Hanmomolman

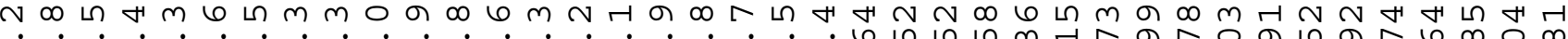

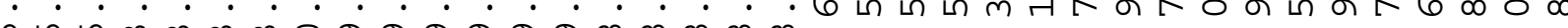
666 6 60

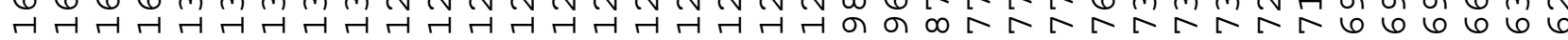
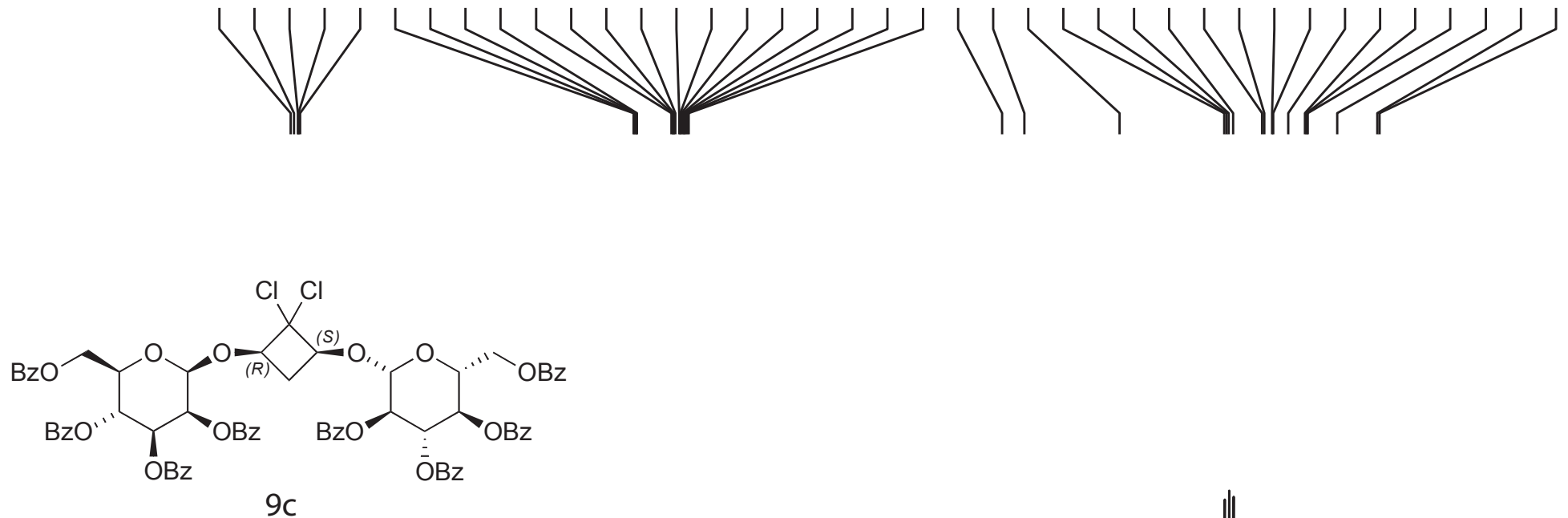

$9 c$

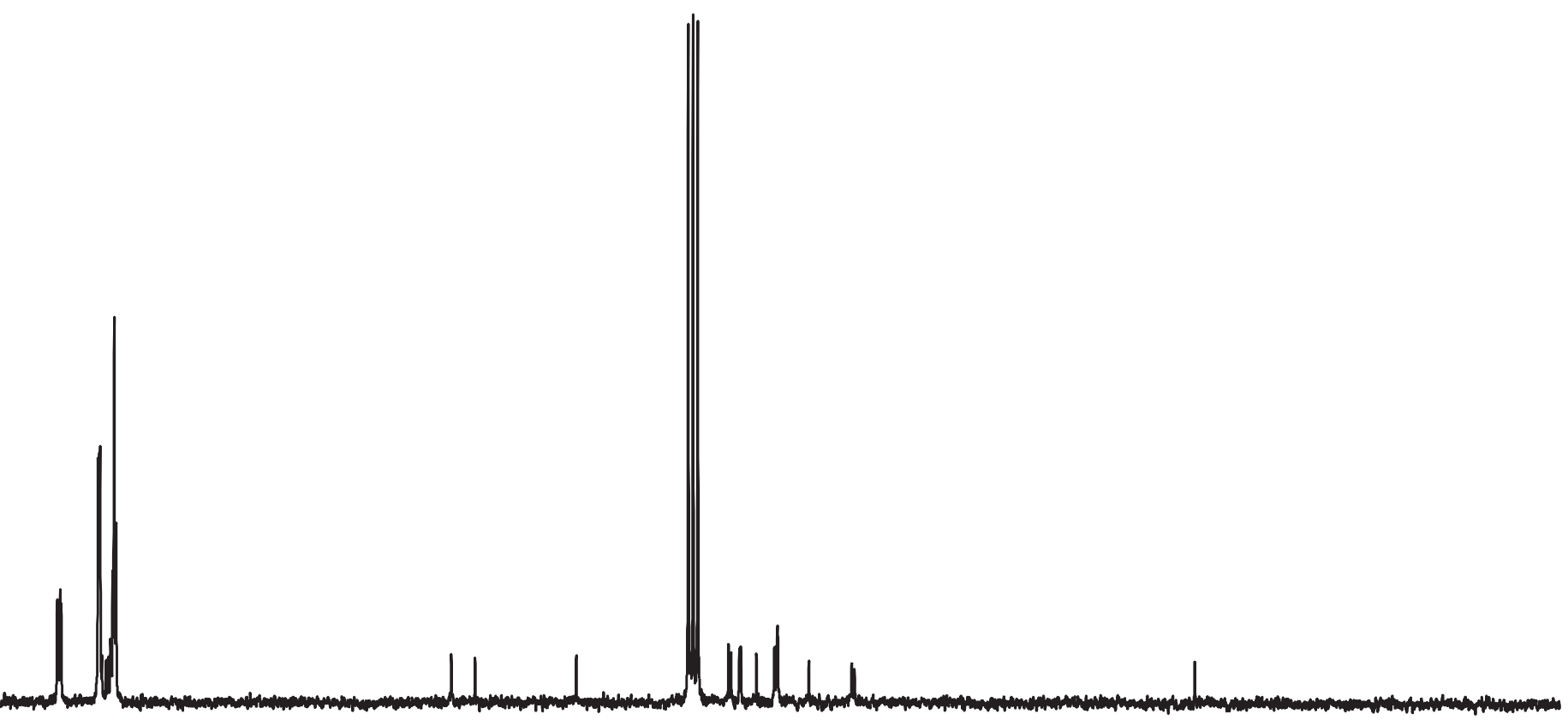

\begin{tabular}{|c|c|c|c|c|c|c|c|c|c|c|c|c|c|c|c|c|c|c|c|}
\hline 190 & 180 & 170 & 160 & 150 & 140 & 130 & 120 & 110 & 100 & 90 & 80 & 70 & 60 & 50 & 40 & 30 & 20 & 10 & ppm \\
\hline
\end{tabular}



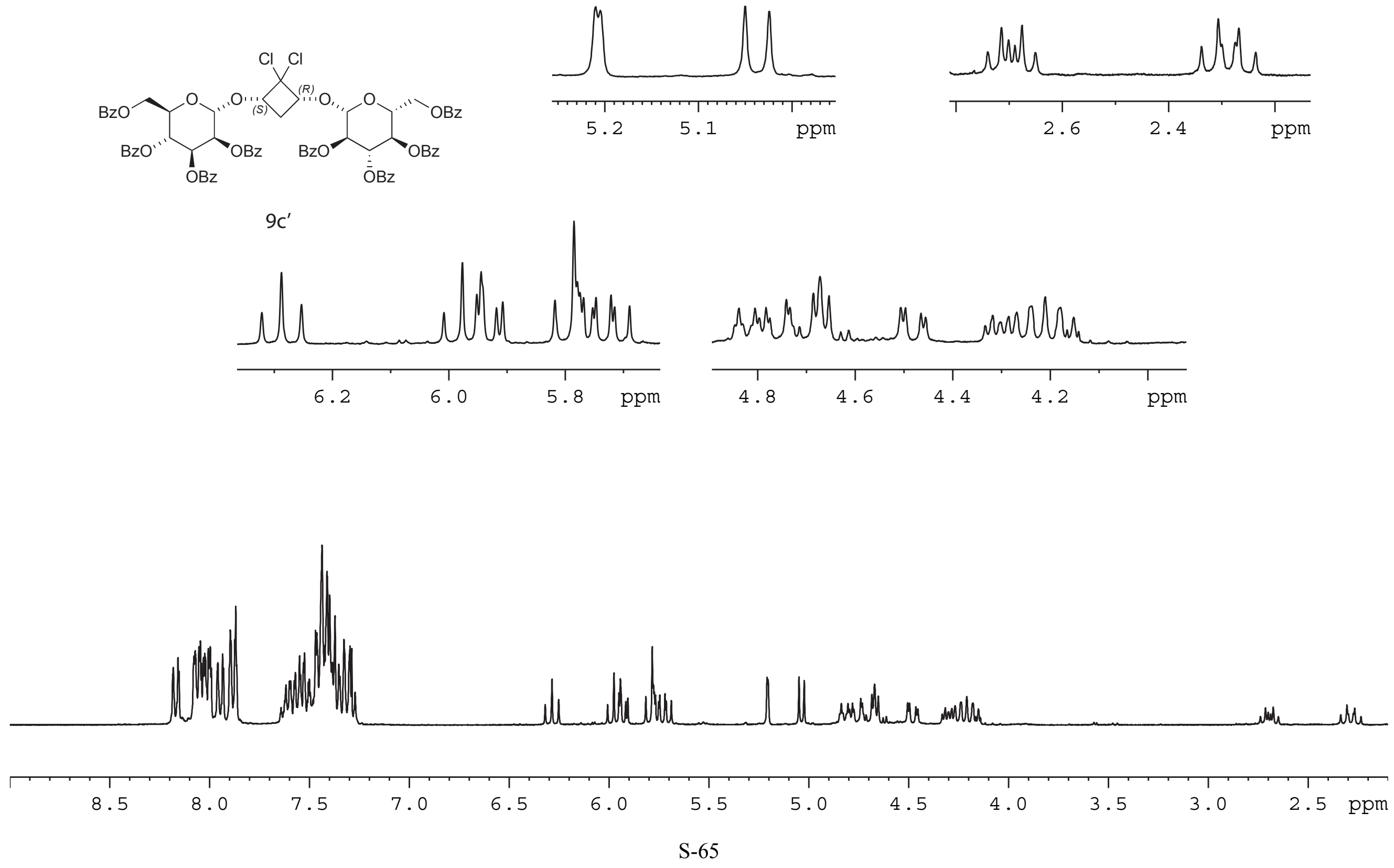


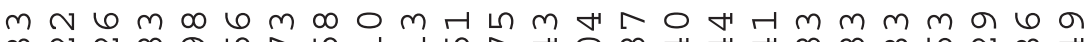

$m N N \infty$ a N

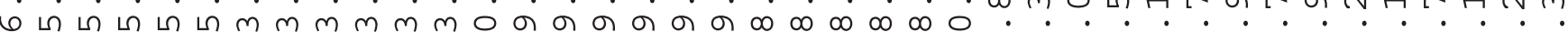

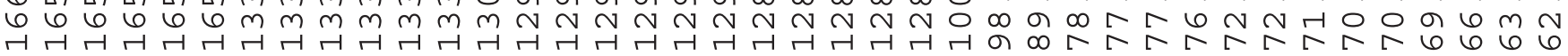
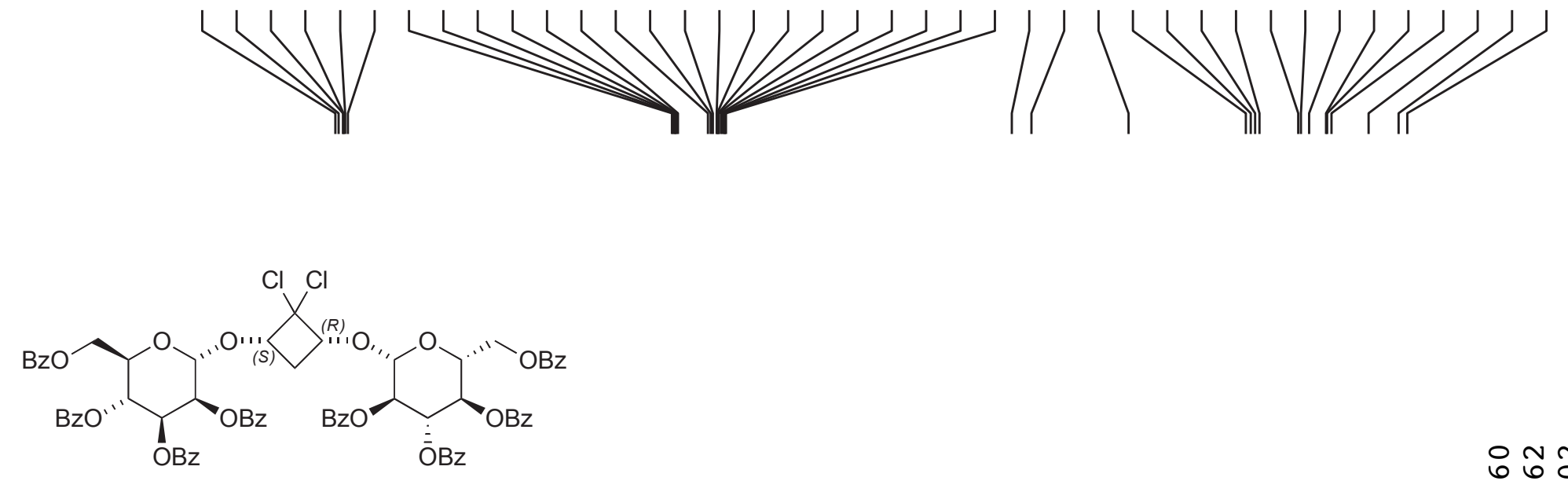

$9 c^{\prime}$
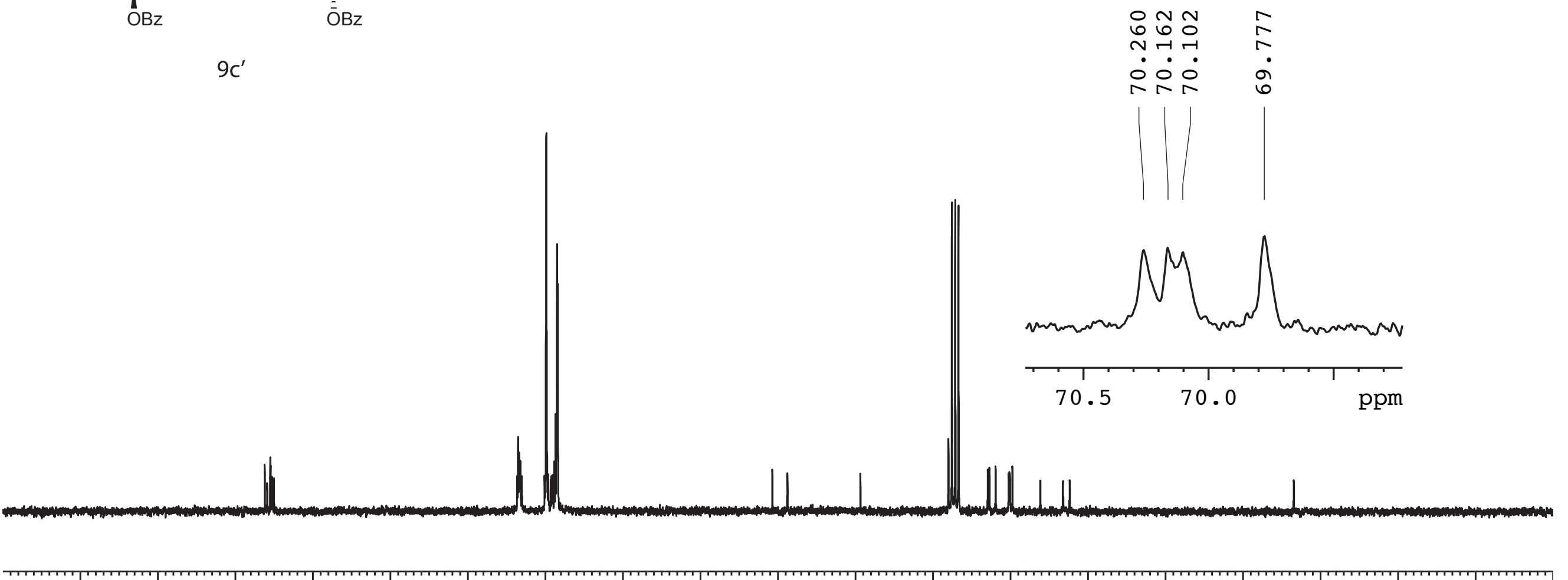

$\begin{array}{llllllllllllllllllll}190 & 180 & 170 & 160 & 150 & 140 & 130 & 120 & 110 & 100 & 90 & 80 & 70 & 60 & 50 & 40 & 30 & 20 & 10 & \text { ppm }\end{array}$




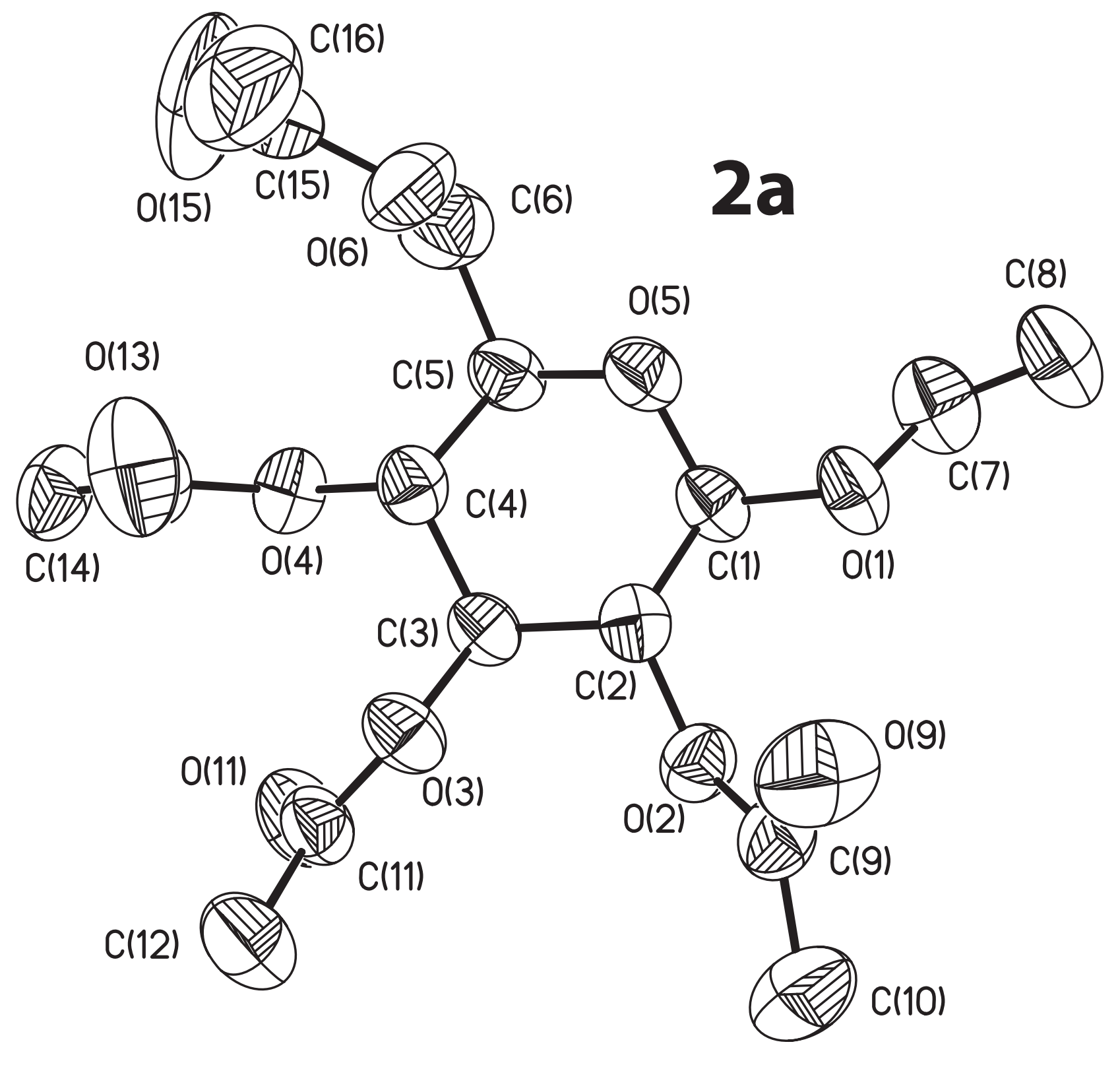




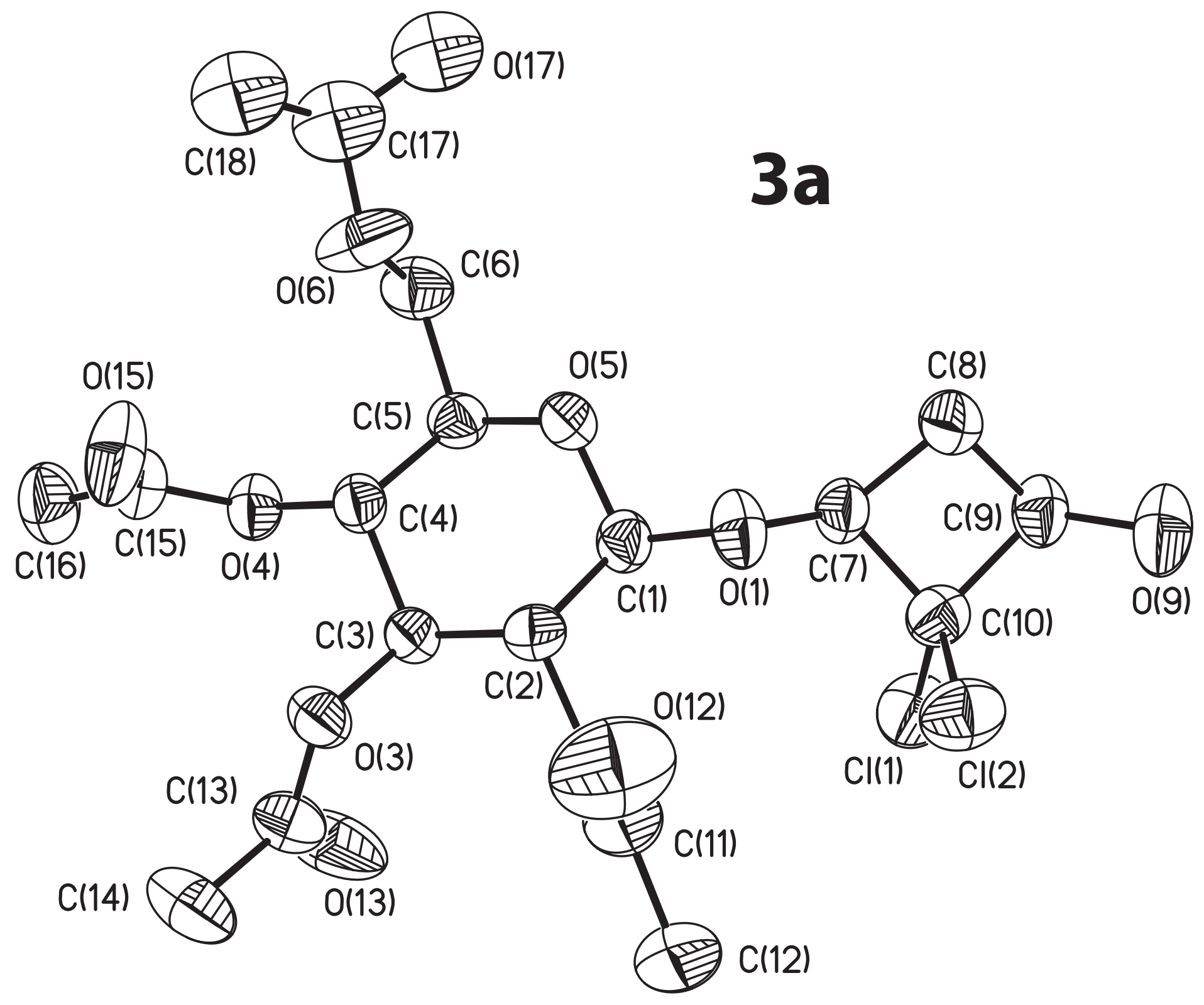




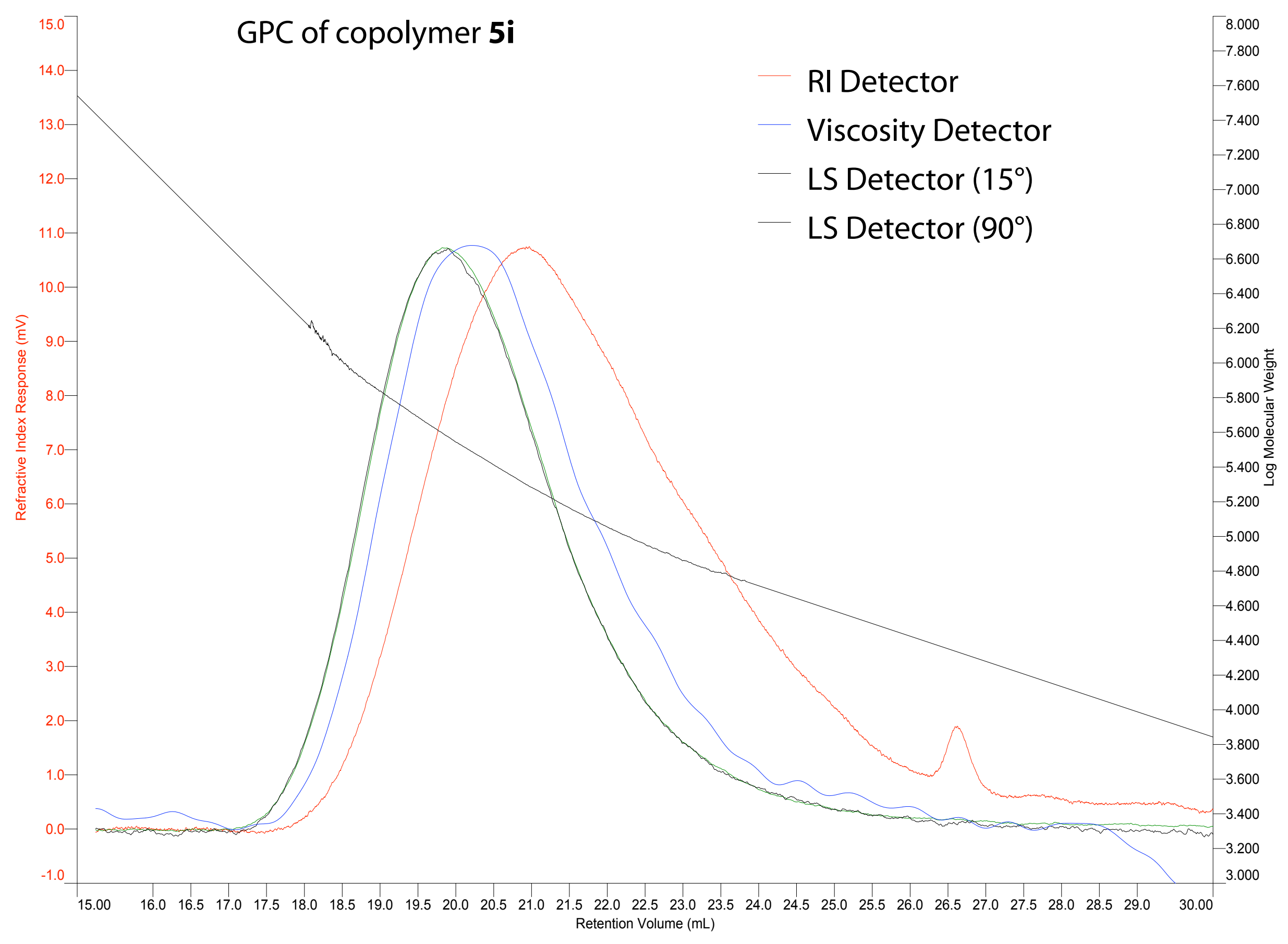

